\title{
Rockefeller University
}

\section{Digital Commons@RU}

Student Theses and Dissertations

2014

\section{HIV Specific B Cell Response in Patients With Broadly Neutralizing Serum Activity}

Johannes F. Scheid

Follow this and additional works at: http://digitalcommons.rockefeller.edu/ student_theses_and_dissertations

Part of the Life Sciences Commons

\section{Recommended Citation}

Scheid, Johannes F., "HIV Specific B Cell Response in Patients With Broadly Neutralizing Serum Activity" (2014). Student Theses and Dissertations. Paper 223. 


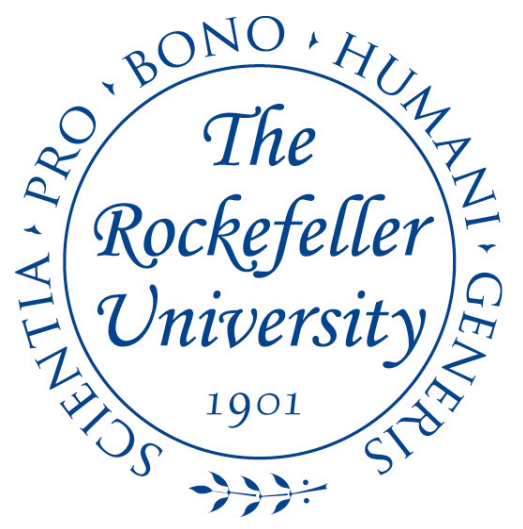

HIV SPECIFIC B CELL RESPONSE IN PATIENTS WITH BROADLY NEUTRALIZING SERUM ACTIVITY

\author{
A Thesis Presented to the Faculty of \\ The Rockefeller University \\ in Partial Fulfillment of the Requirements for \\ the degree of Doctor of Philosophy
}

by

Johannes F. Scheid

June 2014 
(C) Copyright by Johannes F. Scheid 2014 


\title{
HIV SPECIFIC B CELL RESPONSE IN PATIENTS WITH BROADLY NEUTRALIZING SERUM ACTIVITY
}

\author{
Johannes F. Scheid, Ph.D. \\ The Rockefeller University 2014
}

Antibodies to conserved epitopes on the HIV surface protein gp140 can protect against infection in non-human primates, suggesting that vaccines that elicit such antibodies would be protective. Some HIV infected individuals develop high titers of broadly neutralizing $\operatorname{IgG}$ antibodies in their serum, but until recently very little was known about the specificity and activity of these antibodies. To characterize the broadly neutralizing memory antibody responses to HIV we cloned 1078 antibodies from HIV envelope binding memory B cells from eight HIV infected patients with broadly neutralizing antibodies. We found that in these patients, the B cell memory response to gp140 is composed of up to 50 independent clones expressing high affinity antibodies to the gp120 variable loops, the $\mathrm{CD} 4$ binding site, the co-receptor binding site, to a new neutralizing epitope that is in the same region of gp120 as the CD4 binding site and to gp41. In four patients highly potent broadly neutralizing antibody clones directed to the CD4 binding site were isolated. Despite extensive hypermutation, these broadly neutralizing CD4bs antibodies shared a consensus sequence of $68 \mathrm{IgH}$ chain amino acids and arose independently from two related $\mathrm{IgH}$ genes. Thus, the IgG memory B cell compartment in the selected group of patients with broad serum activity to HIV is comprised of multiple 
clonal responses. Neutralizing activity is directed against several epitopes on gp120 with some closely related CD4 binding site directed antibody clones showing highly potent neutralizing activity.

For the first time, this study has attempted to systematically describe on a monoclonal level the composition of broadly neutralizing serum activity against HIV.

The techniques and antibodies presented in this work are transforming our understanding of possible targets and routes for HIV vaccine strategies and provide powerful tools for possible HIV treatment approaches. 
"What we want to do is remain innovative and always keep our eyes on the disease."

\author{
Ralph Steinman
}




\section{Acknowledgments.}

Firstly, I would like to thank Michel for an outstanding time in his laboratory. Entering the HIV field together with you has been exciting and formative scientifically as well as personally. Your guidance during this endeavor, including instrumental experimental advice and support in challenging and intense phases of our projects has been a key element in our success.

Most of all, I am very grateful for the gift of your friendship and mentorship.

I thank all members of the Nussenzweig Laboratory for their help and discussions, in particular Hugo Mouquet, Mila Jankovic, Klara Velinzon, Sergey Yurasov, Anna Gazumyan and Hedda Wardemann.

Ralph Steinman, Charles Rice and David Ho from my thesis committee for guidance and support. Ralph's infectious excitement for medically relevant basic research will remain a constant source of inspiration throughout my career.

I thank all of our collaborators. Without their help this work could not have been performed. Most of these collaborators have not only provided reagents and scientific input but also played a key role in introducing us into the HIV field. In particular Bruce Walker, Florencia Pereyra, Pamela Bjorkman and Jeff Ravetch. 
For the invaluable patient samples I thank the donors as well as the patient coordinators Arlene Hurley, Emily Stone Cutrell and Kristin Moss.

I would like to thank The Rockefeller University for providing an ideal environment to pursue exciting scientific questions.

The NIH, HHMI, Bill and Melinda Gates Foundation, "Deutscher Akademischer Austauschdienst" and the Charite Berlin for funding and support.

I also thank the Fred Hutchinson Cancer Research Center for awarding this thesis work with the "Harold M. Weintraub Award".

Finally, I would like to thank my parents for their unconditional love and support. 


\section{Table of Contents}

Acknowledgements $\quad$ iv

Table of Contents vi vi

List of Figures viii

List of Tables $\quad$ X

Chapter 1: Introduction 1

The HIV Vaccine Problem 1

HIV Envelope Antibody Response and Escape 4

$\begin{array}{ll}\text { Broadly Neutralizing Sera } & 7\end{array}$

Monoclonal HIV Neutralizing Antibodies $\quad 18$

Application of neutralizing antibodies $\quad 21$

Memory B cells as a target to study HIV B cell responses 25

Chapter 2: $\quad$ Broad diversity of anti-gp140 memory antibodies 28

Characteristics of anti-gp140 memory antibodies $\quad 28$

Epitopes recognized by anti-gp140 memory antibodies $\quad 39$

Affinity of anti-gp140 antibodies $\quad 42$

Anti-gp120 ${ }^{\text {core }}$ antibodies $\quad 44$

HIV neutralizing activity $\quad 48$

Discussion $\quad 56$ 
Chapter 3: Sequence and Structural Convergence of Broad and Potent HIV Antibodies that Mimic CD4 Binding 59

$\begin{array}{ll}\text { Introduction } & 59\end{array}$

Primers for the identification of highly mutated antibodies $\quad 61$

Anti-2CC-core memory antibodies from four donors $\quad 66$

Epitopes and polyreactivity of anti-2CC-core memory antibodies 71

$\begin{array}{ll}\text { HIV neutralizing activity } & 74\end{array}$

Anti-2CC-core antibodies in the bone marrow plasma cell

$\begin{array}{ll}\text { compartment } & 84\end{array}$

$\begin{array}{ll}\text { Affinity of anti-2CC-core antibodies } & 89\end{array}$

CD4 agonistic function of 2CC-core antibodies $\quad 92$

$\begin{array}{ll}\text { Sequence conservation of HAADs } & 94\end{array}$

$\begin{array}{ll}\text { Structural conservation of HAADs } & 103\end{array}$

$\begin{array}{ll}\text { Discussion } & 105\end{array}$

$\begin{array}{lll}\text { Chapter 4: Discussion } & 107\end{array}$

$\begin{array}{llr}\text { Chapter 5: } & \text { Methods } & 115\end{array}$

$\begin{array}{ll}\text { Chapter 6: } & \text { References } \\ & 125\end{array}$ 


\section{List of Figures}

Figure 1 HIV surface trimer with binding regions of monoclonal broadly neutralizing antibodies

Figure 2 Serum adsorption by YU2-gp140 trimer and binding to control monoclonal antibodies

Figure 3 Anti-gp140 antibody cloning

Figure 4 Anti-gp140 antibody repertoire

Figure 5 Anti-gp140 mapping by ELISA

Figure 6 Surface plasmon resonance measurements for interaction between selected antibodies and gp140

Figure 7 Binding of anti-gp120core antibodies

Figure 8 Effect of deglycosylation on BAL gp120 binding

Figure 9 Anti-gp140 antibody neutralizing activity

Figure 10 Highly mutated antibodies captured with new primers

Figure 11 Recovery of highly mutated immunoglobulin heavy chains with specific

primers

Figure 12 Ig V heavy and light chain sequences of new VRC01 clonal members 65

Figure $13 \quad 2 C C$-core captures CD4bs antibodies 70

Figure 14 Polyreactivity of anti-HIV antibodies 72

Figure 15 Binding and neutralization of mutated and germline antibodies 73

Figure 16 Antibodies captured by 2CC-core have broad and potent HIV neutralizing activity 
Figure 17 Clone specific amplification of IgG genes from CD138+ bone marrow plasma cells

Figure 18 Detection of antibodies by mass spectrometry 86

Figure 19 Binding properties of antibodies 90

Figure $20 \quad$ Affinity of RU01 clone members 91

Figure 21 Effect of sCD4 or monoclonal antibodies on binding of a CD4i antibody to 293 T cells expressing two different HIV spikes

Figure 22 Sequence and structural conservation of HAADs 96

Figure 23 Phylogenetic tree of IgVH and Ig light chain germline sequences 98

Figure 24 Somatic hypermutation analysis of selected antibodies for

immunoglobulin heavy chain gene, light chain kappa and light

chain lambda gene sequences

99 


\section{List of Tables}

Table 1 IgH and IgL chain gene sequence information and antibody reactivity and neutralization assay results of anti-gp140 antibodies

Table 2 Affinity measurements of b12 and selected patient antibodies by surface

plasmon resonance

Table $3 \quad$ Anti-gp140 antibody neutralizing activity

Table 4 Primers for amplification of highly mutated Immunoglobulin V heavy

chain genes

Table 5 IgH and $\operatorname{IgL}$ chain gene sequence, antibody reactivity, neutralization assay results for cloned antibodies

Table 6 Neutralizing activity of 2CC-core binding antibodies against a basic virus

panel

Table 7 Neutralizing activity of selected antibodies against an extended Tier 2 virus panel

Table 8 Antibody sequences from one expanded neutralizing clone in each

Pt1, Pt3 and Pt8

Table 9 Affinity of IgG antibodies to YU2-gp140 and 2CC-core ligands measured by surface plasmon resonance

Table 10 Replacement/Silent mutation ratios for heavy and light chain sequences of 10 selected antibodies 


\section{Chapter 1}

\section{Introduction}

\section{The HIV Vaccine Problem}

Since its discovery in 1981, HIV has killed over 25 million people and currently more than 33 million humans are infected worldwide. Despite extensive research efforts over the last three decades, a vaccine against HIV remains elusive(Karlsson Hedestam et al., 2008; McElrath and Haynes, 2010; Moir et al., 2011; Walker and Burton, 2008). This introduction will portray some of the main challenges in HIV vaccine design and discuss the role of neutralizing antibodies in addressing them.

\section{HIV Envelope}

In order to allow infection, the HIV envelope protein (env) needs to interact with surface receptors on the target cell. This makes env the main target of an HIV vaccine. Early approaches using soluble envelope protein or inactivated virus as immunogens have not met with the same success as for other pathogens, such as influenza. This failure roots in HIV envelope diversity and other structural traits that still are not entirely understood.

\section{Diversity}

HIV displays a large diversity of envelope versions within each patient and in the population(Keele et al., 2008; Salazar-Gonzalez et al., 2009; Taylor and Hammer, 2008;

Wei et al., 2003). Like other retroviruses, HIV depends on a reverse transcriptase to amplify its genome. The HIV reverse transcriptase exhibits an exceedingly high error 
rate(Keulen et al., 1997; Roberts et al., 1988). In addition, sub-lethal levels of the human anti-viral protein APOBEC3G might further enhance HIV diversity by introducing A-G mutations(Keele et al., 2008; Rose and Korber, 2000; Wood et al., 2009).

\section{Envelope Structure}

Limited structural understanding of the native HIV envelope protein poses another impediment on HIV vaccine design. So far, crystal structures are only available for artificially stabilized forms of the envelope subunits(Cardoso et al., 2005; Chan et al., 1997; Chen et al., 2005; Diskin et al., 2010; Kwon et al., 2012; Kwong et al., 1998;

Pancera et al., 2010; Shi et al., 2010; Weissenhorn et al., 1997). The main limitations for crystallization of the entire HIV envelope protein are both extensive glycosylation and structural flexibility.

However, cryo-electron microscopy images have shed some light upon the assembly of functional envelope spikes on HIV particles(Liu et al., 2008; Mao et al., 2012; Zhu et al., 2006). Although limited in resolution, the images show the envelope spike as a trimer of gp120-gp41 heterodimers. The three gp41 monomers provide the transmembrane domain and form a mushroom shaped structure at the base of the trimer(Liu et al., 2008). The three gp120 monomers are placed on top of the gp41 base. In addition, the images provide insight into the orientation of the gp120 variable loops $1 / 2$ and 3 , which were deleted from previous core crystal structures. The loops seem to be oriented toward the apex of the trimer with variable loops $1 / 2$ stabilizing the spike using strong intermonomeric contacts(Liu et al., 2008). This is in contrast to the arrangement suggested by an unliganded simian immunodeficiency virus (SIV) core crystal structure, which placed 
the V1/2 loops at the base of the trimer(Chen et al., 2005). The reasons for this discrepancy are not clear and underscore the necessity for structural characterization of diverse HIV strains in different conformational states.

High levels of diversity and limited understanding of the envelope structure pose challenges for HIV vaccine design. But reports of broadly neutralizing serum responses suggest that the human immune system is able to target conserved parts of the HIV envelope(Doria-Rose, 2010; Gray et al., 2011; Mikell et al., 2011; Sather et al., 2008; Simek et al., 2009; Stamatatos et al., 2009; Walker et al., 2010; Weiss et al., 1985; Weiss et al., 1986). The perspective of copying such immune responses with a vaccine has placed the characterization of broadly neutralizing antibody responses against HIV into the centre of HIV vaccine research. 


\section{HIV Envelope Antibody Response and Escape}

\section{HIV envelope in early infection}

HIV infection most commonly is mediated by a small number of virions. Around $80 \%$ of heterosexual transmissions are established by a single virus(Abrahams et al., 2009; Keele et al., 2008). The rates of multiple-variant transmissions are higher among men who have sex with men(Li et al., 2010) and in association with inflammatory genital infection(Haaland et al., 2009). Thus, transmission seems to pose a significant bottleneck to the virus, which is supported by early signature mutations in the envelope that might increase infectivity. One example for such a signature mutation is the loss of a possible N-linked glycosylation site (PNLG) at residues 413-415(Derdeyn et al., 2004;

Gnanakaran et al., 2011). After this bottleneck the viral population rapidly diversifies, allowing formation of up to 50 versions of a single given epitope within a few weeks and escape from early $\mathrm{T}$ cell mediated selective pressure(Wood et al., 2009) (Fischer et al., 2010)

\section{HIV envelope antibody response is delayed}

The first detectable serum antibody response to HIV env arises shortly before the peak viremia in the third week (reviewed in (Cohen et al., 2011; McMichael et al., 2010)). Initially, this response is directed to gp41 and is believed to have little effect on early viral dynamics(McMichael et al., 2010; Tomaras et al., 2008). Gp120 antibodies develop after the gp41 response and are believed to preferentially target the variable loop 3(Davis et al., 2009; Tomaras et al., 2008). In serum neutralization assays, autologous neutralizing activity requires at least 4-14 weeks to develop. Heterologous neutralization is 
significantly delayed and therefore rarely detected within the first year of infection(Gray et al., 2007; Liao et al., 2013; Mikell et al., 2011; Richman et al., 2003; Wei et al., 2003). Of note, most of these observations were acquired with polyclonal serum neutralization tests in conjunction with sequence analysis of patient envelope genes. More recent efforts have identified antibody mediated selection pressure earlier than detectable in serum neutralization assays by combining single envelope genome analysis with monoclonal antibody characterization. In the patients studied, the epitopes targeted in this early effective antibody response included the V1/2 and V3 loops and the gp120 outer domain as well as the CD4 binding site (CD4bs)(Bar et al., 2012; Liao et al., 2013).

\section{HIV envelope escapes from antibody pressure}

HIV avoids autologous neutralization through escape mutations. This was first demonstrated for HIV in a series of experiments that tested serum neutralizing activity against autologous viruses from different time points. Serum was able to neutralize virus from previous time points better than contemporaneous virus(Richman et al., 2003; Wei et al., 2003). Escape mutations often involve PNLG's (Wei et al., 2003) (Rong et al., 2009). As each N-linked glycan can reach the size of one entire V3 loop these mutations lead to considerable changes on the envelope surface. This observation introduced the model of a mobile glycan shield as a means of continuous viral escape (Wei et al., 2003). Interestingly, escape is mediated both by loss and gain of glycosylation sites(Gnanakaran et al., 2011; van Gils et al., 2011). Escape from neutralizing glycan-antibodies is achieved by loss of glycan sites such as N188(Gnanakaran et al., 2011) whereas addition of other glycan sites helps to shield targets of neutralizing activity. Other escape mechanisms in 
chronic HIV infection involve amino acid mutations and additions in the V3 and in V1/2, which are believed to mediate neutralization resistance by shielding parts of the envelope spike (see below and(Euler et al., 2012; Moore et al., 2009; Rong et al., 2009)). Recently, a first study combining monoclonal anti-HIV B cell isolation and viral envelope characterization has prospectively followed in one patient the evolution of a broadly neutralizing antibody clone and the concomitant viral escapes (Liao et al., 2013). In this case the interplay between constant viral escape and strong selection pressure by a CD4bs directed antibody clone eventually lead to the development of strong heterologous neutralization after more than 70 weeks of infection (Liao et al., 2013). In summary, there is ample evidence for a delayed development of an effective antibody response in HIV infection. Once mounted, this response exerts selective pressure on the virus by following a constantly evading viral population. The recent development of high throughput single env genome analysis combined with monoclonal antibody studies hopefully will provide a more detailed portrait of this continuous dialogue between antibodies and env. 


\section{Broadly Neutralizing Sera}

\section{Definition and Frequency}

Reports of neutralizing serum activity early in the epidemic (Weiss et al., 1985; Weiss et al., 1986) were difficult to interpret because most HIV neutralization assays at that time used T cell line adapted HIV strains. These were found to be readily neutralized and do not reflect true primary isolates in natural infection(Li et al., 2005). The recent development of standardized, tiered neutralization assays (Li et al., 2005) for large-scale HIV patient screens has established that $10-30 \%$ of patients eventually develop a broadly neutralizing antibody response against difficult to neutralize primary isolates(Doria-Rose, 2010; Gray et al., 2011; Mikell et al., 2011; Sather et al., 2008; Simek et al., 2009; Stamatatos et al., 2009; Walker et al., 2010). 1\% of patients seem to fall into a more stringently defined category of "elite neutralizers". These sera are able to potently neutralize more than one strain in four different clade groups of a selected panel of isolates(Simek et al., 2009).

\section{Factors associated with broad neutralization are unknown}

Broad neutralization usually is acquired over several years(Gray et al., 2011; Sather et al., 2009) and peaks around four years after infection. It is not understood what the clinical relevance of broad serum neutralization in patients is, as it does not lead to viral control or slower disease progression(Euler et al., 2010; Pereyra et al., 2008). Also, it is not clear what causes this activity. Several studies found a correlation between the development of broad neutralization and either low CD4 counts or high viral loads or both(Doria-Rose et al., 2009; Gray et al., 2011; Sather et al., 2009; van Gils et al., 2009). 
One of the studies(Gray et al., 2011)only found this correlation if CD4 counts and viral loads from set point (6 months into infection) and not from later time points were included in the analysis. This correlation implies, that early events in infection might influence the later development of broad neutralization. In addition, analysis of envelope sequences from 69 patients uncovered signature sequences in env that are associated with high or low neutralizing activity in the same patients(Gnanakaran et al., 2010). As discussed below, the recruitment of particular germline progenitor B cells into germinal center reactions is important for initiating the development of broadly neutralizing serum activity. Therefore, the idea that certain viral envelopes might be more efficient in engaging the "right" germline progenitors is an intriguing concept.

In summary, the reasons why some individuals develop broadly neutralizing serum activity are not yet clear. However, early CD4 counts and viral loads as well as certain viral envelope features might play a role in this evolution.

\section{Targets of broad Neutralization}

In an attempt to identify the targeted epitopes, broadly neutralizing serum samples have been extensively characterized by serum fractionation using mutant forms of the env protein. The results of these studies and their implications are reviewed here.

Serum fractionation studies are limited for several reasons: Firstly, they are unable to identify monoclonal antibodies and therefore display a limited resolution. Also, it is difficult to evaluate neutralization potency of an antibody fraction in a bulk mixture, in

which the quantitative representation of single antibody clones is unknown. Nevertheless, these studies have provided a first insight into broadly neutralizing epitopes. 


\section{Gp120}

\section{CD4 binding site}

Paramagnetic-bead-immobilized gp120 depletes significant neutralizing activity in a large fraction (around 50\%) of broadly neutralizing sera(Binley et al., 2008; Tomaras et al., 2011; Walker et al., 2010). Some of this activity is directed to the CD4 binding site (CD4bs), the site of interaction between env and its main receptor on the target cell. Since the discovery of CD4 as the main receptor for HIV infection (Dalgleish et al., 1984; Sattentau et al., 1986)the CD4bs on gp120 has received widespread attention(Weiss et al., 1988). In particular the observation that soluble CD4 neutralizes HIV broadly(Smith et al., 1987), has raised the question if antibodies might structurally mimic this interaction.

The first gp120 core crystal structure was obtained in complex with CD4 and an antibody to the CD4 induced site (see below)(Kwong et al., 1998). This landmark study has helped define the CD4bs on gp120. CD4 contacts the inner domain, outer domain and bridging sheet of gp120. This contact site forms two cavities on gp120 that accommodate residues with sequence variability. They are surrounded by highly conserved residues such as $\mathrm{Asp}^{368}, \mathrm{Glu}^{370}, \operatorname{Trp}^{427}$ and $\mathrm{Asp}^{457}$ (Kwong et al., 1998). Two of these residues, Asp ${ }^{368}$ and $\mathrm{Glu}^{370}$ at the Phe ${ }^{43}(\mathrm{CD} 4)$ cavity are also important contact sites of the neutralizing CD4bs antibody b12(Burton et al., 1991; Wyatt et al., 1998), which confirmed that neutralizing antibodies can target structurally conserved parts of the CD4bs (Binley et al., 2004; Wyatt et al., 1998). 
A point mutant in one of these conserved sites, gp120 ${ }^{\mathrm{D} 368 \mathrm{R}}$, was used in serum fractionation studies(Binley et al., 2008; Li et al., 2007; Tomaras et al., 2011; Walker et al., 2010). In some sera with gp120 directed broad neutralization, adsorption with the mutant left neutralization unaltered. In these cases, neutralization could be mapped to the CD4bs. Intriguingly, some of these fractions displayed potent neutralizing activity against b12 resistant viruses (see below)(Li et al., 2007), suggesting that monoclonal CD4bs antibodies superior to b12 might exist (see below).

\section{CD4 induced site}

The CD4 induced site (CD4i) is an epitope on gp120 that is exposed after binding of gp120 to CD4(Sattentau et al., 1993; Thali et al., 1993) and overlaps with the coreceptor binding site of gp120(Rizzuto et al., 1998; Wu et al., 1996). The epitope involves the $\beta 20-\beta 21$ ribbon of the outer domain and stems of variable loops $1 / 2$ which upon CD4 binding together form the bridging sheet(Chen et al., 2005). The epitope's conservation among different viral strains makes it an attractive target for broad neutralization(Kwong et al., 1998; Rizzuto et al., 1998). On the other hand, the epitope is concealed by variable loops V1/V2 and V3(Kwong et al., 1998) and is assembled properly only after CD4 binding(Chen et al., 2005). This might explain why the best antibody of this group, 17b, shows only limited neutralization breadth and potency against primary isolates(Seaman et al., 2010).

The role of CD4i antibodies in broad serum neutralization could not be clearly defined by serum fractionation. Some studies did not find significant activity to this epitope(Binley 
et al., 2008; Tomaras et al., 2011). Another study did reveal some broad CD4i activity (Li et al., 2009)using a point mutant of the key residue, gp120

In summary, the CD4i is a conserved but well concealed epitope on gp120. Serum fractionation might not be an appropriate tool to characterize the role of CD4i antibodies in broad neutralization. The recent identification of CD4bs directed antibodies that are sensitive to the CD4i point mutation gp120 $0^{\mathrm{I} 20 \mathrm{R}}$ (see below) renders this reagent insufficient to clearly differentiate between CD4bs and CD4i directed activity. However, CD4i antibodies in serum do neutralize broadly in the presence of CD4(Decker et al., 2005) and are believed to maintain CD4 dependence of HIV during infection(Kolchinsky et al., 2001).

\section{Variable Loop V3}

To directly evaluate the role of antibodies directed to variable loops V1/2 and V3, sera with gp120 directed broad neutralization were fractionated with a gp120 core that lacks these variable loops(Dhillon et al., 2007; Tomaras et al., 2011). The inability to adsorb gp120 directed neutralization with gp120 core in some cases suggests that a significant fraction of broad neutralization in those patients is directed to the variable loops (Dhillon et al., 2007; Tomaras et al., 2011).

Next to the CD4i, the V3 loop is the second site of interaction with the coreceptor on the target cell. Therefore it is required for viral infectivity(Cao et al., 1997) and determines CXCR4 or CCR5 tropism(Hwang et al., 1991). 31-39 amino acids long, the loop is divided into a base, a flexible stem and a $\beta$-hairpin tip(Huang et al., 2005). In the unliganded state the V3 is located laterally on the trimer apex(Liu et al., 2008). It might 
contribute to inter-monomeric interactions(Liu et al., 2008) and to neutralization sensitivity of the envelope spike. Upon binding to CD4 the loop is released from this position and points directly towards the target cell(Liu et al., 2008). This exposed position allows both the base and the tip of the loop to interact with the coreceptor as a "molecular hook"(Huang et al., 2005).

The role of V3 directed antibodies in vaccine design and broad neutralization has been heavily debated. During acute infection, V3 specific antibodies are among the first to show autologous neutralizing activity (Davis et al., 2009; Goudsmit et al., 1988). This observation early on in the HIV epidemic has lead to the term "principal neutralizing domain" and has inspired several vaccination approaches(Goudsmit et al., 1988; Javaherian et al., 1990; Javaherian et al., 1989; Zolla-Pazner et al., 2009). However, restricted neutralizing breadth and potency of V3 directed monoclonal antibodies(Binley et al., 2004; Gorny et al., 2004) has raised the concern, that although immunogenic, the V3 loop might be not accessible to antibodies on difficult to neutralize primary isolates(Hartley et al., 2005; Wu et al., 2008).

In order to assess the contribution of this class of antibodies to broadly neutralizing serum activity, serum studies used V3 loop peptides as inhibitors in neutralization assays(Binley et al., 2008; Dhillon et al., 2007; Li et al., 2008). This approach was justified by the peptide specificity of the most active known V3 loop specific monoclonals (Stanfield et al., 2004; Stanfield et al., 2006) but did not detect any broad V3 peptide specific activity(Binley et al., 2008; Dhillon et al., 2007; Li et al., 2008). However, a recently discovered class of broadly neutralizing antibodies bind to a conformational epitope 
involving the V3 loop (see below). Given their conformational epitope nature, these antibodies were not detected in V3 peptide competition assays.

Overall, the newly identified antibodies have confirmed that the V3 loop indeed is targeted by broadly neutralizing activity. However, these antibodies target conformational epitopes rather than continuous peptides.

\section{Variable Loops V1/2}

Cryo electron microscopy images revealed that the V1/2 loops are located at the tip of the trimer(Hu et al., 2011; Liu et al., 2008). V1/2 loop deleted trimers show a more open structure and heterogeneity of configuration(Hu et al., 2011). This suggests that the loops most likely contribute to gp120 inter-monomeric interactions (Hu et al., 2011). Crystal structures of $\mathrm{V} 1 / 2$ in the context of a scaffold show that the domain folds as four conserved anti-parallel $\beta$ strands with two connecting variable and heavily glycosylated loops(McLellan et al., 2011).

V1/2 loops are not required for viral infectivity but removal leads to increased neutralization sensitivity toward V3 and CD4i antibodies(Cao et al., 1997; Liu et al., 2011). Also, in the course of infection, changes in glycosylation as well as other mutations and insertions are believed to mediate escape from autologous neutralization(van Gils et al., 2011). Despite their important role in neutralization sensitivity, until recently it was not known if variable loops V1/2 are targeted by broadly neutralizing antibodies. In fact their strong glycosylation and variability suggested that this might not be possible(Pantophlet and Burton, 2006). Similar to the serum fractionation results obtained with $\mathrm{V} 3$ peptides, $\mathrm{V} 1 / 2$ derived peptides were not able to 
block broadly neutralizing serum activity(Li et al., 2008). However, recently a group of broadly neutralizing antibodies was identified, that penetrates the glycan shield at gp120 residue N160 and also targets the base of V1/2 (see below, PG9, PG16(Walker et al., 2009), CH01-04(Bonsignori et al., 2011), PGT141-145(Walker et al., 2011)). Following this, several serum studies identified broadly neutralizing sera that target this region. These experiments were performed using V loop mutant viruses and adsorption on gp120 point mutants(Tomaras et al., 2011; Walker et al., 2010). Differences among these antibodies in their ability to bind to monomeric gp120 and point mutants suggest that there are different approaches to target this epitope(Tomaras et al., 2011).

\section{Gp41}

After interactions of gp120 with CD4 and the coreceptor, gp41 undergoes conformational changes that allow fusion of the virus with the target cell.

In this process, the $\mathrm{N}$-terminal fusion peptide is inserted into the target cell membrane and the two gp41 triple-stranded heptad repeat regions HR-N and HR-C are maximally separated. This state is also referred to as the 'prehairpin intermediate'(Chan and Kim, 1998) and is targeted by the fusion inhibitor Enfuvirtide(Wild et al., 1992). The three strands then fold back into three hairpins and form a stable six-helix bundle. This brings the viral and target cell membranes into close proximity and establishes a stably locked membrane pore(Markosyan et al., 2009).

Using monoclonal antibodies and polyclonal sera in ELISA based assays, five partly overlapping binding clusters were identified as antibody targets on gp41 (reviewed in 
(Pietzsch et al., 2010b)). Of these, clusters I, II and the membrane proximal region (clusters III and IV) have received the greatest attention.

Cluster I lies in the so-called immunodominant region between the two heptad repeat coils. Although this epitope is accessible on pre-hairpin as well as pre-fusion states of the gp41 molecule(Frey et al., 2008) no neutralizing antibodies to this epitope were isolated to date. Possible explanations for this include poor epitope accessibility on the native membrane-bound trimer and inability to inhibit fusion even after antibody binding(Finnegan et al., 2002).

Cluster II lies in the c terminal heptad-repeat region, adjacent to the membrane proximal region (MPER). Antibodies to this part of gp41 have also not shown broadly neutralizing activity so far. However, the epitope might be involved in binding to the phage display neutralizing antibody m44(Zhang et al., 2008). Although binding studies to cell surface expressed trimers had suggested otherwise(Finnegan et al., 2002), cluster II antibodies seem to bind to gp41 only in the postfusion conformation, which would explain their inability to neutralize(Frey et al., 2010). Both of these studies used the same monoclonal antibodies and the discrepancies between the results corroborate the need to understand more about the native envelope structure in its different fusion states.

Finally, the MPER is the target of broadly neutralizing antibodies 2F5, 4E10, Z13 and 10E8 (see below and (Zwick et al., 2001a) (Huang et al., 2012; Pejchal et al., 2009)). Inspired by the broad and potent activity of these monoclonal antibodies, serum studies have assessed if this epitope is targeted frequently by broadly neutralizing antibodies. 
One of these studies identified three donors with broad MPER activity among 156 patients(Gray et al., 2009). This is in contrast to a recent screen of 72 neutralizing serum samples that found a significantly higher frequency (27\%) of MPER directed broadly neutralizing activity(Huang et al., 2012).

In summary, different areas of the MPER seem to be targeted by broadly neutralizing activity in some patients. If other parts of gp41 also are involved in broad neutralization is not known so far. A neutralizing phage display derived antibody, m44, binds to a conformational gp41 epitope (Zhang et al., 2008). But it is unlikely, that this antibody was made in an immune response. Finally, our structural understanding of gp41 is still poor. Cryo-electron microscopy studies of native trimers come to different conclusions regarding the overall gp41 structure in a tripod configuration(Mao et al., 2012; Zhu et al., 2006; Zhu et al., 2008) or a compact stalk(Zanetti et al., 2006). Also, although recent crystal structures have added the MPER and fusion peptide(Buzon et al., 2010), the integration of the MPER into the viral membrane is not well defined.

In summary, a large fraction of broadly neutralizing serum activity can be adsorbed by gp120. In other cases, neutralizing activity is directed to the MPER or could not be adsorbed at all. HIV neutralizing serum activity is diverse, even within single patients, and the CD4 binding site is often targeted. However, mapping of neutralizing activity has to be re-evaluated, since several new neutralizing conformational epitopes involving the variable loops have been identified (see below). Also, undefined neutralizing activity still remains a significant fraction in several cases and underscores the importance of increasing our structural understanding of the native HIV spike. 
In the future, serum fractionation studies will be able to guide other technologies with higher resolution. As the body of monoclonal broadly neutralizing antibodies will grow, adsorption studies will be able to evaluate, how far we are from a complete deconvolution of broad HIV serum neutralization.

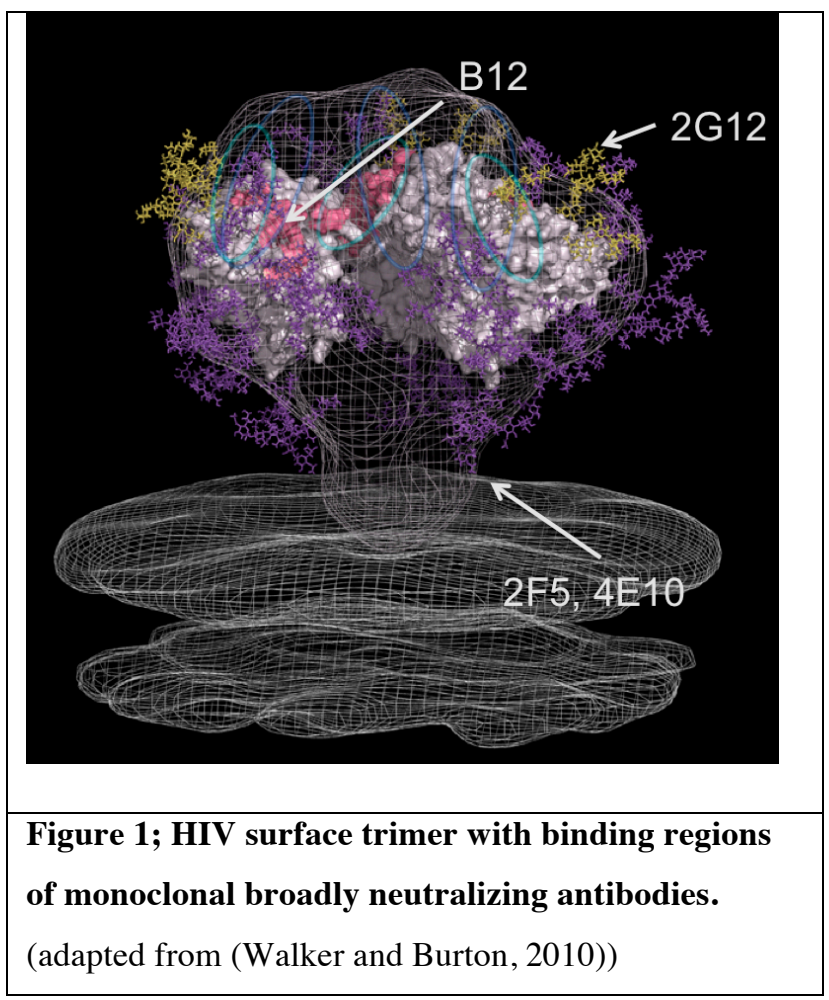




\section{Monoclonal HIV Neutralizing antibodies}

Up to the year 2009, almost three decades of significant research efforts had yielded only four broadly neutralizing monoclonal antibodies, 2F5, 4E10, 2G12 and b12.

\section{F5 and 4E10}

Antibodies 2F5 and 4E10 were isolated from patient peripheral blood mononuclear cells (PBMCs) using EBV immortalization and electrofusion(Buchacher et al., 1994; Purtscher et al., 1994). They target adjacent, continuous epitopes on the membrane proximal region (MPER) of gp41(Fig.1)(Muster et al., 1993; Ofek et al., 2004; Zwick et al., 2001a). Co-crystallization of both antibodies with peptides revealed that considerable parts of the CDR3 regions, in particular the tip, are not interacting with the respective peptide epitopes(Cardoso et al., 2005; Ofek et al., 2004), suggesting further interactions between the antibodies and the adjacent viral lipid membrane. This has been confirmed for 4E10 using nuclear magnetic resonance, electron paramagnetic resonance and surface plasmon resonance(Sun et al., 2008). Also, mutation studies in $2 \mathrm{~F} 5$ have shown, that alteration of the hydrophobic CDR3 tip markedly reduces neutralizing activity while leaving the affinity to the peptide epitope unchanged(Ofek et al., 2010). Together, this data places the MPER epitopes of 2F5 and 4E10 into the context of the viral lipid membrane and might explain in part why vaccination with gp41 has not been able to elicit this type of antibodies yet(Dennison et al., 2009; Dennison et al., 2011; Kim et al., 2007). However, the exceptional neutralization breadth of 4E10(Binley et al., 2004) as well as impaired infectivity of viral escape variants(Manrique et al., 2007) reflect the 
conservation of the MPER epitope among the majority of HIV clades and thus makes it an important vaccine target (Dennison et al., 2011).

\section{$2 \mathrm{G} 12$}

$2 \mathrm{G} 12$ is a monoclonal antibody directed to gp120. As antibodies $2 \mathrm{~F} 5$ and 4E10, $2 \mathrm{G} 12$

was isolated from patient PBMCs using EBV transformation and electrofusion(Trkola et al., 1996). The epitope of 2 G12 lies in the "glycan shield" of the trimer (Fig. 1). A large part of the HIV envelope spike surface (50\% of its molecular weight) consists of Nlinked glycosylation sites. This "glycan shield" seems to increase and shift in the course of infection and escape from autologous antibody responses(van Gils et al., 2011; Wei et al., 2003; Wyatt et al., 1998; Wyatt and Sodroski, 1998). As N-linked glycosylation is performed by the eukaryotic enzyme machinery in the endoplasmatic reticulum, these sites are recognized as "self" by the immune system, which poses another mechanism of viral immune evasion.

Co-crystallization of 2G12 with the disaccharide Mano1-2Man and the oligosaccharide $\mathrm{Man}_{9} \mathrm{GlcNAc}_{2}$ characterized the interaction of $2 \mathrm{G} 12$ with its epitope and identified a novel interlocked VH domain-swapped dimer Fab structure(Calarese et al., 2003). This structure allows the interaction with a dimer interface region in addition to the two classical antigen recognition sites. 


\section{b12}

In contrast to the above mentioned antibodies, b12 was isolated from an HIV patient using random heavy and light chain pairing in a phage display library(Burton et al., 1991; Burton et al., 1994). Therefore, structural insights derived from this antibody must be interpreted carefully.

Despite this limitation, b12 has introduced the CD4 binding site as an important target of broadly neutralizing serum responses (Fig. 1). Docking the crystal structure of b12 onto gp120 in the CD4 bound conformation(Saphire et al., 2001) and direct co-crystallization (Zhou et al., 2007)have defined a footprint of the b12 binding area on gp120. 


\section{Application of neutralizing antibodies}

\section{Protection through transfer of neutralizing antibodies}

The discovery of antibodies 2G12, 4E10, 2F5 and b12 has impacted our structural understanding of the HIV surface trimer and pointed out possible vaccine targets.

However, their direct value as protective or therapeutic agents against HIV has also been extensively assessed in vivo.

One of the first passive transfer studies in macaques used bulk IgG instead of monoclonal antibodies. The polyclonal IgG had been isolated from macaques that had developed a neutralizing response after being infected with a variety of clade B strains (Shibata et al., 1999). Passive immunization followed by intravenous challenge with $\mathrm{SHIV}_{\mathrm{DH} 12}$ showed that complete protection was possible but dose dependent and only conferred by IgG that showed in vitro neutralization against the challenge virus(Shibata et al., 1999). Protection against intravenous challenge was also achieved in macaques using HIVIG and monoclonal antibodies 2G12 and 2F5 (Mascola et al., 1999). However, in order to reach sterile protection, a combination of these three reagents was required and passive immunization with either 2G12, 2F5 or HIVIG alone was not sufficient in the setting of intravenous virus challenge(Mascola et al., 1999).

At the same time, passive transfer of monoclonal antibodies $2 \mathrm{G} 12$ or b12 alone mediated protection against vaginal virus challenge(Mascola et al., 2000; Parren et al., 2001). Finally, the vaginal application of a total of $5 \mathrm{mg}$ of the monoclonal antibody b12 was able to protect 4/4 macaques against vaginal SHIV challenge(Veazey et al., 2003). 
In summary, these studies have lent support to the model of antibody based protection from intravenous and mucosal HIV challenge and thus invigorated efforts to find a way to elicit these classes of antibodies with a vaccine. At the same time, high concentrations of antibodies were required in order to reach protective levels due to the relatively limited potency of the antibodies used. This limitation at the time diminished hopes to widely use these antibodies as reagents in passive immunization or even reach sufficient levels by vaccination(Mascola and Nabel, 2001).

As discussed below, the recent identification of highly potent HIV antibodies by us and other groups has changed the potential of achieving HIV protection by vaccination or passive immunization dramatically (Balazs et al., 2012). So far we still are far from using these new antibodies in the clinical setting as protective reagents against HIV or even achieving this activity by active immunization. However, the unprecedented potency and breadth of these new reagents and modified versions thereof(Song et al., 2010) as well as the growing number of neutralizing target epitopes make these goals significantly more feasible as just a few years ago.

\section{Treatment approach of established HIV infection with broadly neutralizing}

\section{antibodies}

In addition to protection against viral challenge, monoclonal antibodies potentially could offer modification or even reduction of an established HIV infection.

This was first studied in 14 antiretrovirally treated HIV infected subjects whose viral isolates were highly sensitive to broadly neutralizing antibodies(Trkola et al., 2005). Antibodies 2G12, 2F5 and 4E10 were passively administered over a period of 11 weeks 
during which antiretroviral treatment was paused. Overall, the mixture of antibodies was able to delay viral rebound in $2 / 8$ chronically infected participants(Trkola et al., 2005). In acutely infected individuals the viral rebound was delayed in 6/6 cases(Trkola et al., 2005), although this is hard to interpret because these cases were not internally controlled for viral rebound without antibody treatment. Nevertheless, the more pronounced delay of rebound in acutely infected individuals might be attributable to a less diverse viral population in recently infected patients, leading to a reduced likelihood of preexisting escape mutants to the respective antibodies.

There are numerous limitations to this study including the fact that b12 as one of the more potent monoclonal antibodies known at that time was not included and plasma levels of $2 \mathrm{~F} 5$ and $4 \mathrm{E} 10$ were significantly lower than for $2 \mathrm{G} 12$. Resistance to $2 \mathrm{G} 12$ was acquired in the majority of cases but to $2 \mathrm{~F} 5$ and $4 \mathrm{E} 10$ in only $3 / 14$ and $0 / 14$ of the cases respectively. Therefore, 2F5 and 4E10 might not have been present in concentrations sufficient to exert selective pressure.

Nevertheless, this study has introduced a potential therapeutic application of broadly neutralizing antibodies in humans and proven that this type of antibodies can exert selective pressure in an established HIV infection.

Similar to HIV protection by passive antibody administration (see above), HIV antibody therapy has to be completely reassessed since the recent discovery of highly potent broadly neutralizing antibodies. First experiments in humanized mice (Klein et al., 2012b) have yielded prolonged control of viral loads in animals treated with a combination of 5 antibodies. 
This finding transformed the longstanding dogma that HIV envelope spike diversity and capacity to mutate would preclude any attempt to use it as a target in HIV antibody treatment. Several studies are now underway to investigate how this treatment compares to traditional HAART and if these two treatment modalities might be combined in humans.

In summary, until 2009 three decades of intense research efforts had produced only 4 broadly neutralizing antibodies using EBV immortalization, electrofusion and phage display libraries. These antibodies have provided some insight into possible vaccine targets and in vivo applications of monoclonal antibodies including prevention and treatment. However, the fact that broad neutralizing serum activity against HIV is developed in around $10 \%$ of millions of HIV patients demanded a systematic investigation of this activity. 


\section{Memory B cells as a target to study HIV B cell responses}

The thrust of our study was to design a way to efficiently and systematically study the B cell response against HIV in patients with broadly neutralizing serum activity. This would allow us to learn more about possible vaccine targets and isolate highly potent monoclonal antibodies for possible clinical applications. For this, we started with a large screen of 470 serum samples from HIV patients with low to intermediate viral loads. In accordance with previous studies (Doria-Rose, 2010; Gray et al., 2011; Mikell et al., 2011; Sather et al., 2008; Simek et al., 2009; Stamatatos et al., 2009; Walker et al., 2010) we found that $5 \%$ of patients display broadly neutralizing serum activity. But where is this activity generated and which cells would be appropriate to study in order to characterize the monoclonal components of polyclonal serum activity?

\section{Germinal Centers}

Specificity and high affinity of antibodies are created in germinal center reactions(Berek and Milstein, 1987; Eisen and Siskind, 1964; Jerne, 1951; McKean et al., 1984; Weigert et al., 1970). Initially believed to be the anatomical site of lymphocyte production, germinal centers change in size and mitotic activity following injection of foreign antigens(reviewed in (Nieuwenhuis and Opstelten, 1984)). This mitotic activity was attributed to dividing B cells(Nieuwenhuis and Opstelten, 1984), which connected germinal center formation with the development of antigen specific B cell responses. Somatic hypermutation and affinity maturation of immunoglobulins are key elements of antigen specific B cell responses (Berek and Milstein, 1987; McKean et al., 1984; Weigert et al., 1970) and are located at the site of germinal center reactions(Berek et al., 
1991; Jacob et al., 1991b). In vivo studies(Allen et al., 2007a; Allen et al., 2007b; Hauser et al., 2007; Schwickert et al., 2007) provided insight into the dynamic structure of the germinal center reaction:

In the initiation of a germinal center reaction, mature naive $\operatorname{IgM}^{+} \mathrm{B}$ cells are recruited based on their antigen affinity and subsequently undergo several rounds of affinity maturation of their immunoglobulin genes(Berek et al., 1991; Jacob et al., 1991a; Jacob et al., 1991b; Nieuwenhuis and Opstelten, 1984; Victora and Nussenzweig, 2012). Migrating back and forth between dark and light zones of the germinal center, the B cells proliferate and mutate in the dark zone before returning to the light zone in order to bind to antigen presented by follicular dendritic cells and receive stimulation through $\mathrm{T}$ helper cells(Allen et al., 2007a; Allen et al., 2007b; Hauser et al., 2007; Schwickert et al., 2007). After probing the affinity of the mutated B cell receptor (BCR), the B cells then return to the dark zone for a further round of proliferation and mutation before returning to the light zone again(Victora and Nussenzweig, 2012).

The key enzyme involved in the process of somatic hypermutation as well as class switch recombination in the dark zone is Activation Induced Deaminase (AID), which deaminates cytidine residues in the VDJ and switch regions of Ig genes(Neuberger et al., 1999; Nussenzweig and Nussenzweig, 2010; Pavri and Nussenzweig, 2011). The mutation rate of AID is approximately $10^{-3}$ per base pair per cell division and its activity targets transcribed regions displaying ssDNA, therefore posing a potential threat to other parts of the B cell genome(Muschen et al., 2000; Nussenzweig and Nussenzweig, 2010; Odegard and Schatz, 2006; Pasqualucci et al., 2001; Shen et al., 1998). One could 
speculate, that AID mediated somatic hypermutation might partly explain increased rates of B cell lymphomas during chronic infections, such as HIV(Gaidano et al., 2003).

\section{Memory B cells}

The outcome of a germinal center reaction are antibody secreting plasma cells as well as memory B cells(Blink et al., 2005; Phan et al., 2006), both of which carry immunoglobulins with high affinity to their antigen. Post germinal center memory B cells are non-cycling cells that do not require stimulation by antigen in order to persist for long periods of time(Maruyama et al., 2000). However, they expand rapidly in response to antigen and develop into plasma cells that reside in the bone marrow and produce large quantities of antibodies(Dorner and Radbruch, 2005, 2007).

Given their high density of specific surface Ig, memory B cells potentially are ideal targets to investigate the B cell response against a specific antigen(Greenstein et al., 1980; Hayakawa et al., 1987; McHeyzer-Williams et al., 1991; Scheid et al., 2009b). Using fluorescently linked antigens, we proposed to first identify the HIV envelope specific memory B cell response in donors with high levels of broadly neutralizing serum activity. We then planned to use fluorescence activated cell sorting (FACS) of single antigen specific memory B cells, followed by single cell reverse transcription and specific immunoglobulin gene amplification(Wardemann et al., 2003). This would allow us to analyze, clone and potentially reproduce the immunoglobulins of the HIV envelope specific B cell population on a monoclonal level. 


\section{Chapter 2}

\section{Broad diversity of anti-gp140 memory antibodies}

\section{Characteristics of anti-gp140 memory antibodies}

We characterized the antibodies produced by memory B cells purified from the blood of six patients with broadly neutralizing anti-HIV antibodies and viral titers ranging from 49-12,709 copies/ml. One of the patients was a non-progressor(Binley et al., 2004; Cao et al., 1995), three were elite controllers(Binley et al., 2004; Deeks and Walker, 2007; Walker, 2007), one a slow progressor(Binley et al., 2004; Li et al., 2007), and one was infected two years ago(Scheid et al., 2009a). Artificially trimerized YU2 gp140 protein composed of gp120 and cytoplasmic tail truncated gp41 was used to identify and purify HIV specific B cells because it is believed to resemble the envelope spike in some respects(Farzan et al., 1998; Pancera et al., 2005; Yang et al., 2000; Yang et al., 2002; Zhu et al., 2006). Most importantly, we were able to adsorb the anti-gp120 and -gp41 IgG antibodies in the serum of the patients with trimerized YU2-gp140 (Fig. 2). 


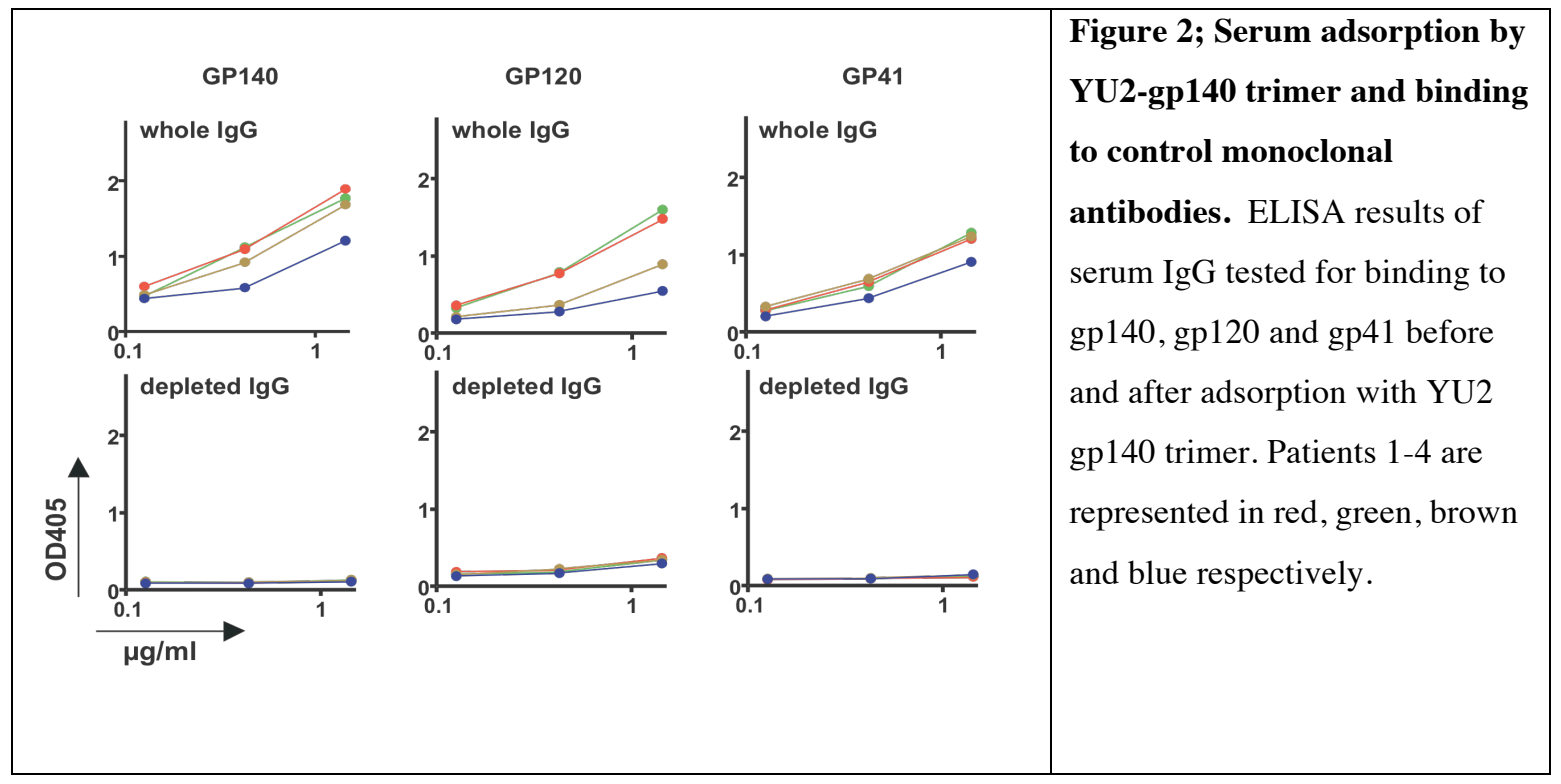

Small numbers of B cells that bound the gp140 trimer were readily detected in the $\mathrm{IgG}^{+}$ memory B cell compartment in the patients but not in uninfected controls (Fig. 3a). Individual gp140 binding memory B cells were purified by cell sorting, and Ig heavy and light chains cloned from single cell cDNA libraries(Scheid et al., 2009b; Tiller et al., 2008). We were able to amplify an average of 114 matching Ig heavy and light chain genes from each of four HIV infected individuals and smaller numbers from two others(Scheid et al., 2009a).

In contrast to random antibody cloning from memory B cells(Mietzner et al., 2008; Tiller et al., 2007), and to the antibodies isolated from B cells that did not bind to gp140 from the same subjects, we found many clonally related antibodies in the gp140 binding B cell repertoire of all six HIV infected individuals (Fig. 3b and Table 1). The number of B cell clones varied among patients from 22-50, and each clone was expanded to varying 
degrees ranging from 1-39 family members (Fig. 3b and Table 1). In all cases the majority of the antibodies derived from gp140 binding memory B cells belonged to clones with more than one member and in patient \#2 all of the 141 antibodies were members of 22 expanded families related by somatic mutations (see below). The finding that most of the antibodies isolated from the four more complete patients belonged to expanded clones suggested that we captured a significant fraction of the gp140-reactive memory B cell repertoire.

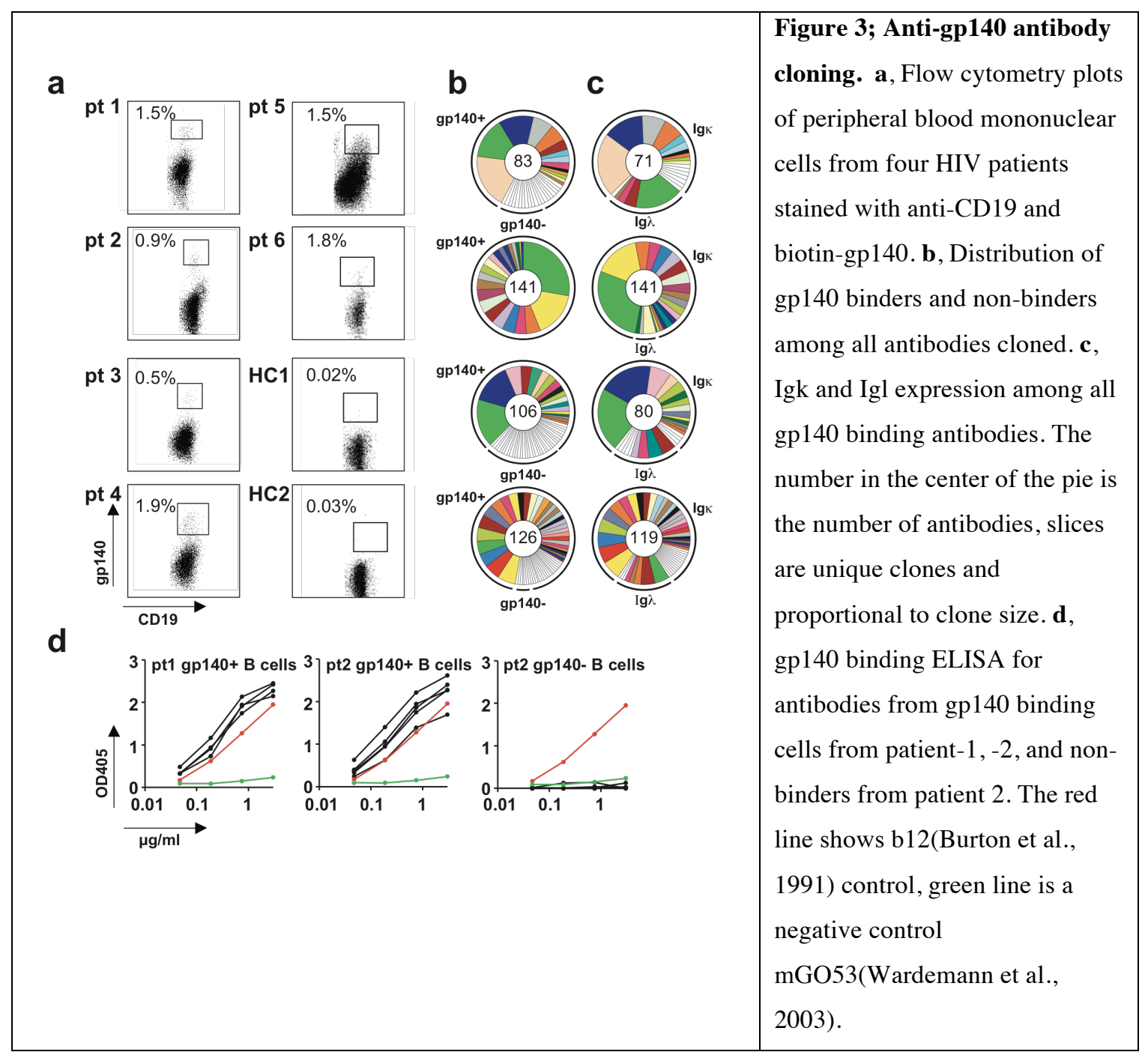


Individual antibodies were expressed as complete IgG molecules by transfection and tested for reactivity to gp140 by ELISA. $86 \%$ of all of the antibodies cloned from gp140 binding B cells were gp140 reactive (Fig. 3B). In contrast, none of the 51 antibodies obtained from the non-gp140 binding memory B cells from two of the same patients were gp140 specific (Fig. 3D and Table 1). In total, out of 501 cloned antibodies we obtained 432 antibodies that bound to gp140, and they belonged to 132 different B cell clones (Table 1). The expanded clones of gp140 binding B cells contained antibodies that were related by mutation with a maximum number of 66 mutations separating the individual clonal relatives (Table 1, and see below). 


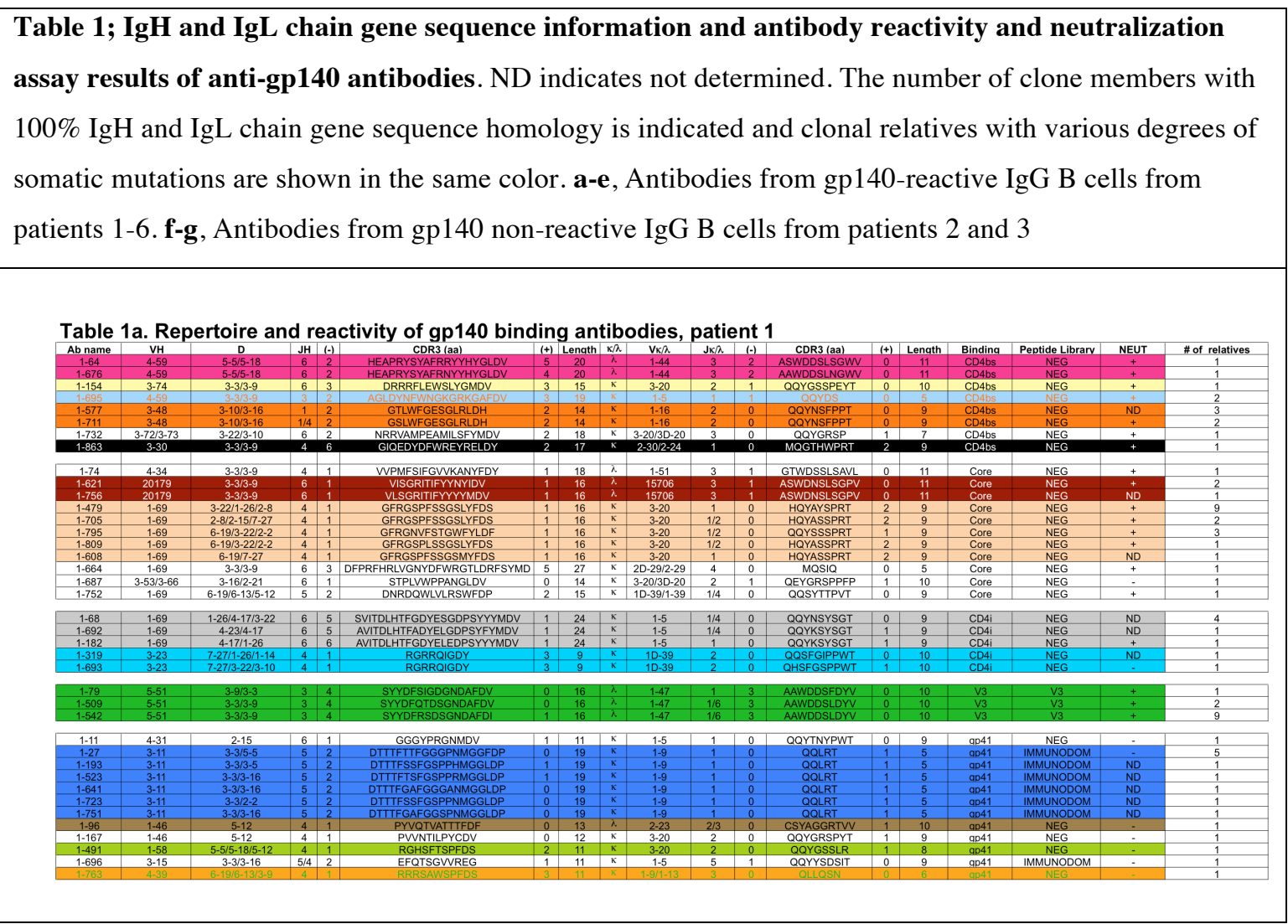


Table 1b. Repertoire and reactivity of gp140 binding antibodies, patient 2

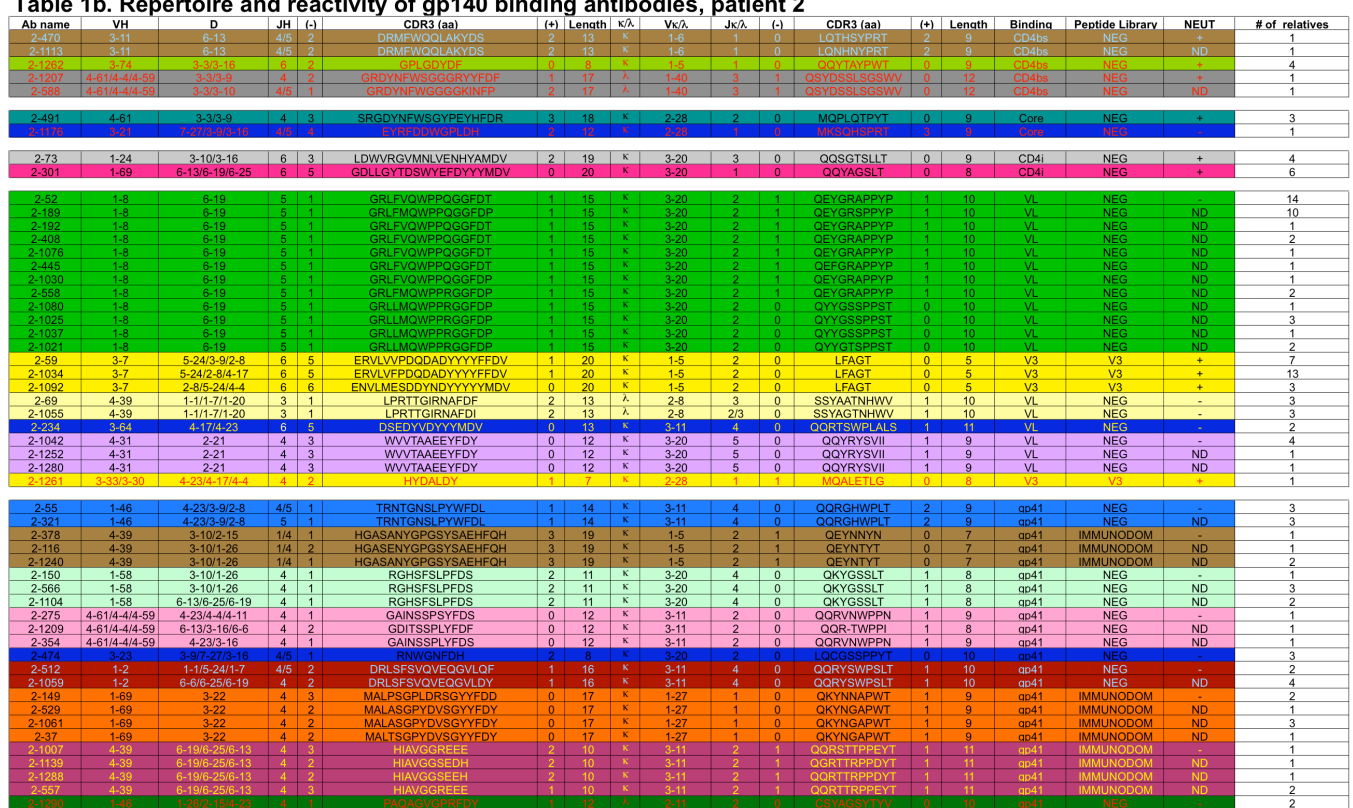

Table 1c. Repertoire and reactivity of gp140 binding antibodies, patient 3
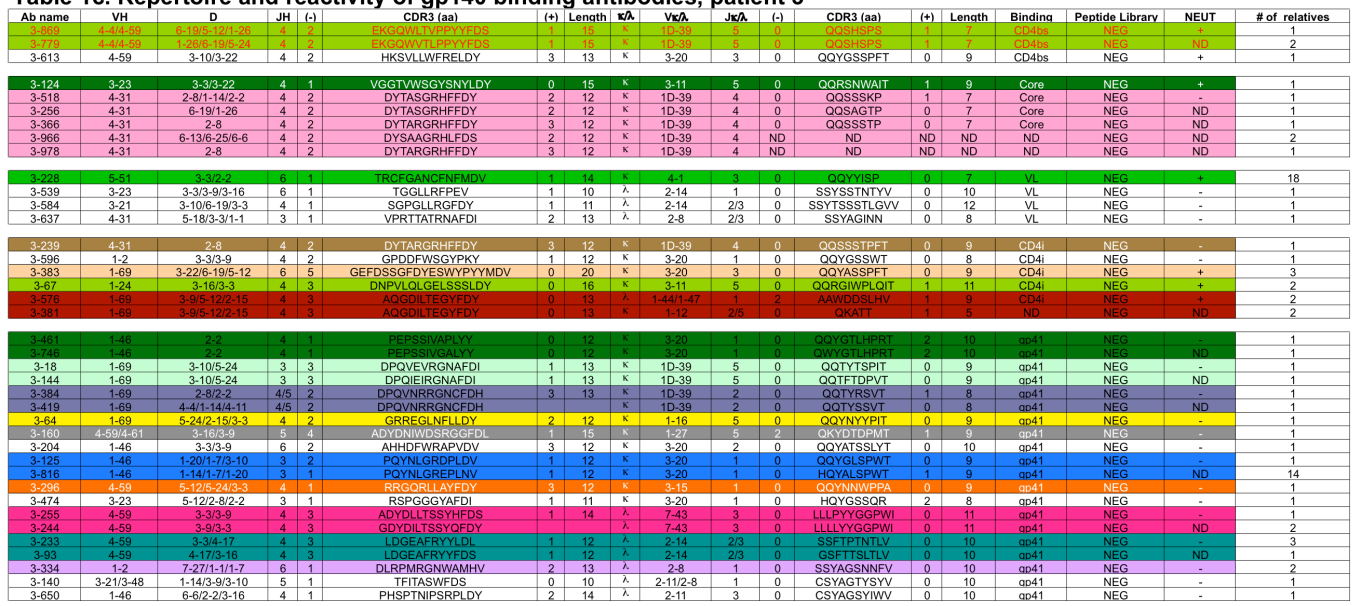
Table 1d. Repertoire and reactivity of gp140 binding antibodies, patient 4
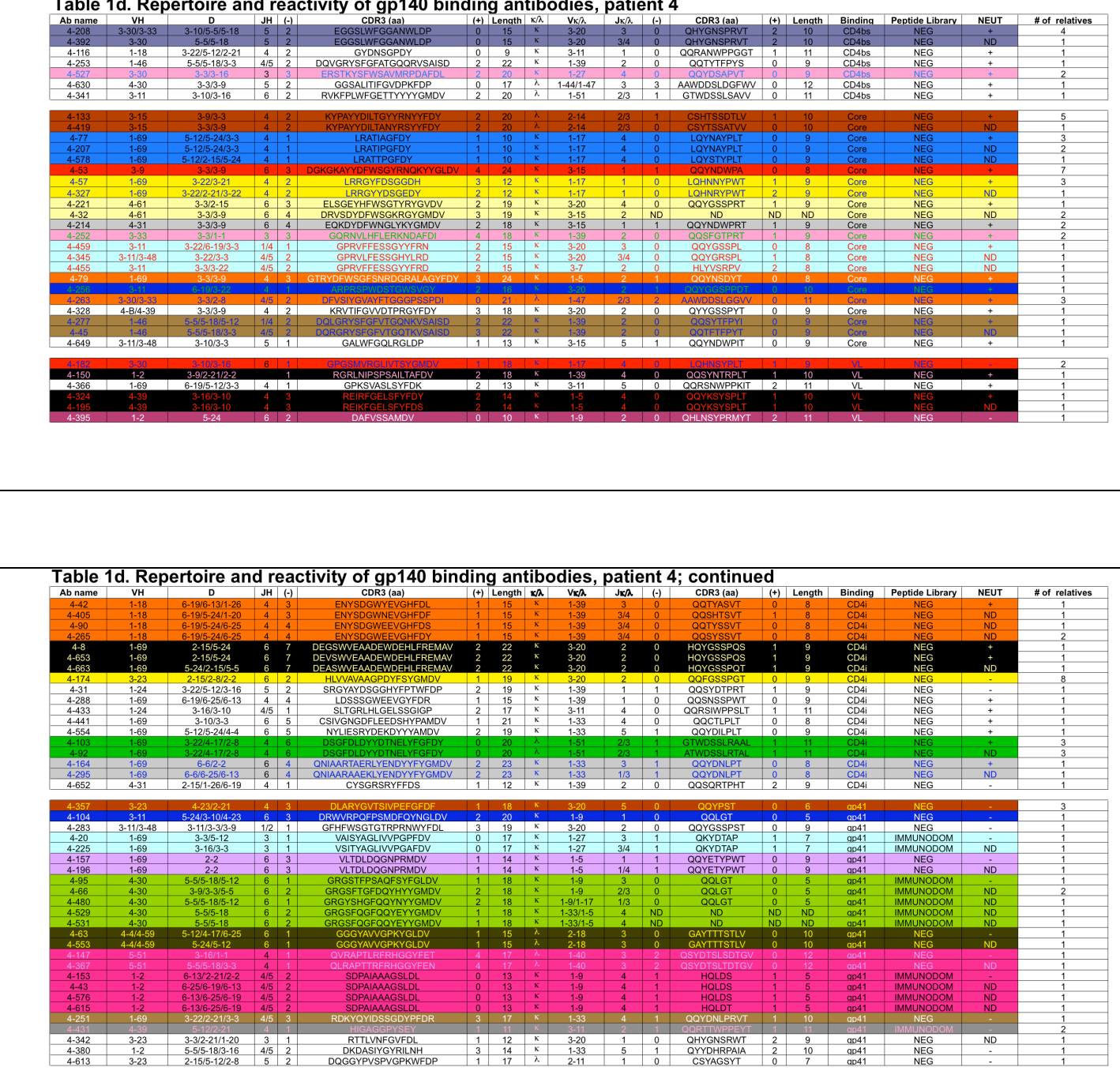

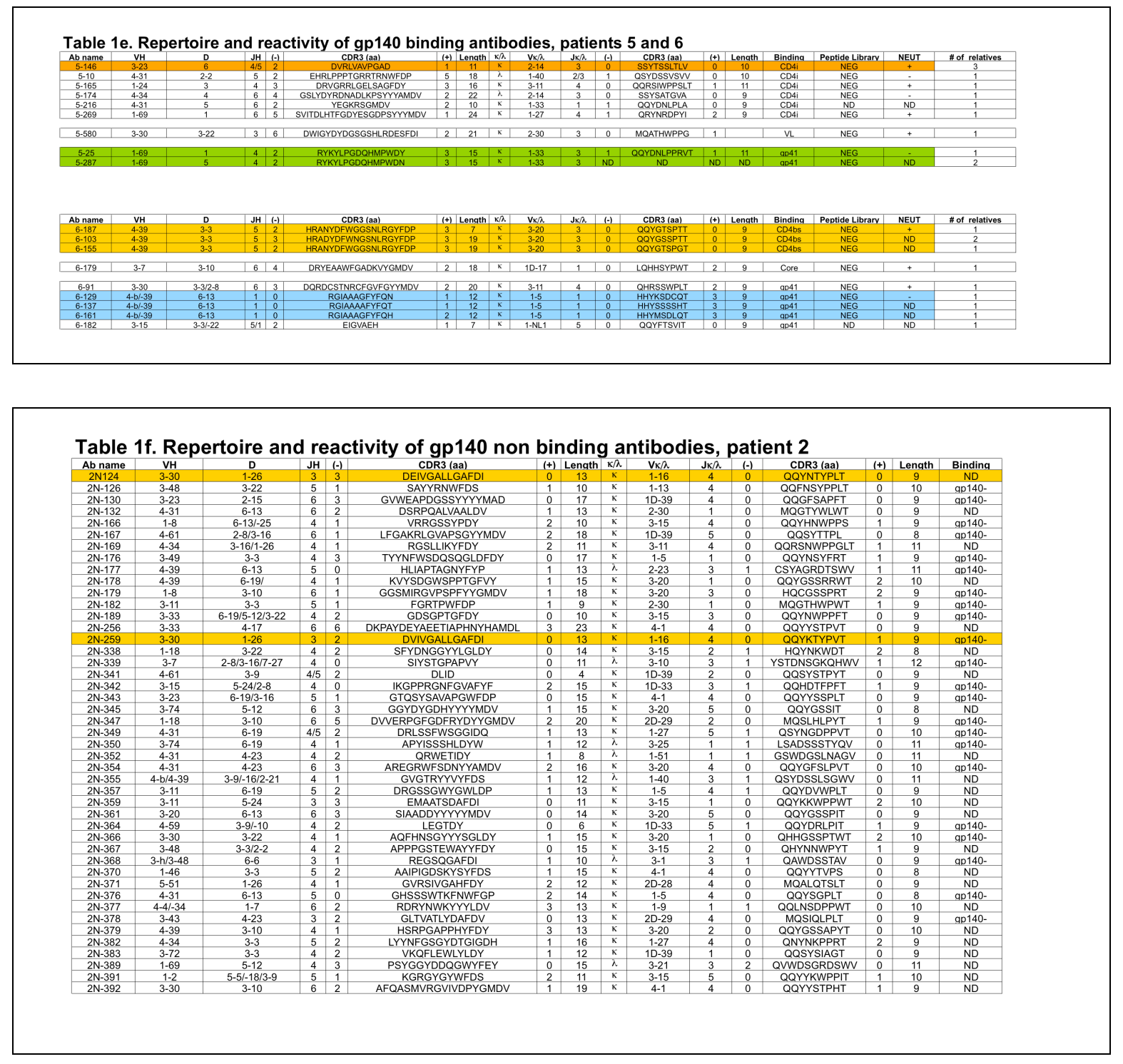
Table 1g. Repertoire and reactivity of gp140 non binding antibodies, patient 3

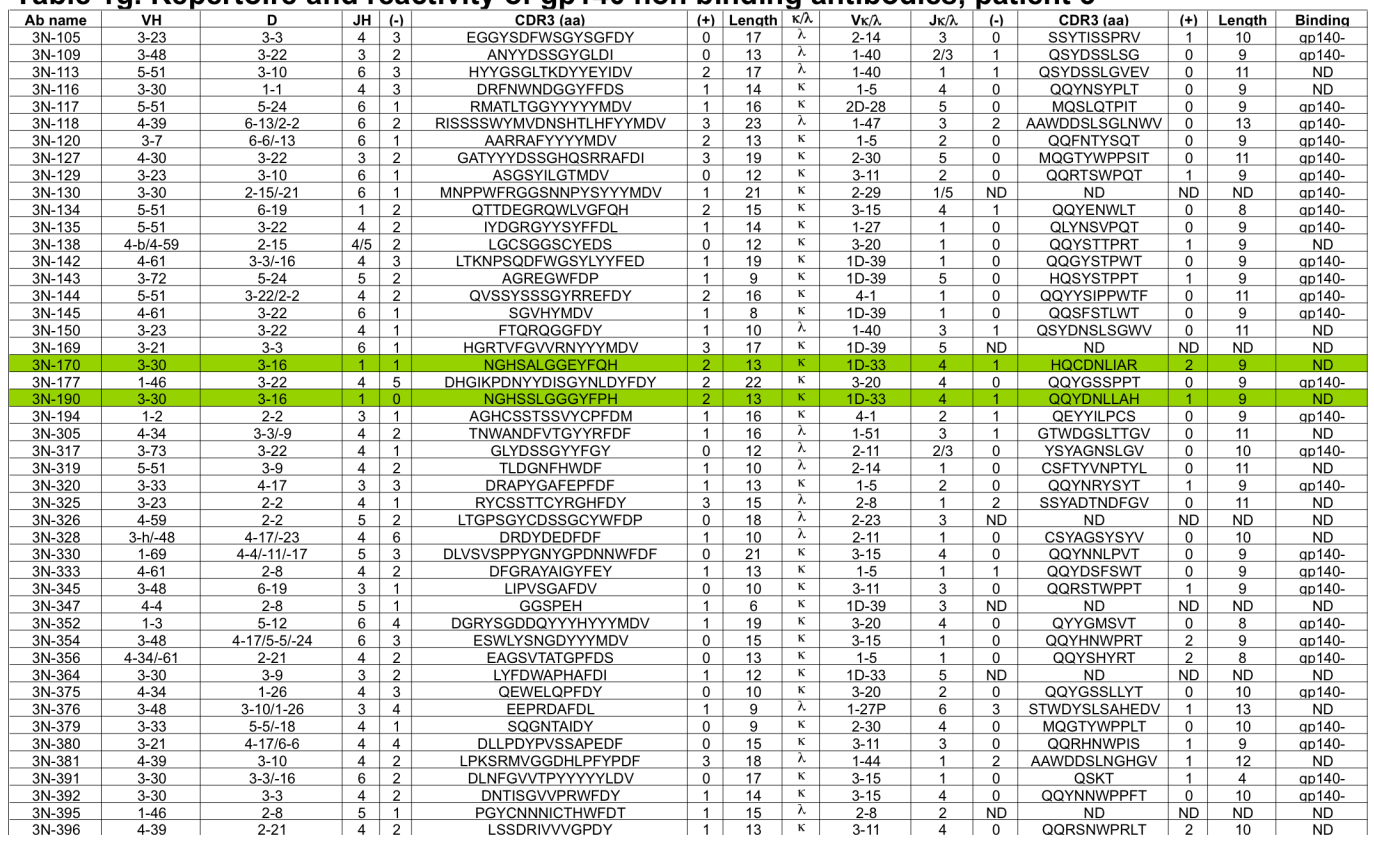




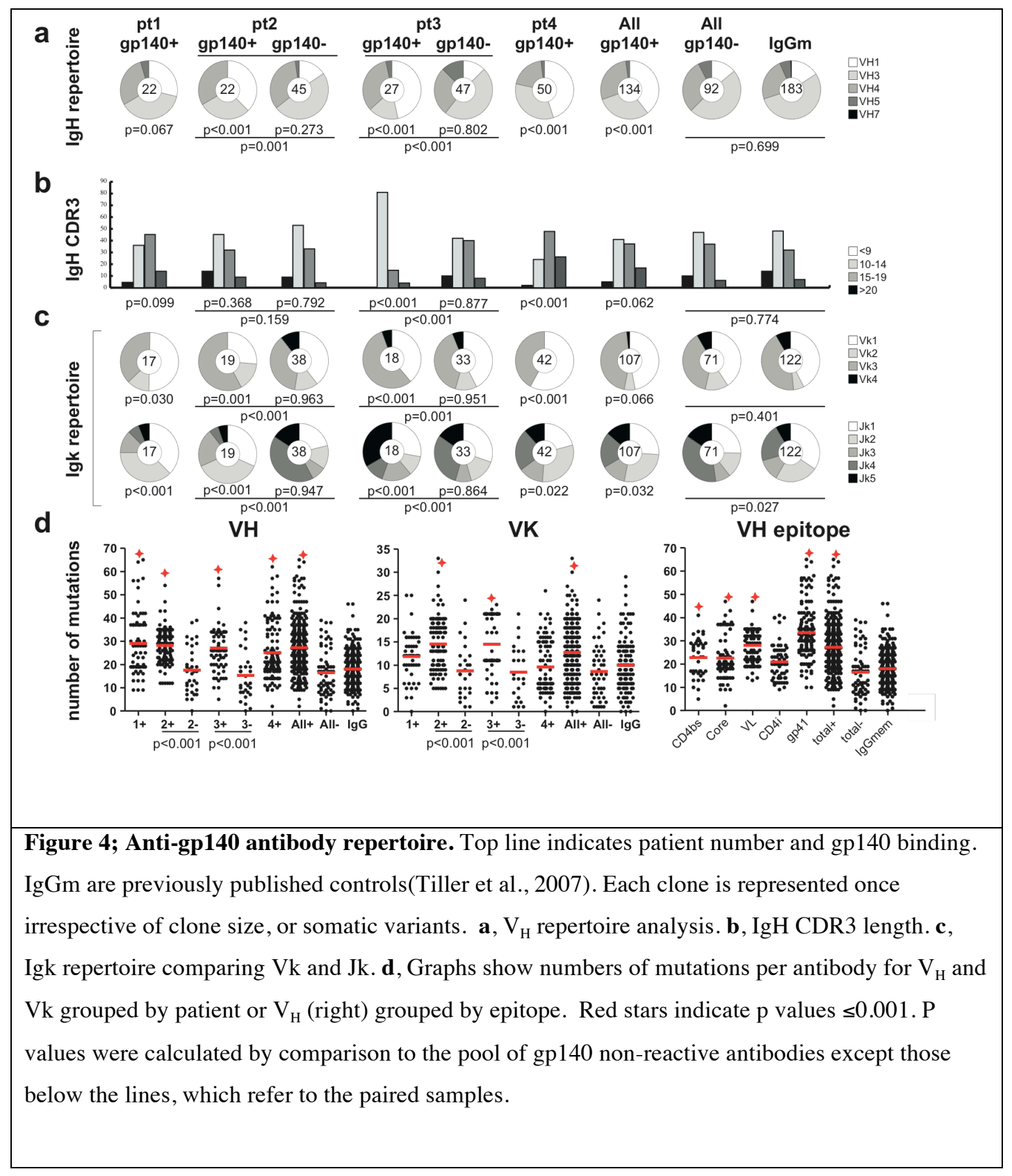


When compared to IgG antibodies derived from non-gp140 binding B cells from the same patients or $\mathrm{IgG}^{+}$memory B cells from historical controls(Tiller et al., 2007) the gp140 binding antibodies were enriched for $\mathrm{V}_{\mathrm{H}} 1$ (Huang et al., 2004), Igk vs. Igl, and Jk2 or Jk5 (Figs. 3c and 4a, b and c). Individual patients showed longer or more charged IgH CDR3s but these features were not found in all of the patients (Fig. 4b). An unexpected finding was that anti-gp140 antibodies were highly mutated when compared to nongp140 binding antibodies from the same patients or randomly cloned IgG memory antibodies from historical controls (Fig. 4d). This difference in mutation frequency was found for both $\mathrm{V}_{\mathrm{H}}$ and $\mathrm{Vk}$ and was highly significant whether we included all antibodies or counted individual clones only a single time (Fig. 4d)(Scheid et al., 2009a). We conclude that anti-gp140 memory B cells are highly selected post-germinal center cells skewed to Igk and $\mathrm{V}_{\mathrm{H}} 1$ usage. The exceptionally high level of mutation found in these antibodies may reflect chronic B cell immune responses to HIV with persistent somatic hypermutation and selection. Previous studies have shown that re-entry of memory B cells into germinal centers occurs in humans(Bende et al., 2007). In the case of HIV, the immune system is confronted with a chronic and constantly mutating pathogen, which could lead to repeated recruitment of memory cells into germinal center reactions, thus leading to ongoing AID mediated somatic hypermutation. 


\section{Epitopes recognized by anti-gp140 memory antibodies}

To map the antigenic specificity of the gp140 binding antibodies we initially performed ELISA experiments with purified gp120 and gp41. We found that $70 \%$ of the gp140 antibodies bound to gp120 and 30\% were gp41 specific (Fig. 5a, b, and c). Thus, the majority of the antibodies cloned from gp140 binding memory B cells in patients with broadly neutralizing anti-HIV antibodies are directed to gp120.

Anti-gp41 antibodies were further screened against a peptide library consisting of overlapping 15mers including the membrane proximal region that binds to two broadly neutralizing anti-gp41 monoclonal antibodies 2F5 and 4E10(Muster et al., 1993; Zwick et al., 2001a). None of the 131 anti-gp41 antibodies assayed bound to the membrane proximal peptides and only five antibodies bound to peptides corresponding to the previously reported immunodominant region of gp41(Xu et al., 1991)(Table 1). We conclude that the majority of the gp41 antibodies produced by gp140 binding memory B cells in patients with broad serum neutralizing activity recognize conformational determinants and that antibodies to the membrane proximal region are difficult to detect in the gp140 trimer binding B cells in these patients despite the fact that both $2 \mathrm{~F} 5$ and 4E10 bind to the trimer and that the trimer adsorbs the majority of the anti-gp41 antibodies in the patients serum (Fig. 2, and (Scheid et al., 2009a)). 


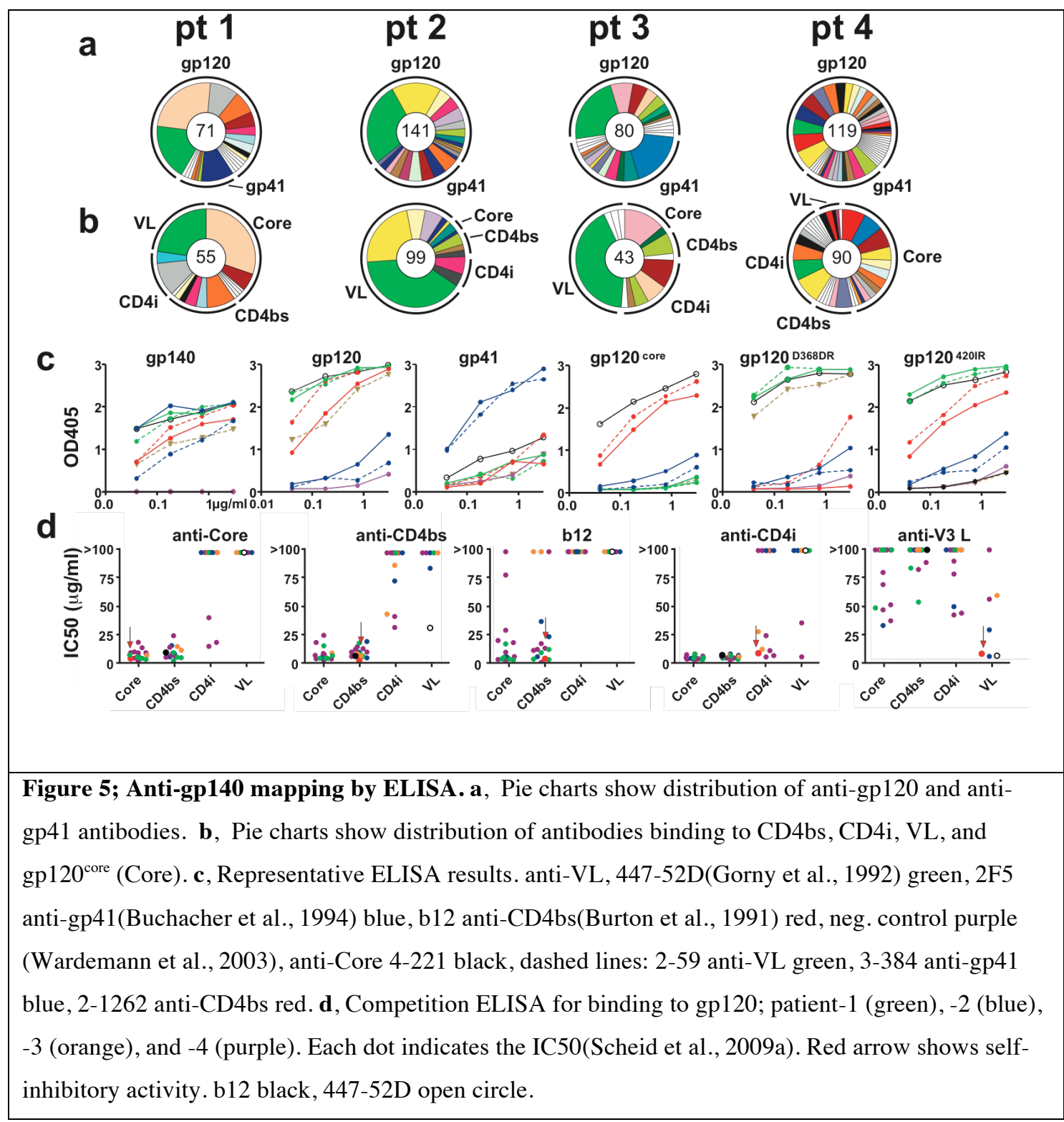

The specificity of the anti-gp120 binding antibodies was further mapped using a collection of mutant proteins: gp120 ${ }^{\mathrm{D} 368 \mathrm{R}}$ interferes with binding to CD4 and all known anti-CD4 binding site (anti-CD4bs) antibodies including b12(Olshevsky et al., 1990;

Pantophlet et al., 2003; Roben et al., 1994; Thali et al., 1991); gp120 ${ }^{\mathrm{I} 20 \mathrm{R}}$ interferes with CD4 induced co-receptor binding site antibodies (anti-CD4i) including 17b(Thali et al., 
1993); gp120 $0^{\text {core }}$ lacks the variable loops (VLs) and interferes with anti-VL and CD4i antibodies(Kwong et al., 2000; Kwong et al., 1998; Wyatt et al., 1998). Antibodies that bound to gp120, gp120 core, $\mathrm{gp} 120^{\mathrm{I} 220 \mathrm{R}}$ but not to gp $120^{\mathrm{D} 368 \mathrm{R}}$ were classified as CD4bs directed. Similarly, those that bound to gp120, gp120 ${ }^{\mathrm{IL20R}}$ but not to gp $120^{\text {core }}$ were classified as anti-VL antibodies, and those that bound to gp120 and gp $120^{\mathrm{D} 368 \mathrm{R}}$, but not to gp120 ${ }^{\mathrm{I} 20 \mathrm{R}}$ were classified as anti-CD4i antibodies. Anti-CD4bs, -CD4i, and -VL antibodies were found in all 4 of the more complete patients but their relative representation varied significantly between patients (Fig. 5b). Among all anti-gp140 antibodies anti-CD4bs made up 9\%, anti-CD4i 16\% and anti-VL 27\% (Fig. 5b). All of these antibodies were also screened for binding to a library of overlapping $15 \mathrm{mer}$ peptides covering all of gp120. Only three of the anti-gp120 antibodies bound to linear peptides and all of these bound to the region within the V3 loop that is also targeted by the previously described antibody 447-52D(Gorny et al., 1992)(Table 1). 


\section{Affinity of anti-gp140 antibodies}

To examine the kinetic binding properties of the anti-CD4bs, -CD4i and -VL antibodies to gp140 we performed surface plasmon resonance experiments with gp140 trimer comparing the binding of 13 such antibodies with the b12 anti-CD4bs monoclonal (Fig. 6 and Table 2). We found that all of the antibodies had rapid association and slow dissociation constants with $\mathrm{K}_{\mathrm{D}}$ 's ranging from $10^{-8}-10^{-11} \mathrm{M}$; b12 performed at the lower end of the spectrum with a $\mathrm{K}_{\mathrm{D}}$ of $1.2 \mathrm{X} 10^{-8} \mathrm{M}$ (Fig. 6 and Table 2). Thus, the gp140 directed IgG memory B cells obtained from the patients studied expressed high affinity antibodies specific for the CD4bs, the CD4i site and the VLs and there was no immunodominant epitope. 


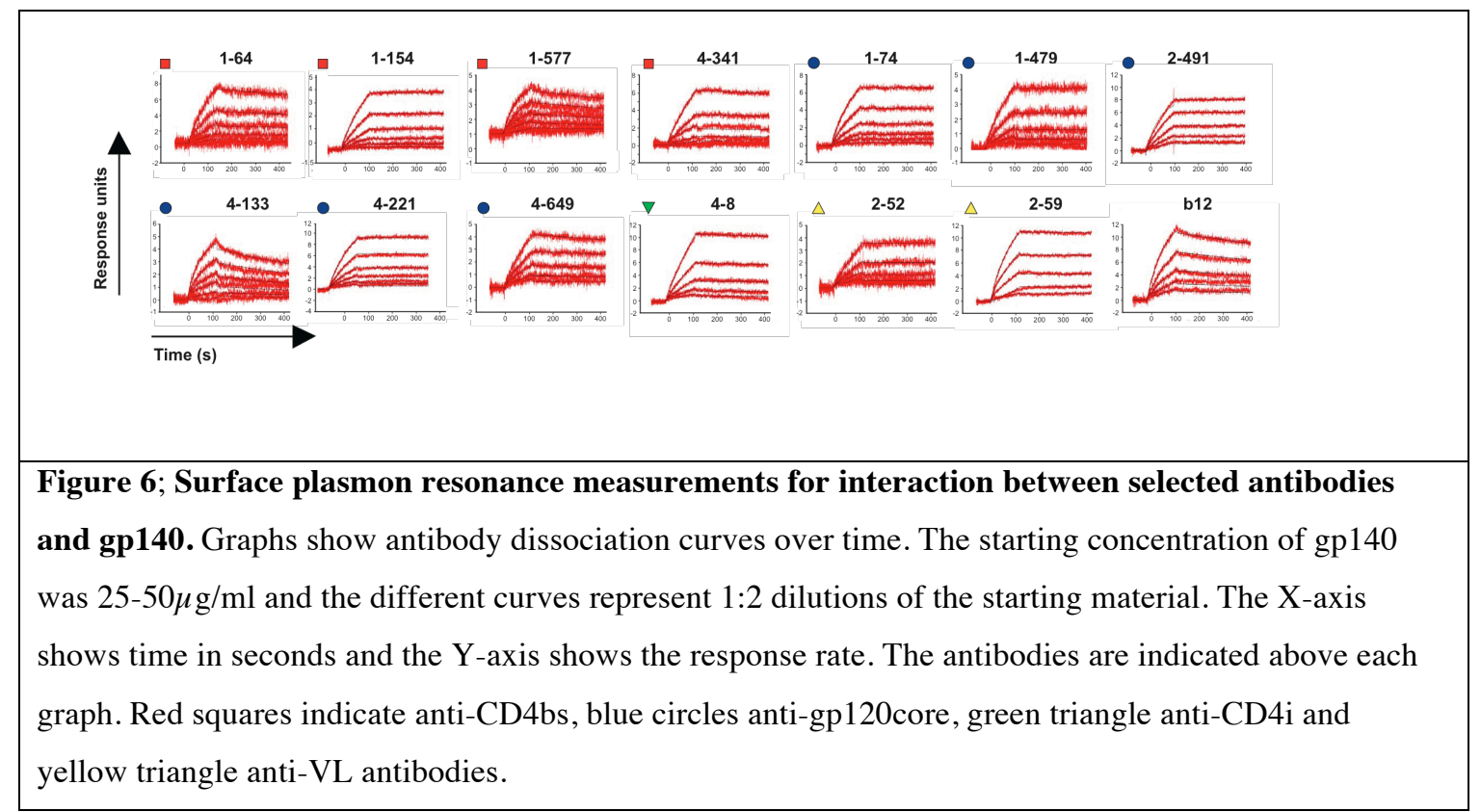

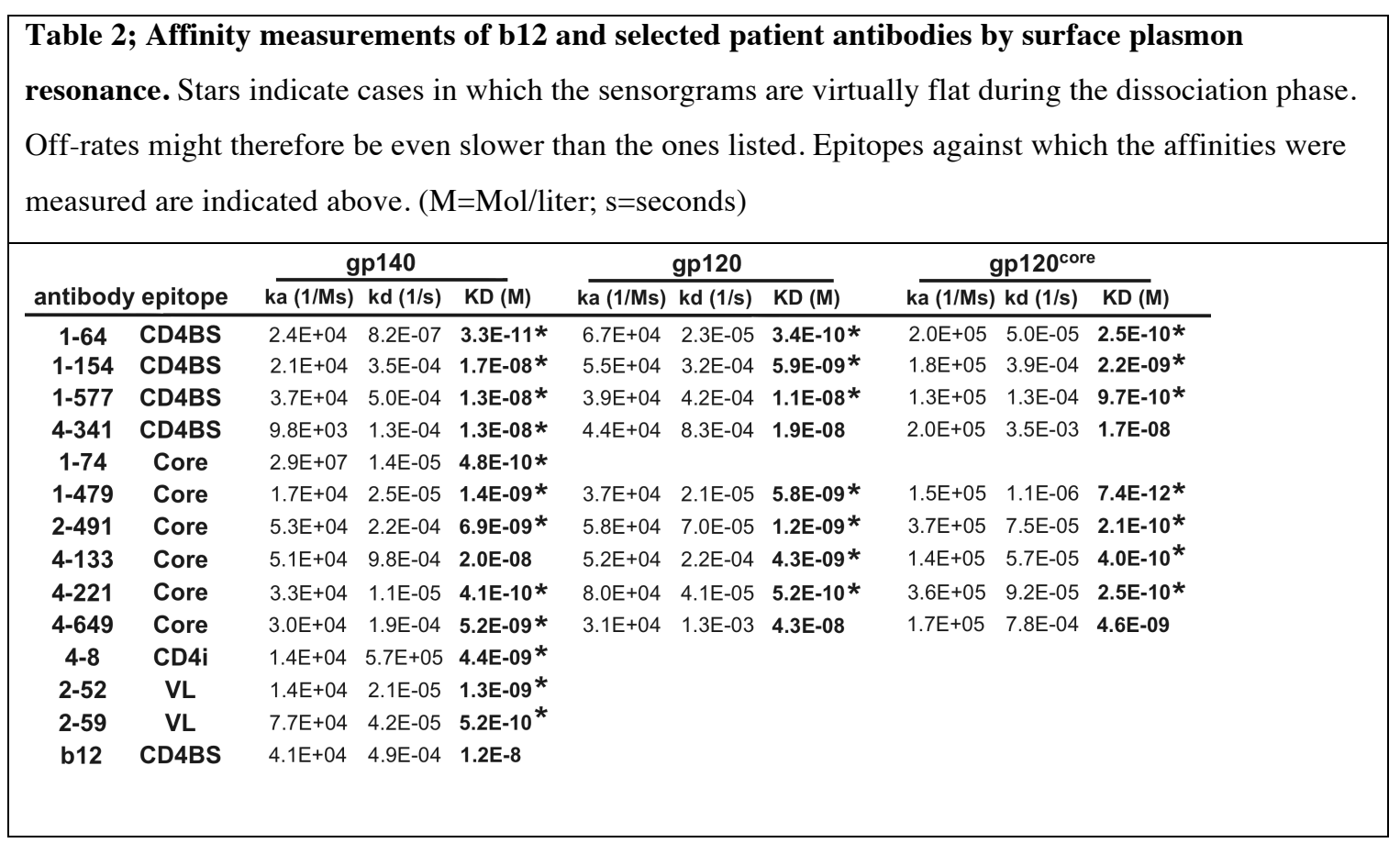




\section{Anti-gp120 ${ }^{\text {core }}$ antibodies.}

In addition to anti-CD4bs, -CD4i, and -VL antibodies we found a group of antibodies that bound to gp120, gp120 ${ }^{\text {core }}, \mathrm{gp} 120^{\mathrm{D} 368 \mathrm{R}}$, and $\mathrm{gp} 120^{\mathrm{I} 20 \mathrm{R}}$ that we refer to as anti-gp120

(Fig. 7). These antibodies also bound to gp120 $368 / 370 \mathrm{AA}$ harboring a double mutation, which also interferes with binding to many of the known anti-CD4bs antibodies and CD4(Li et al., 2007; Olshevsky et al., 1990).

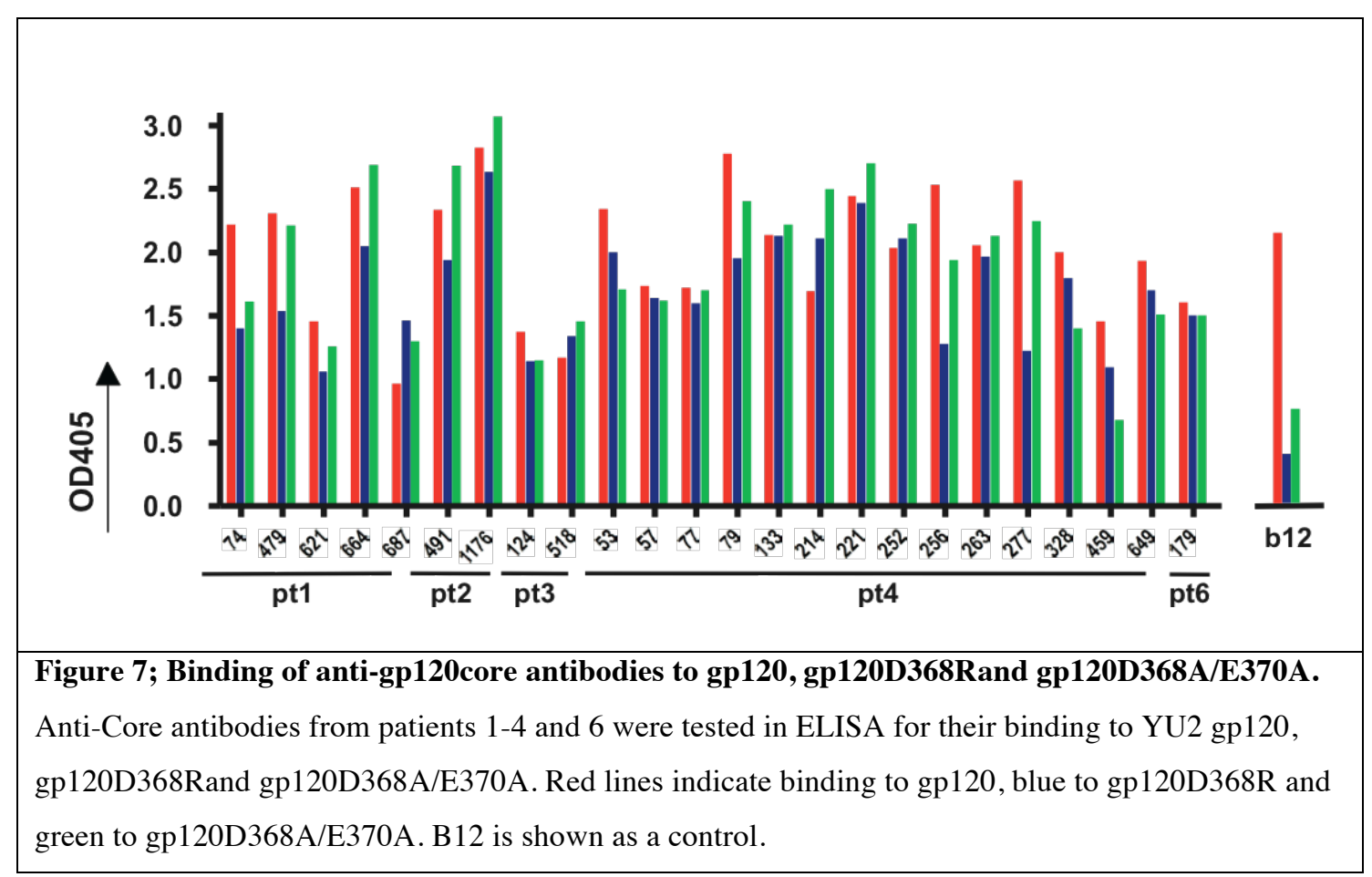




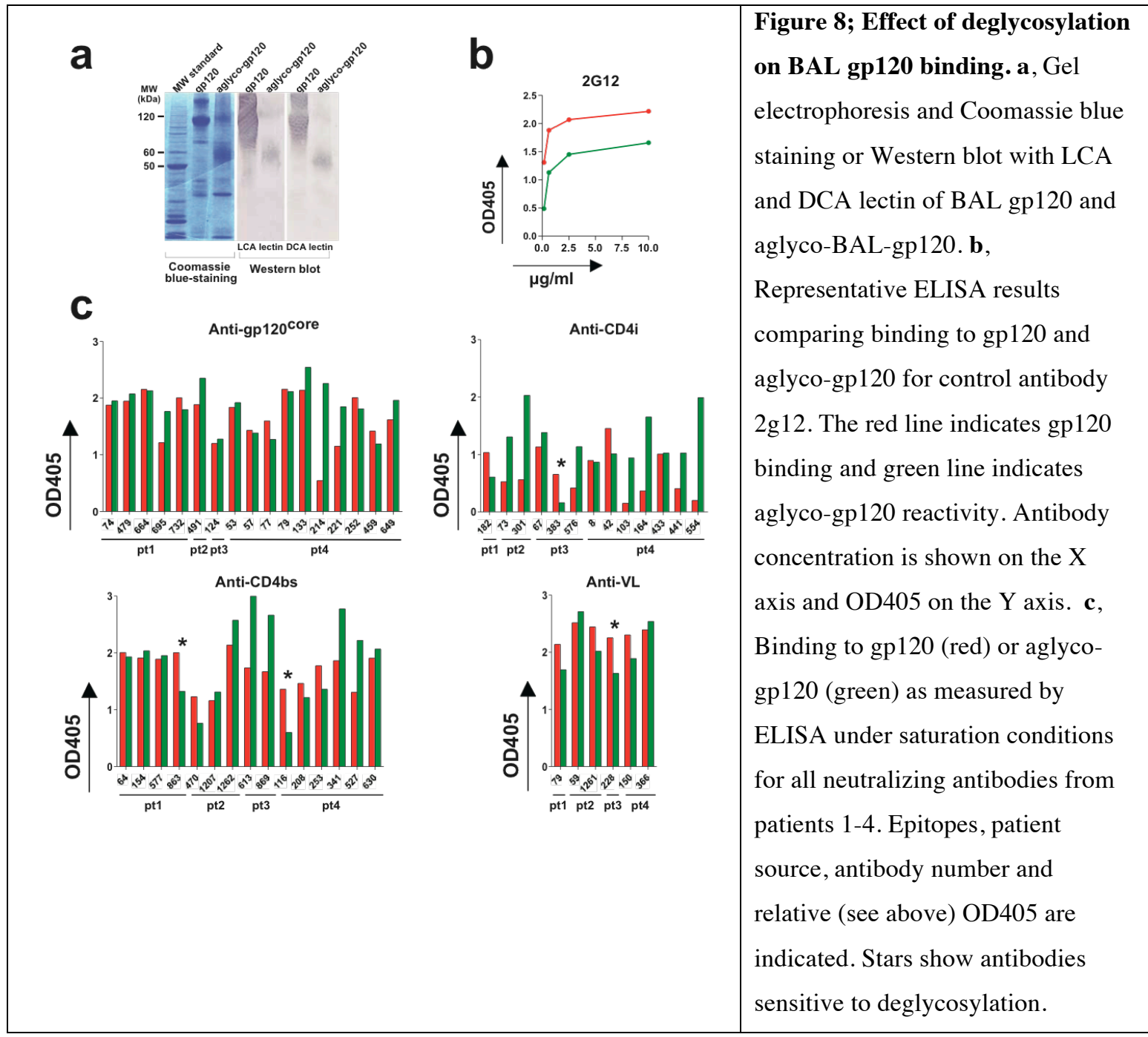

Anti-gp120 core antibodies make up 18\% of all anti-gp140 antibodies cloned from gp140

binding memory B cells varying between patients from 3-35\% of the repertoire (Fig. 5b

and Table 1). In order to determine how many of these antibodies are glycan-directed we compared binding to wild type and deglycosylated BAL gp120. None of the antigp120 $0^{\text {core }}$ antibodies were sensitive to deglycosylation (Fig. 8). Therefore, these antibodies are not predominantly directed to sugar moieties on gp120. In addition, none of the anti-gp $120^{\text {core }}$ antibodies bound to a peptide library consisting of overlapping 15 mers of gp120. 
To further examine the properties of the anti-gp120 $0^{\text {core }}$ antibodies we performed inhibition ELISA experiments using biotin labeled neutralizing antibodies to the CD4bs (b12 and 164), or CD4i (1-182), or the V3L (1-79) or a representative member of the gp120 core specific group (2-491)(Binley et al., 2004) (Fig. 5d and Table 1). As expected the results for the two anti-CD4bs antibodies b12 and 1-64 were similar and both were inhibited by other neutralizing anti-CD4bs antibodies but not by CD4i or VL specific antibodies (Fig. 5d). In contrast, neutralizing anti-CD4i, 1-182, was inhibited by all of the neutralizing anti-CD4bs antibodies, but only by $50 \%$ of the other anti-CD4i (possibly due to differences in affinity) and 29\% of the anti-VL antibodies (Fig. 5d and Table 1). The selected neutralizing anti-V3L antibody was strongly inhibited by the other anti-V3L antibodies and not by anti-CD4bs, anti-CD4i, or other neutralizing anti-VLs that were not V3L-NNNTRKSINIGPGRA peptide specific (Fig. 5 and Table 1). These results are consistent with structural and physiologic data suggesting that the CD4bs is in close proximity to the $\mathrm{CD} 4 \mathrm{i}$ site and that the conformation of the $\mathrm{CD} 4 \mathrm{i}$ site is dependent on the CD4bs(Kwong et al., 1998; Liu et al., 2008; Rizzuto et al., 1998; Thali et al., 1993; Wyatt et al., 1998).

Anti-gp $120^{\text {core }}$ antibodies resembled b12 and CD4bs antibodies in that they inhibited the binding of the selected anti-gp $120^{\text {core }}$, anti-CD4bs, and anti-CD4i, but they did not inhibit binding of the anti-V3L antibody. Conversely, the 2-491 anti-gp120 core antibody was inhibited by the other anti-gp120 $0^{\text {core }}$ and the anti-CD4bs antibodies (Fig. $5 \mathrm{~d}$ and Table 1). However, only three out of thirteen of the anti-CD4i antibodies and none of the seven 
anti-VL antibodies inhibited binding of the anti-gp120 ${ }^{\text {core }}$ (Fig. 5d). The affinity of antigp120 $0^{\text {core }}$ antibodies to gp140 is similar to that of the anti-CD4bs antibodies $\left(\mathrm{K}_{\mathrm{D}}\right.$ 's ranging from $2 \times 10^{-8}$ to $4.8 \times 10^{-10} \mathrm{M}$, Fig. 6 and Table 2 ). In addition, both classes of antibodies show similar affinities to gp120 and gp120 core (Table 2). We conclude that anti-gp120 antibodies recognize an immunogenic epitope in the vicinity of the CD4bs and CD4i sites.

In a follow up study we were able to further characterize the gp $120^{\text {core }}$ epitope by using screening of gp120 alanine mutants(Pietzsch et al., 2010a). ELISA binding assays with the panel of gp $120^{\text {core }}$ antibodies we had isolated (Table1) revealed, that this group of antibodies shares an epitope at the outer/inner domain junction on gp120(Pietzsch et al., 2010a). Furthermore, in experiments using mutant BAL HIV pseudovirus this epitope was essential for viral infectivity(Pietzsch et al., 2010a). 


\section{HIV neutralizing activity}

To examine the neutralizing activity of the memory B cell antibodies we measured their ability to inhibit infection of TZM-bl cells by Env pseudovirus variants(Montefiori, 2005)(Binley et al., 2004). Our panel included one isolate each from clades A and C as well as a group of clade B viruses with different levels of resistance to known neutralizing antibodies(Li et al., 2005; Li et al., 2006; Montefiori, 2005) ranging from tier-1 strains like SF162.LS that are easily neutralized to tier-2 strains like TRO.11 which are not neutralized even by potent broadly neutralizing anti-CD4bs antibody b12(Li et al., 2005)(Fig. 9 and Table 3). Although most of the antibodies were tested against the entire panel, some that did not neutralize any of the tier 1 viruses were not tested against tier 2 viruses (Fig. 9 and Table 3). Finally, purified serum IgG from the patients was assayed on the same viruses for comparison (Fig. 9 and Table 3). Purified IgG neutralized the majority of strains tested, but the activity was most pronounced for the more easily neutralized tier-1 HIV variants while high concentrations of serum IgG were required for the more resistant strains (Fig. 9 and Table 3). Interestingly, 76\% of all anti-gp120s and none of the anti-gp41 clonal families showed neutralizing activity (Fig. 9 and Table 3).

All anti-CD4bs and $88 \%$ of all anti-gp $120^{\text {core }}$ antibodies showed some neutralizing activity (Fig. 9 and Table 3). 


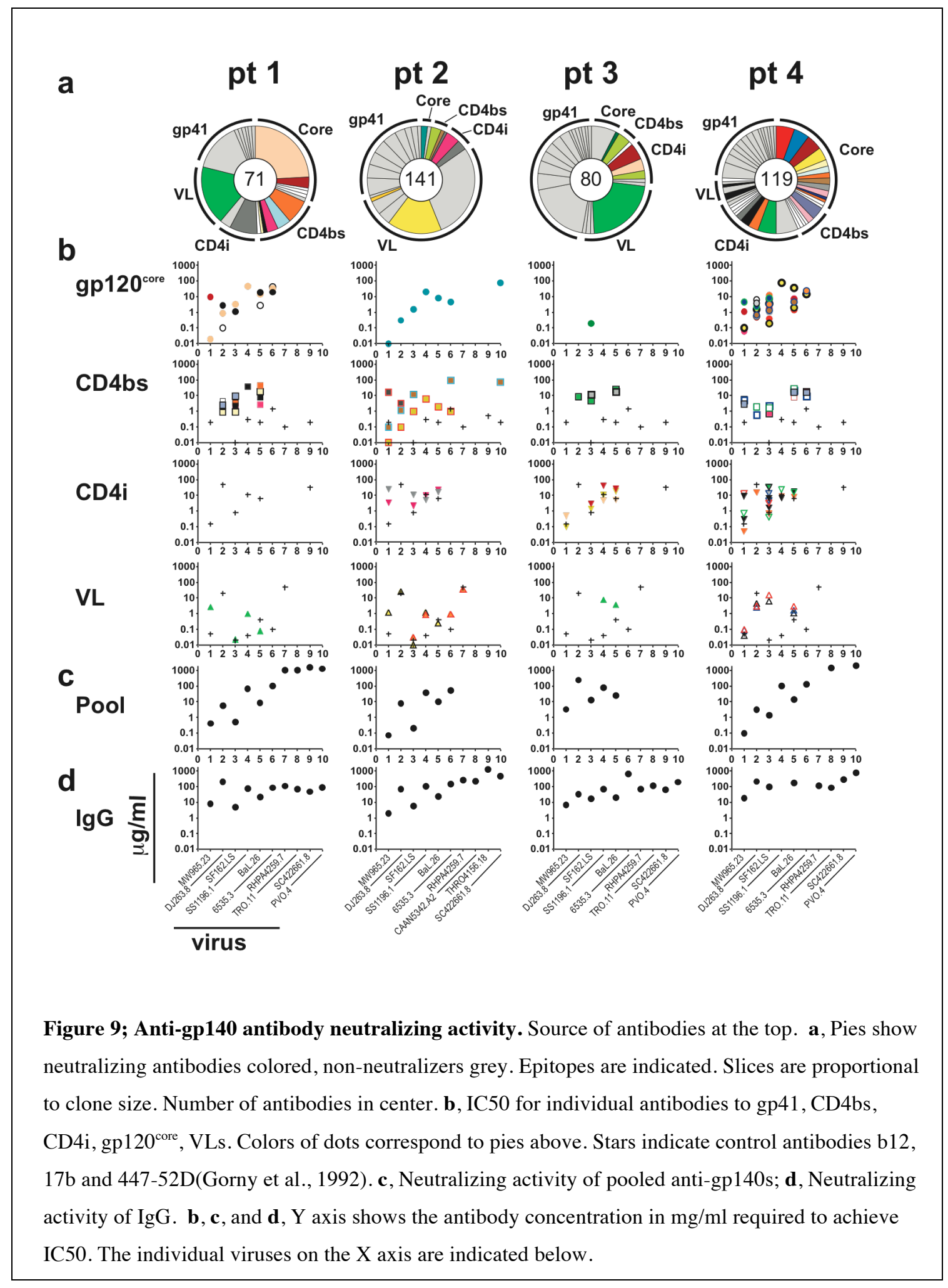


Table 3; In vitro Tzm-bl neutralization assay. Numbers indicate IC50s for the specific monoclonal antibody, serum IgG, or pooled antibodies in the Tzm-bl assay measuring inhibition of infection by the indicated viral strains. X indicates activity that did not reach IC50 values at the concentration tested. ad, patients 1-4 and previously described control antibodies; e, patients 5, 6 .

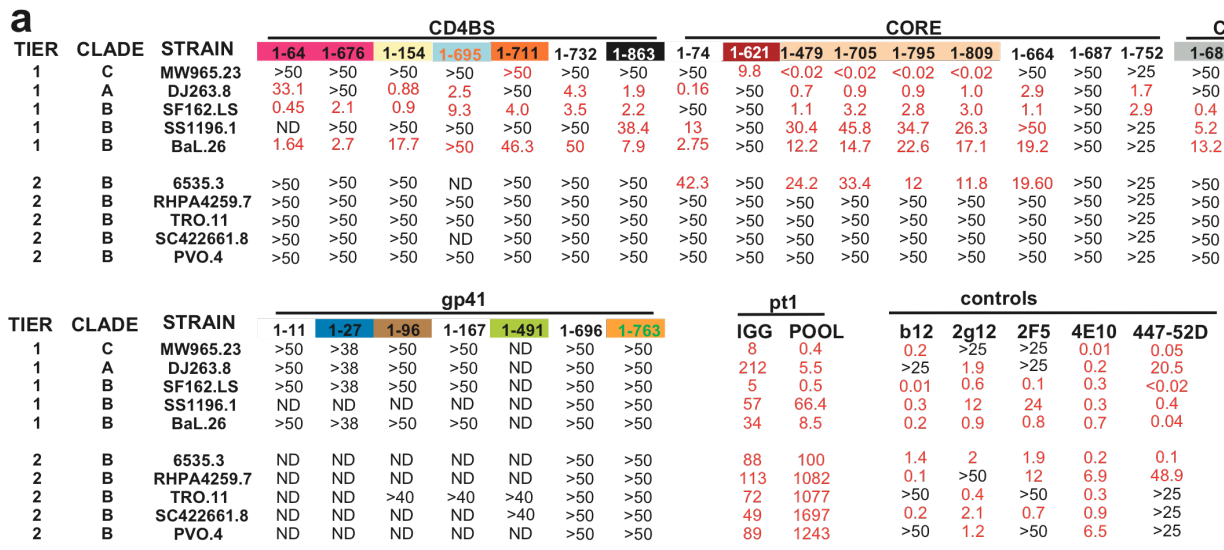

b CD4BS CORE CD4i

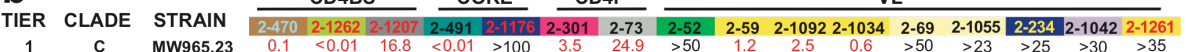

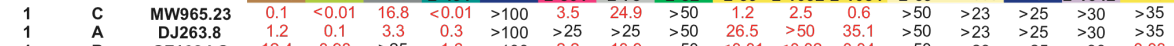
$\begin{array}{lllllllllllllllll}\text { DJ263.8 } & 1.2 & 0.1 & 3.3 & .13 & >100 & >2.5 & >25 & >50 & 26.5 & >00 & 35.1 & >50 & >23 & >25 & >30 & >35 \\ \mathbf{S F 1 6 2 . L S} & 12.4 & 0.98 & >25 & 1.6 & >100 & 2.2 & 10.9 & >50 & <0.01 & <0.02 & 0.04 & >50 & >23 & >25 & >30 & 0.03\end{array}$

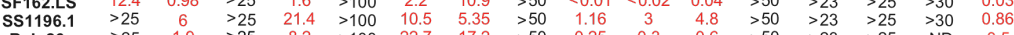
\begin{tabular}{lllllllllllllllll}
\hline 19 & $>25$ & 8.2 & $>100$ & 22.7 & 17.2 & $>50$ & 0.25 & 0.3 & 0.6 & $>50$ & $>23$ & $>25$ & ND & 0.5
\end{tabular}

$\begin{array}{llllllllllllllllllll}2 & \text { B } & 6535.3 & 99 & 0.97 & >50 & 4.6 & \text { ND } & >25 & >25 & >50 & >50 X & >50 & >50 X & >50 & >23 & >25 & >30 & 0.92 \\ 2 & \text { B } & \text { RHPA4259.7 } & >100 & >25 X & >25 & >25 & \text { ND } & >25 & >25 & >50 & >50 X & >50 & >50 X & >50 & >23 & >25 & >30 & 35 \\ 2 & \text { B } & \text { CANA342A } & >100 & >25 & >25 & >25 & \text { ND } & >25 & >25 & >50 & >50 & >50 & >50 & >50 & >23 & >25 & >30 & >35\end{array}$

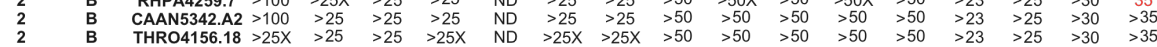

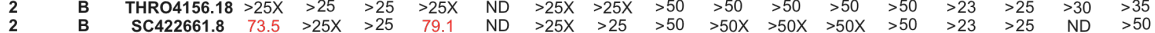

\begin{tabular}{|c|c|c|c|c|c|c|c|c|c|c|c|c|c|}
\hline \multirow[b]{2}{*}{ TIER } & \multirow[b]{2}{*}{ CLADE } & \multirow[b]{2}{*}{ STRAIN } & \multicolumn{9}{|c|}{ p41 } & \multicolumn{2}{|c|}{ pt2 } \\
\hline & & & $\overline{2-55}$ & $2-378$ & $2-150$ & & & -512 & 2-149 & 2-1007 & & & POOL \\
\hline & c & MW965 & & -7 & 23 & $>45$ & $>40$ & $>20$ & & $>40$ & 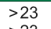 & & \\
\hline & B & & $>$ & $>50$ & $>23$ & $\begin{array}{l}>45 \\
>>45\end{array}$ & $>40$ & $>20$ & $>2$ & $>40$ & $>2$ & 72 & 7 \\
\hline & . & SS11 & $>25$ & $>50$ & $>23$ & $>45$ & $>4$ & $>20$ & $>23$ & $>40$ & $>2$ & 104 & 38. \\
\hline & & BaL.26 & $>25$ & $>50$ & $>23$ & $>45$ & & $>20$ & & & & & \\
\hline & B & & $>25$ & $>50$ & & 5 & $>40$ & 20 & 23 & $>40$ & $>23$ & & \\
\hline & . & & 5 & $>50$ & 23 & $\begin{array}{l}>45 \\
>45\end{array}$ & $\begin{array}{l}>40 \\
>40\end{array}$ & $\begin{array}{l}>20 \\
>20\end{array}$ & $>23$ & $\begin{array}{l}>40 \\
>40\end{array}$ & $\begin{array}{l}>2 \\
>2\end{array}$ & 6 & 100 \\
\hline & B & THRO4156.18 & $>25$ & $>50$ & $\begin{aligned}>23 \\
>233\end{aligned}$ & $>45$ & $>40$ & $\begin{array}{l}>20 \\
>20\end{array}$ & $>23$ & $>40$ & $>2$ & 1258 & 1500 \\
\hline
\end{tabular}




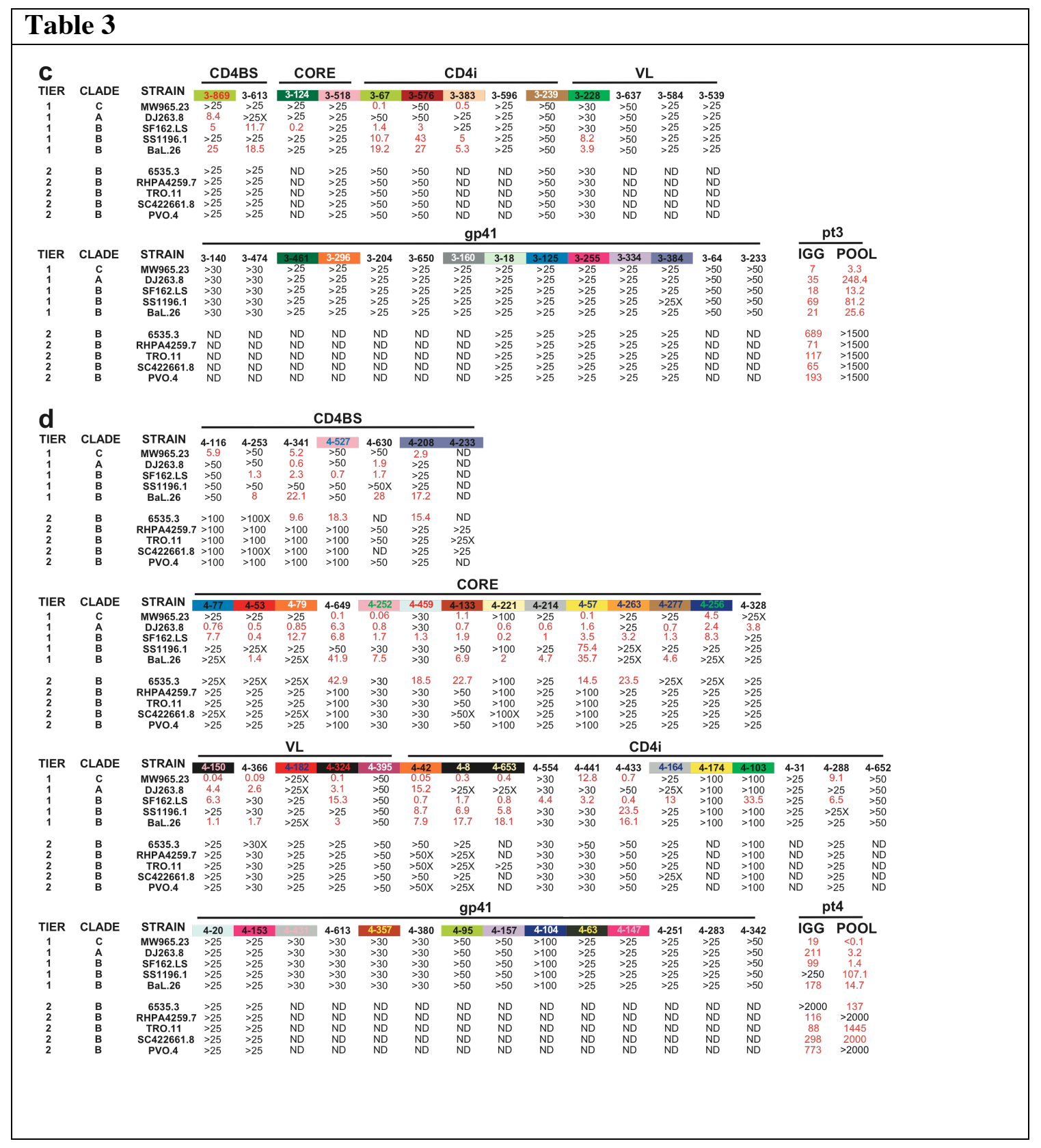




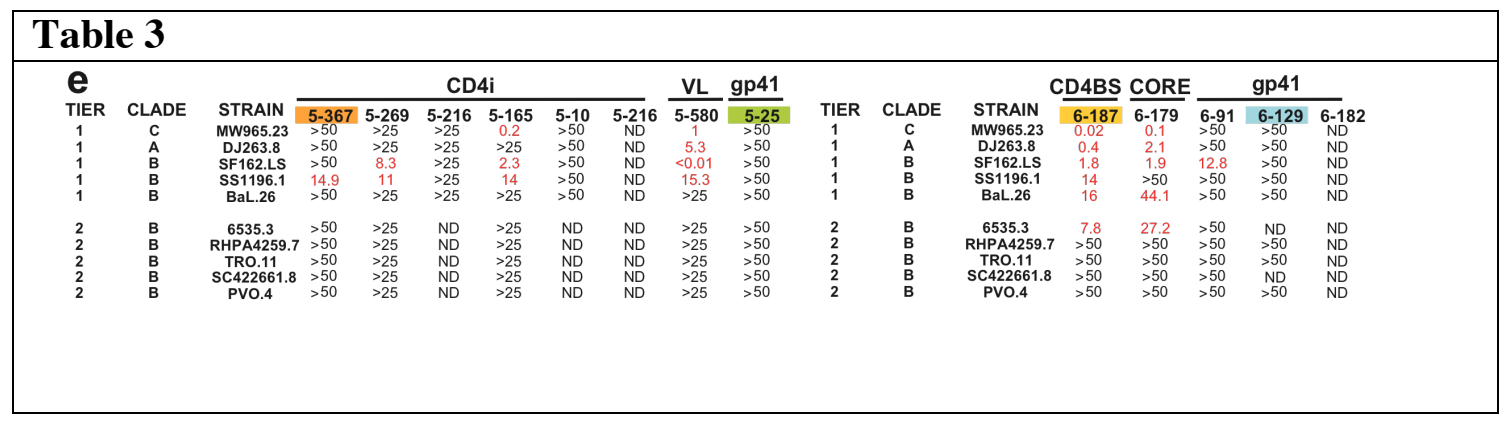


Of a total of 64 independent clonal families of neutralizing antibodies 22 were antigp120 ${ }^{\text {core }}, 18$ were anti-CD4bs, 16 were anti-CD4i, and 8 were anti-VL including all three of anti-V3L antibodies (Fig. 9 and Table 3). As a group, the antibodies to the CD4bs and gp $120^{\text {core }}$ showed the highest levels of neutralizing activity with rare antibodies showing activity against the more resistant tier-2 viruses at high concentrations (Fig. 9 and Table 3). Although the anti-V3L antibodies showed cross-clade neutralizing activity, and one of them neutralized tier-2 viruses at high concentrations, most of the anti-VL antibodies were more restricted (Fig. 9 and Table 3). Neutralizing activity was also found in the anti-CD4i antibodies but only three of these antibodies reached IC50 values against the more difficult to neutralize tier-2 viruses (Fig. 9 and Table 3).

Serum antibody adsorption studies found that neutralization of tier-2 viruses was predominantly achieved by anti-CD4bs with a smaller variable contribution from antiCD4i and un-identified antibodies. However, as mentioned above, the resolution in such studies is limited and they cannot define the nature or number of antibodies to a specific site(Binley et al., 2008; Dhillon et al., 2007; Li et al., 2007; Li et al., 2008; Sather et al., 2008). We found no case where a single monoclonal antibody or class of antibodies in memory B cells accounts for all of the neutralizing activity in serum (Fig. 9 and Table 3). Individual antibodies showed variable levels of activity against different viruses. For example in patient \#1, the clade-C virus MW965.23 was neutralized by gp120 antibodies 1-621 and 1-705 and VL antibody 1-79, with anti- gp120 core $1-705$ showing the highest activity (Fig. 9 and Table 3). In contrast, 1-621 did not neutralize the clade-B virus Bal.26, whereas 1-79 did and was superior to 1-705 (Fig. 9 and Table 3). Similarly 
in patient \#2, the clade-A virus DJ263.8 is neutralized by anti-CD4bs 2-470, anti-VL 259 but not anti-VL antibody 2-1261, whereas the same anti-VL antibody neutralized the clade-B tier-2 virus RHPA4259.7, but neither 2-470 nor 2-59 reached IC50 against this virus (Fig. 9 and Table 3). In conclusion, some degree of neutralizing activity was common among gp120 specific memory antibodies. These antibodies recognized a broad array of epitopes and neutralizing activity was heterogeneous for different viral isolates. Memory B cells are long-lived cells and their antibodies reflect an individuals immune responses over time. Some of these cells differentiate into plasma cells that secrete antibodies but the relative contribution of any given memory B cell to the plasma cell compartment is unknown and therefore a pool of cloned memory B cell antibodies cannot be compared directly to serum. Nevertheless, we created pools of all antibodies for each individual patient and compared the pools to purified serum IgG for neutralization (Fig. 9 and Table 3). The pools contained equal concentrations of each of the anti-gp140 clones irrespective of clone size (Fig. 2), potential competition for epitope binding (Fig. 5) or neutralizing activity (Fig. 9).

Purified IgGs from all four patients studied neutralized nearly all of the tier-1 viruses and the corresponding pools of the recombinant antibodies were also active against these viruses (Fig. 9 and Table 3). In addition, some of the antibody pools neutralized viruses that were not neutralized by the IgG fraction. For example, pt 4 purified IgG did not reach an IC50 against SS1196.1 or 6535.3 (tier-2), but these viruses were neutralized by recombinant antibodies 4-42, 4-8 and 4-433 and by pooled antibodies (Fig. 9 and Table 3). 
In contrast, much higher concentrations of the patients' serum IgG were required for tier2 neutralizing activity ranging from $49-1258 \mathrm{mg} / \mathrm{ml}$. Consistent with the more stringent requirements for tier 2 neutralization, only the pooled monoclonal antibodies from patient 1 and 4 reconstituted this type of activity and only at high concentrations (Fig. 9 and Table 3). For example, RHPA4259.7 and TRO.11 were neutralized by $1.1 \mathrm{mg} / \mathrm{ml}$ of the patient 1 pool (pool of 21 antibodies each at maximum concentration of $52 \mu \mathrm{g} / \mathrm{ml}$ ). Similarly, the TRO.11 virus was neutralized by the pooled antibodies from patient 4 at $1.4 \mathrm{mg} / \mathrm{ml}$ (pool of 50 antibodies). In both cases individual antibodies did not reach IC50 values against these viruses but several antibodies showed low levels of activity (Fig. 9 and Table 3). In conclusion, the memory antibody compartment contains a large mixture of anti-HIV neutralizing antibodies combinations of which can reach the breadth of activity found in the serum but only at high concentrations. 


\section{Discussion}

Since the discovery of HIV numerous monoclonal antibodies to the envelope protein have been produced by random cloning of heavy and light chains in phage display libraries or by selection of antibody secreting hybridomas, but until recently only a few highly active broadly neutralizing antibodies have been obtained(Burton et al., 2005; Karlsson Hedestam et al., 2008; Mascola, 2007; Pantophlet and Burton, 2006; ZollaPazner, 2004). Among these b12(Burton et al., 1991), 2F5 and 4E10(Buchacher et al., 1994; Zwick et al., 2001a), and 2G12(Trkola et al., 1996) had received the greatest attention because of their unique breadth and potency in vitro and in vivo.

The thrust of this work was to establish a new and highly efficient way to identify and characterize the HIV envelope specific memory B cell repertoire in patients with broadly neutralizing antibodies. For the first time we were able to delineate comprehensively the immunoglobulin gene features as well as size and diversity of this particular B cell repertoire.

In contrast to previous models, we found that the antibody repertoire against env is not limited to a few immunodominant regions but rather targets a diversity of epitopes on gp120 and gp41. The epitopes we mapped include a new class of neutralizing antibodies to gp $120^{\text {core }}$, which targets a region at the outer /inner domain junction of gp120. This epitope is essential for viral infectivity and thus possibly has implications in vaccine design. 
We also found, that neutralizing activity in the HIV env directed B cell response is diverse. If broad neutralization in these patients is achieved by targeting multiple epitopes, then a vaccine that phenocopies such a response should also include several epitopes.

However, only in two patients we reconstituted the neutralization breadth of purified serum IgG, and only at high concentrations. This finding implies that we still were missing parts of the serum antibody repertoire of these patients.

Possible reasons for this limitation include the choice of bait used in the staining and sorting of B cells. Neutralizing activity directed to epitopes not displayed on YU2 gp140 would not be recovered with our methods. Furthermore, broadly neutralizing memory B cells could be very rare, making a more targeted bait necessary. We did isolate many clonally related B cells, suggesting that we captured a significant fraction of env specific B cell clones. However, we might not have identified rare clonal members of expanded B cell families with increased neutralizing activity.

Memory and plasma B cell compartments are intertwined and we expect to capture a significant fraction of the serum response against HIV env by investigating memory B cells. But so far no study has portrayed a human antigen specific B cell response with this resolution. Therefore, differences between the antibody secreting plasma cell compartment and the memory B cell compartment provided another possible explanation for the lack of completely reconstructing the serum response in the investigated patients. 
A high level of somatic hypermutation is another feature of this antibody compartment. HIV is a chronic infection with a mutating virus, and ongoing germinal center reactions or even recall of memory B cells into germinal centers might play a role in this process. Our approach relies on PCR amplification and therefore primer binding to supposedly conserved elements in the immunoglobulin genes. Therefore, hypermutation of these conserved regions could limit our ability to fully capture the B cell response in the patients studied. 


\section{Chapter 3}

\section{Sequence and Structural Convergence of Broad and Potent HIV Antibodies that Mimic CD4 Binding}

\section{Introduction}

In our initial studies(Scheid et al., 2008; Scheid et al., 2009a), we established a new and highly efficient method to portrait the B cell response against the gp140 envelope protein in patients with broadly neutralizing serum activity. One of the surprising findings in our experiments was that the gp140 specific B cell repertoire displays high levels of somatic hypermutation. Also, VRC01, an antibody with unusually broad and potent activity directed to the CD4 binding site (CD4bs) shows high levels of somatic mutations that are essential for its activity(Wu et al., 2010; Zhou et al., 2010). As mentioned above, this high frequency of mutations is a potential impediment to antibody identification because the mutated sequences may no longer be complementary to the primers used for immunoglobulin gene amplification(Wardemann et al., 2003).

To avert this potential difficulty, we developed a new primer set specifically designed to address this problem (the 5' primer is set further upstream to avoid the mutated region) (Fig. 10 and Table 4). 
The envelope trimer of HIV is believed to be a flexible structure(Kwon et al., 2012; Poignard et al., 2001). Comparison of the gp120 binding of antibodies b12(Chen et al., 2009; Dey et al., 2007; Dey et al., 2009b) and VRC01 (Wu et al., 2010; Zhou et al., 2010)with non neutralizing antibodies directed to the CD4 binding site have suggested that binding to gp120 in the CD4 bound conformation correlates with neutralizing activity. To systematically study the B cell response to gp120 stabilized in the CD4 bound conformation we included such a core protein (2CC-core(Dey et al., 2009b)) in our staining experiments. In contrast to the resurfaced protein used to clone VRC01(Wu et al., 2010; Zhou et al., 2010), which was designed to focus on antibodies to the CD4bs, the 2CC-core should capture additional antibodies including those specific to the CD4induced co-receptor binding site (CD4i)(Chen et al., 2005; Dey et al., 2009b). 


\section{Primers for the identification of highly mutated antibodies}

The new amplification strategy was tested by sorting single B cells from a patient with high titers of broadly neutralizing antibodies (Pt 8) that bind to 2CC-core lacking the V13 loops (2CC-core(Chen et al., 2005; Dey et al., 2009b), Fig. 10b).

In side-by-side comparisons, the new primer set increased recovery of IgH chains when compared to the original primer set (Fig. 11)(Wardemann et al., 2003). As expected, the antibodies obtained with the new primer set were more mutated (Fig.11 a and c) (average 35.7 vs. $19.8 \mathrm{p}=0.0013$ and maximum 85 vs. 50 for $I g H)$ and included clones not found with the original primer set (Fig. 11, a and b).

Moreover, the new primers also recovered VRC01-related antibodies from cDNA samples isolated from single cells that had been sorted with the original YU2-gp140 trimer probe(Scheid et al., 2009b; Yang et al., 2000)(Fig. 12a and b). We conclude, that VRC01-like antibodies are captured by the YU2-gp140 trimer(Yang et al., 2000), and that primers that are specifically designed to clone highly mutated antibodies capture a larger fraction of HIV antibodies from the memory B cells of patients with high titers of broadly neutralizing antibodies. 


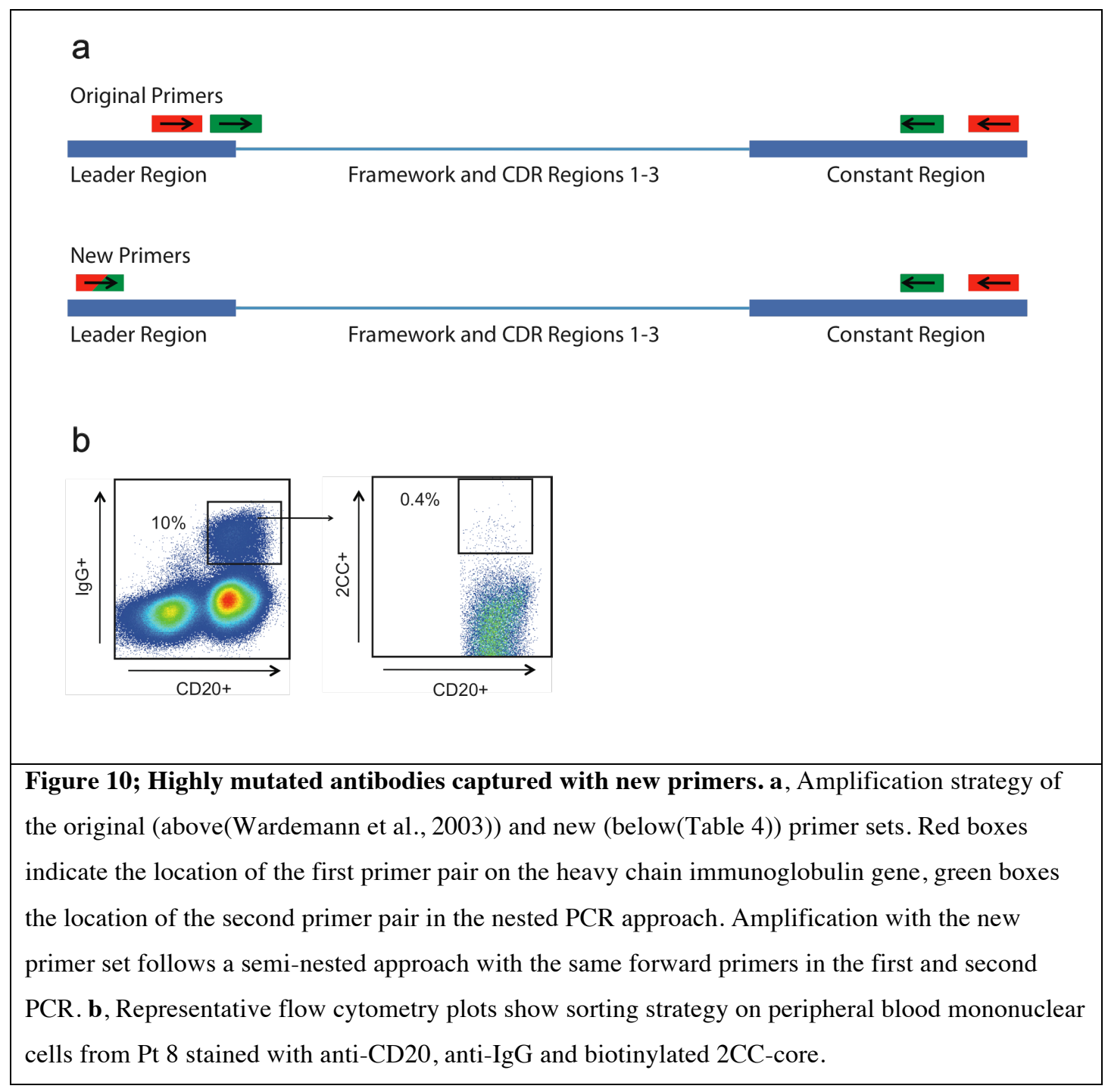




\section{Table 4; Primers for amplification of highly mutated}

Immunoglobulin $\mathbf{V}$ heavy chain genes. Forward priming sites are located in the leader region of the respective $\mathrm{VH}$ genes and allow amplification of highly mutated $\mathrm{VH}$ genes in a semi-nested protocol with 2 reverse priming sites located in the IgG constant region.

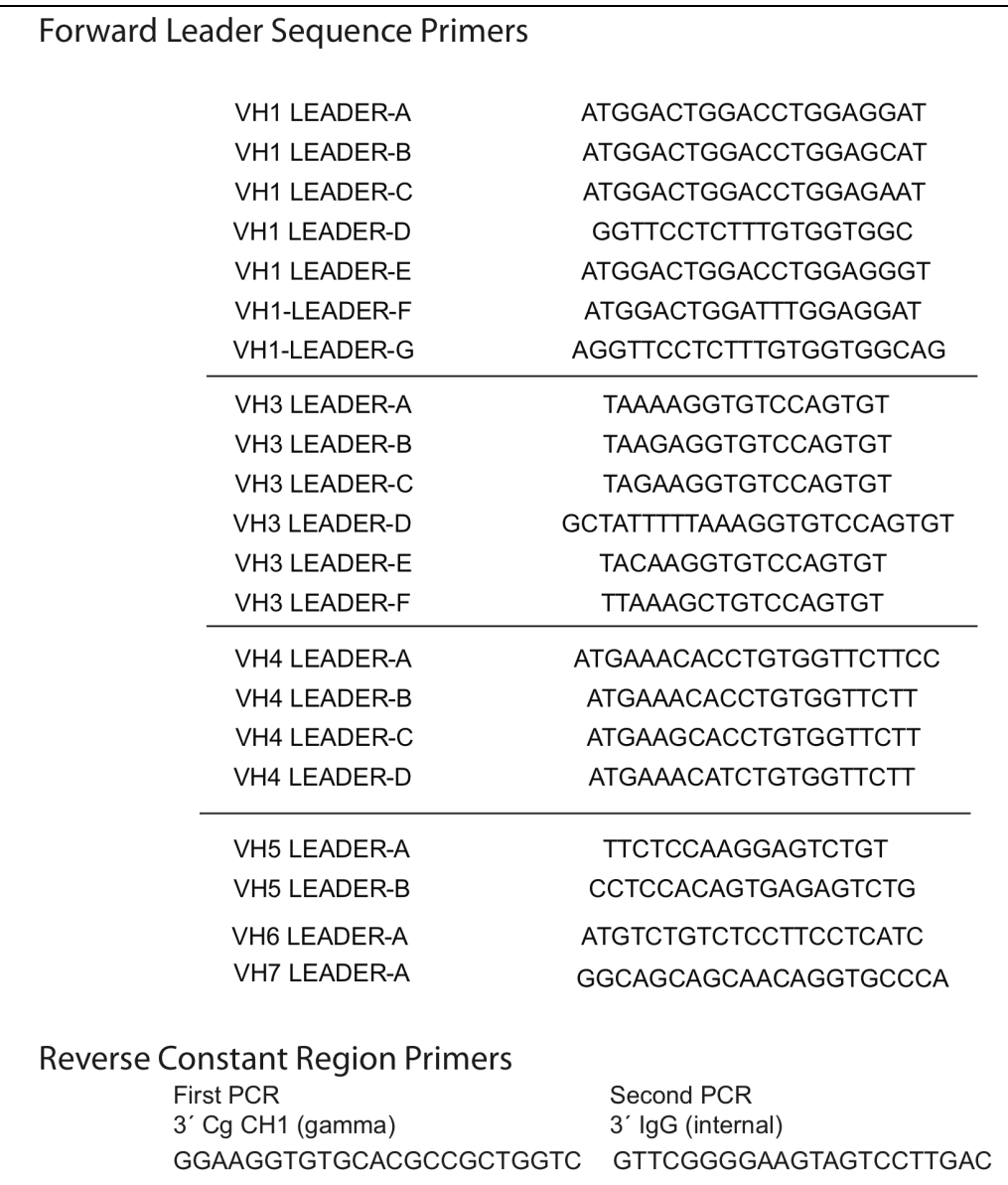




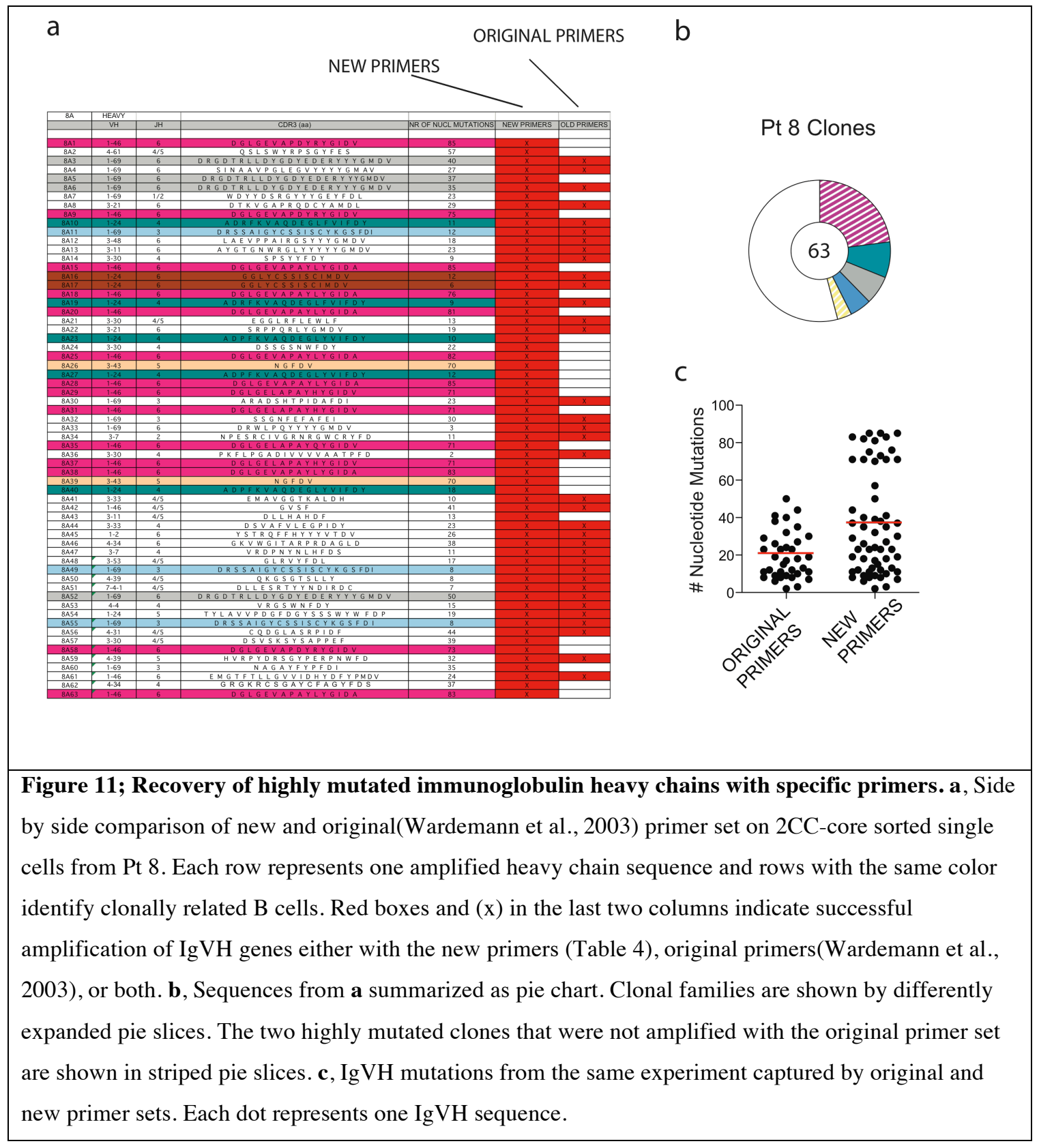


a

VRC01

VRC02

NIH45-46

NIH45-177

NIH45-243

VRC01

VRC02

NIH45-46

NIH45-177

NIH45-243

VRC01

$\mathrm{VRC} 02$

NIH45-46

NIH45-177

NIH45-243

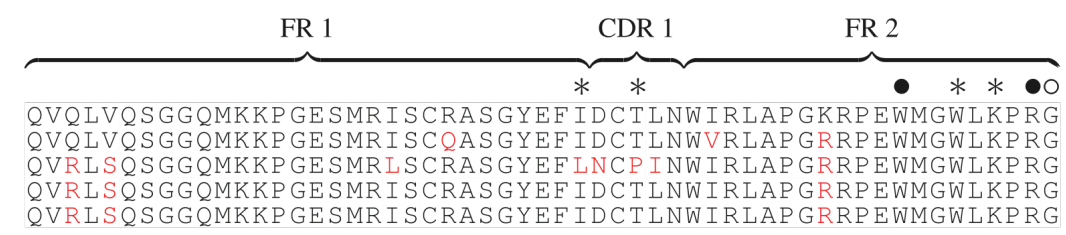

CDR 2

FR 3

CDR 3

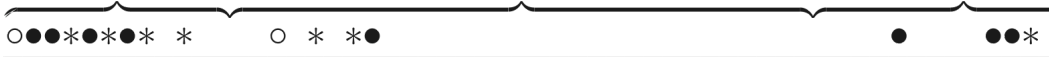

GAVNYARPLQGRVTMTRDVYSDTAFLELRS LTVDDTAVYFCTRGKNCD----YNWDFEHWG GAVNYARP LOGRVTMTRDVYSDTAFLELRSLTADDTAVYYCTRGKNCD-- - YNWDFEHWG GAVNYARKE GRVTMTRDVYSDTAFTEIRSITSDDTAVYFCTRGKYCTARDYYNWDFEHWG GAVNYARPLQGRVTMTRDVYSDTAFLELRSLTADDTAVYFCTRGKNCN--- -YNWDFEHWG GAVNYARSFQGRVTMTRDVYSDTAFLELRSLTADDTAVYFCARGKNCD----YNWDFEHWG

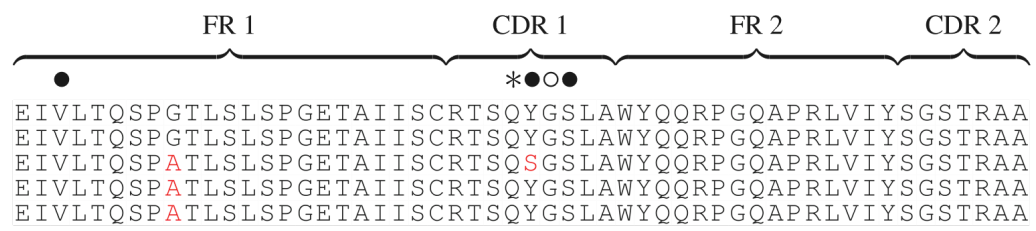

FR 3 CDR 3

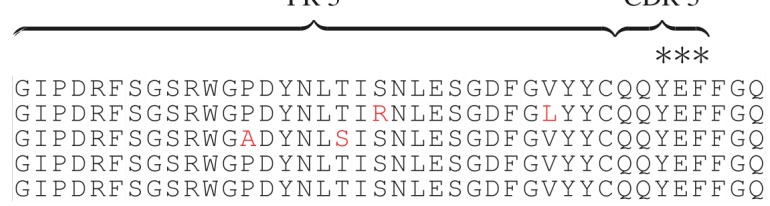

\section{Figure 12; Ig V heavy (a) and light chain (b) sequences of new VRC01 clonal members. Framework}

(FR) and CDR regions are indicated. Red shading shows amino acid differences from VRC01. Contact residues between VRC01 and gp120 are shown above as closed circles for main and side chain interactions, open circles main chain only, and stars side chains only(Zhou et al., 2010). 


\section{Anti-2CC-core memory antibodies from four donors}

Four unrelated HIV infected individuals, showing high titers of broadly neutralizing antibodies were examined using the 2CC-core(Scheid et al., 2011b). Two of these

individuals, Pt1 and Pt3, had been studied previously, but their cloned antibodies could not account for their serologic activity(Scheid et al., 2009a). 576 antibodies from single sorted B cells representing 200 different founder B cell clones that were diversified by mutation in germinal centers were obtained from a starting population of $1.5 \times 10^{5} \mathrm{IgG}^{+}$ memory B cells (Fig. 13 a and Table 5). 


\section{Table 5; IgH and IgL chain gene sequence, antibody reactivity, neutralization assay results for}

cloned antibodies. ND indicates not determined. Letters on the right side of the table indicate close clonal relatives shown below. Previously published antibodies(Scheid et al., 2009a) are indicated with a red star. a-d, Antibodies from 2CC-core reactive IgG B cells from patients 1, 3,8 and 12. The number of clone members with $95 \% \mathrm{IgH}$ and $\mathrm{IgL}$ chain gene sequence homology is indicated and clonal relatives with various degrees of somatic mutations are shown in the same color. e, f, Antibodies from gp140 reactive IgG B cells from patients 3 and 1. Each clone is represented once with the number of relatives indicated.

Table 5A. Repertoire and Reactivity of 2CC binding Antibodies, patient 3

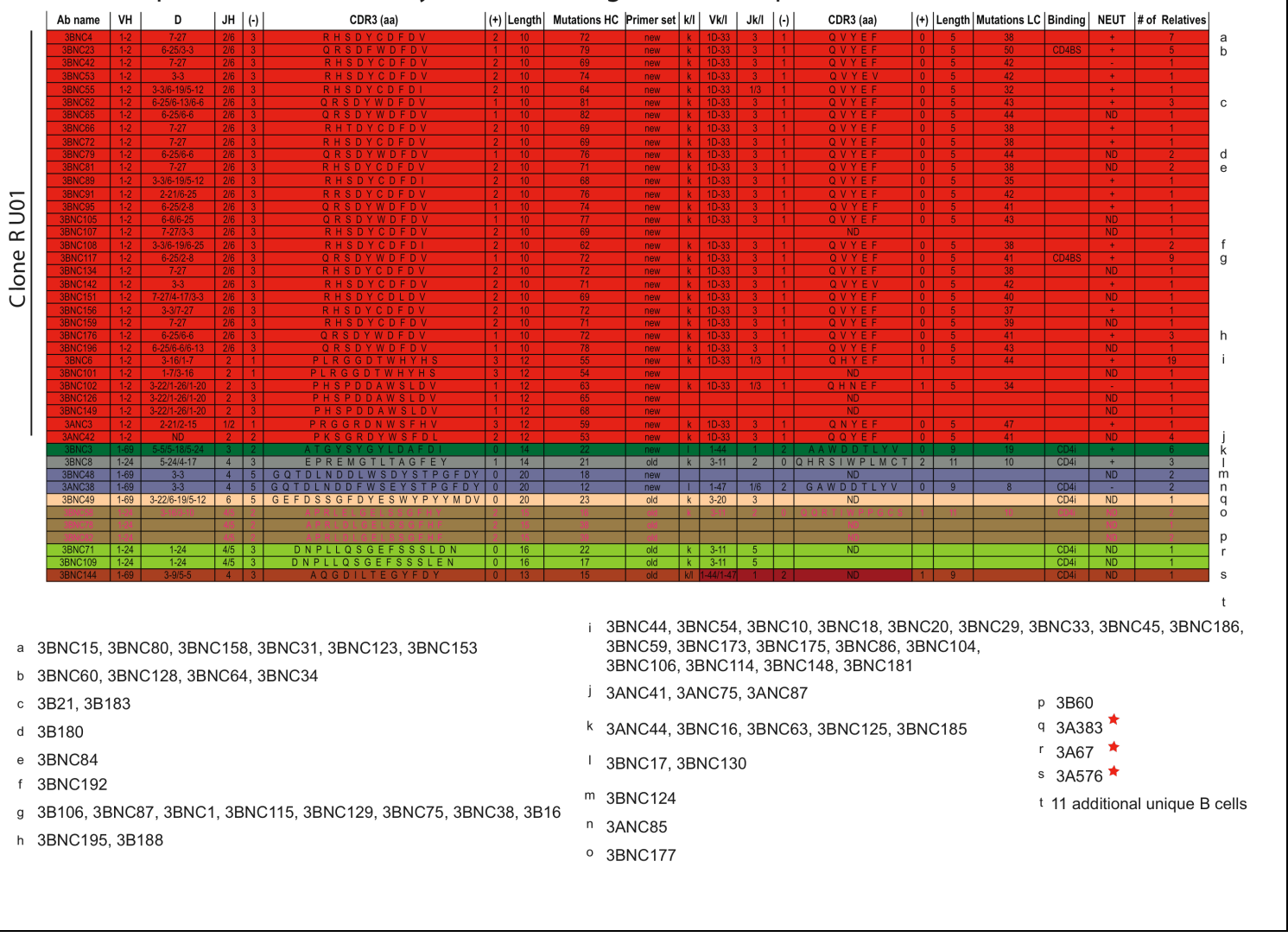


Table 5B. Repertoire and Reactivity of 2CC binding Antibodies, patient 1

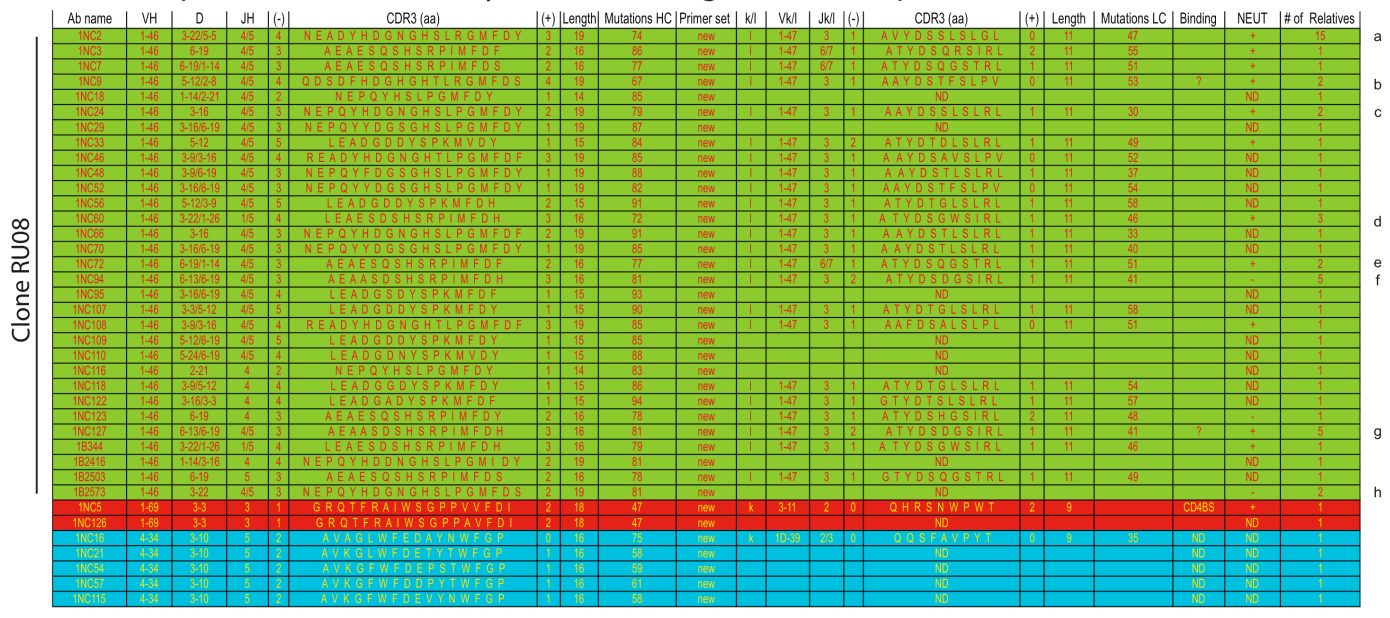

a 1B2436, 1B2361, 1B2483, 1NC11, 1B2538, 1B2578, 1B2609, 1B2630, 1B2665, 1B2490, 1B2640, 1NC8, 1NC34, 1NC82

g 1B2530, 1B2666, 1B2669, 1B2554

b 1 NC117

h 1 B2644

c $1 \mathrm{~B} 2367$

i 13 additional unique $B$ cells

d 1B2351, 1B2525

e $1 \mathrm{NC} 2364$

f $1 B 2586,1 B 2612,1 B 2683,1 B 2339$

Table 5C. Repertoire and Reactivity of $2 \mathrm{CC}$ binding antibodies, patient 8

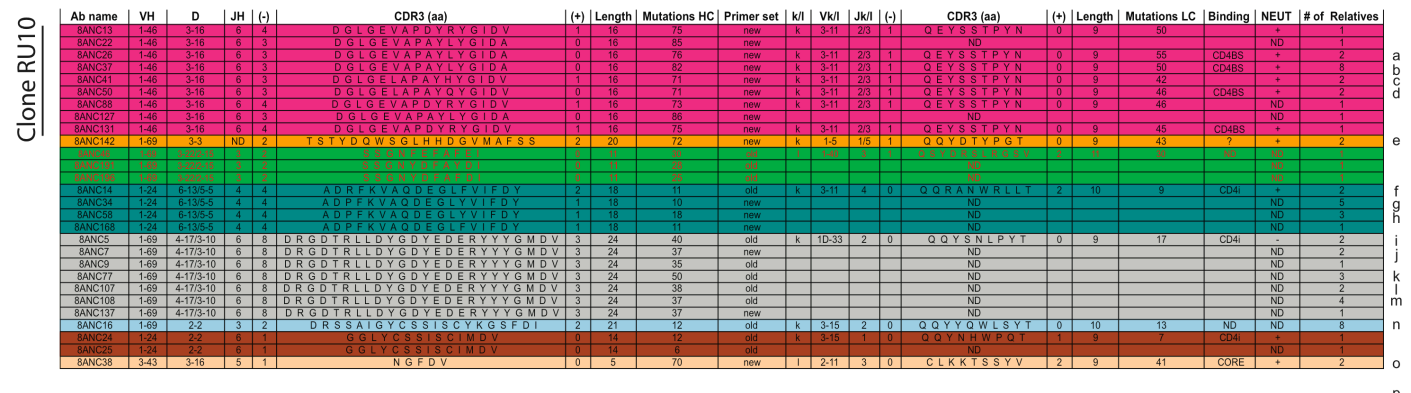

a $8 \mathrm{ANC} 134$

b 8ANC116, 8ANC105, 8ANC53, 8ANC40, 8A275, 8ANC171, 8ANC192

g 8ANC39, 8ANC146, 8ANC150, 8ANC184

c 8 ANC45

d 8 ANC182

i 8 ANC156

e 8ANC195

j 8 ANC126

k 8ANC158, 8ANC166

f 8 ANC27

8 ANC153

m 8ANC115, 8ANC143, 8ANC154

n 8ANC74, 8ANC80, 8ANC114, 8ANC117,

8ANC157, 8ANC169, 8ANC193

- 8ANC57

p 61 additional unique $B$ cells 


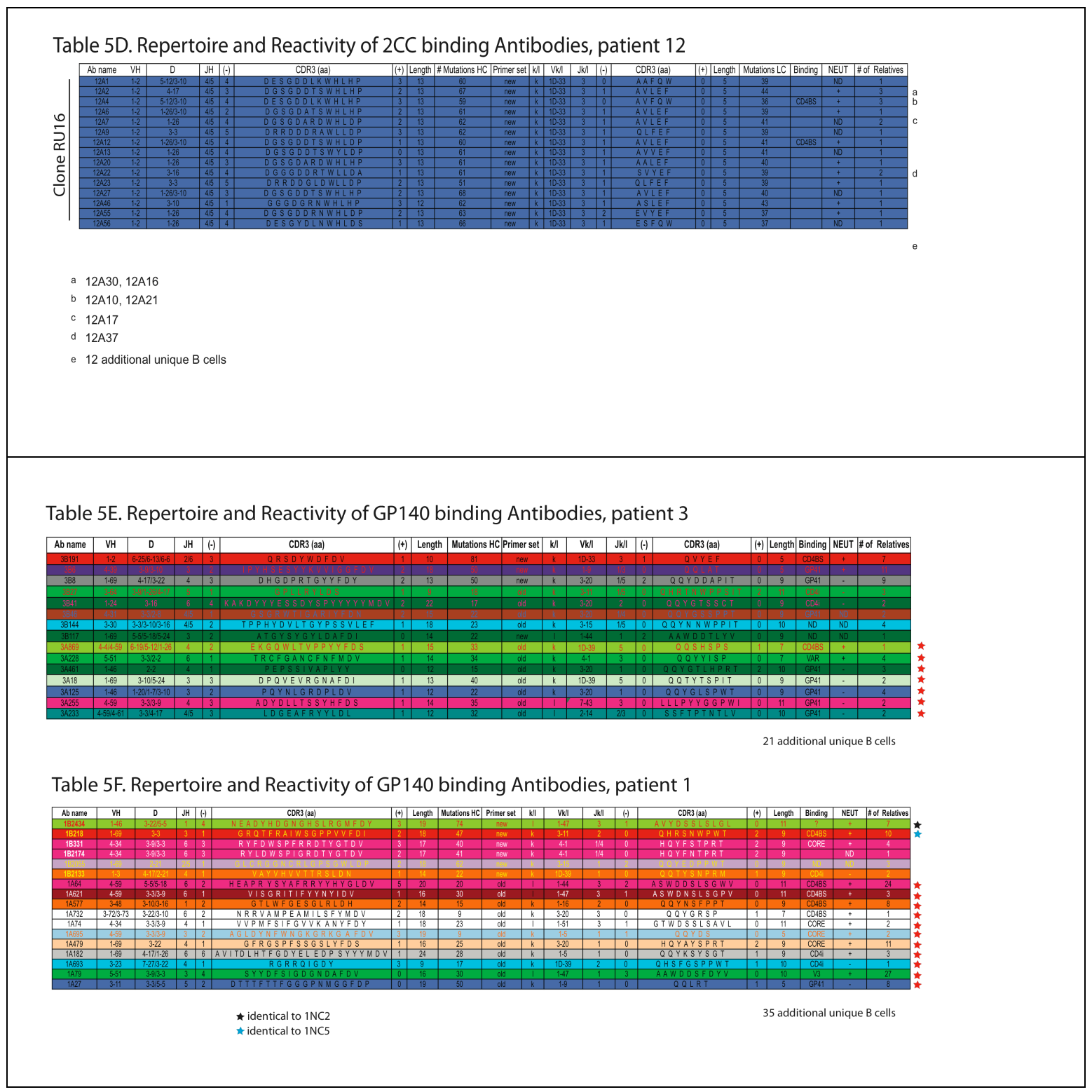




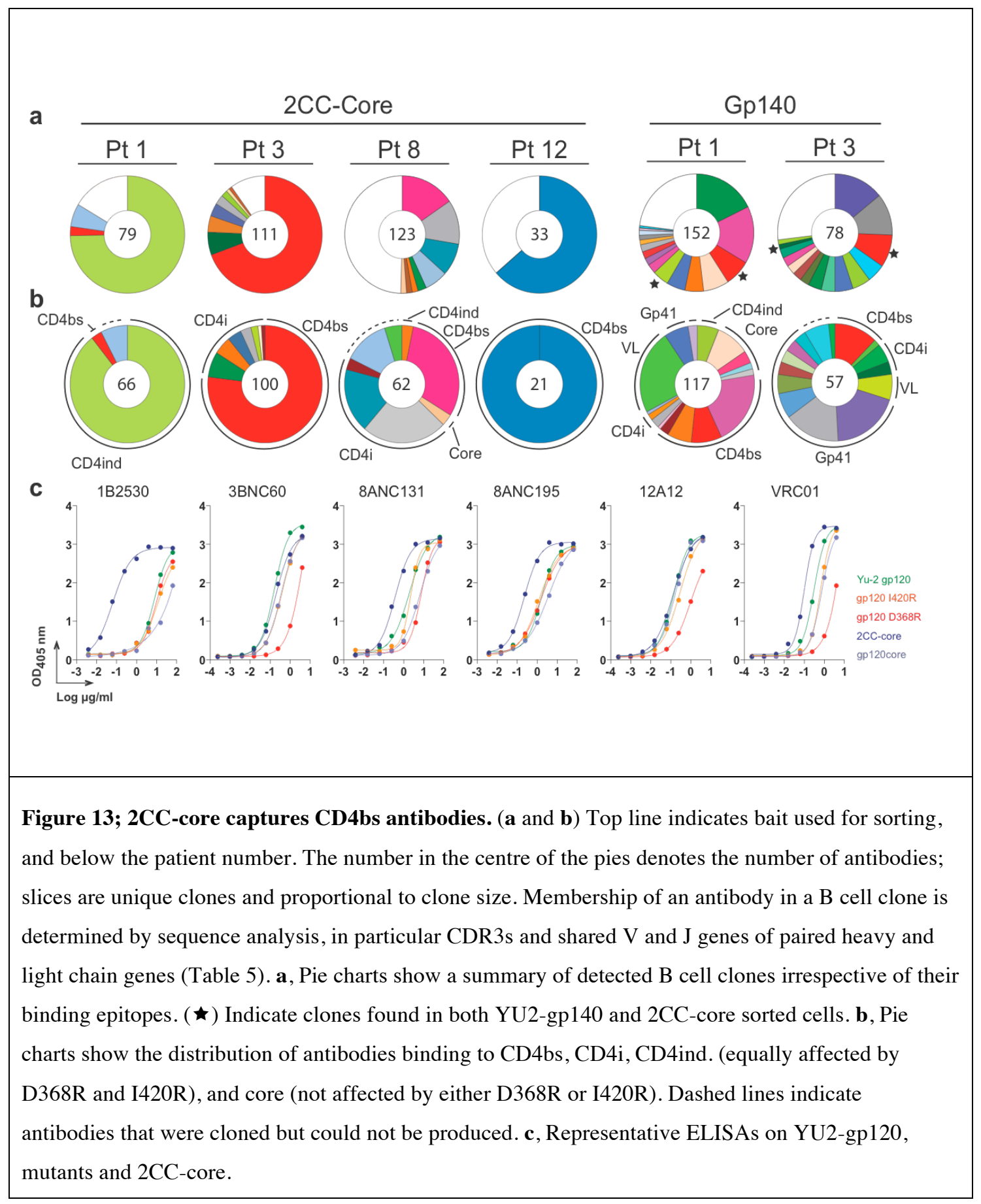




\section{Epitopes and polyreactivity of anti-2CC-core memory antibodies}

Representative members of each expanded founder B cell clone were tested for binding to gp120 and were all positive (Fig. 13b and c and Table 5). The site of antibody binding on the envelope spike was mapped using mutant proteins that interfere with either the CD4bs [gp120(D368R)] (Olshevsky et al., 1990; Pantophlet et al., 2003; Thali et al., 1991), or the CD4i site [gp120(I420R)](Thali et al., 1993). NIH45-46, which is a VRC01 variant, and antibodies 3BNC60, 8ANC131, and 12A12 (antibodies selected on the basis of neutralizing activity, see below) (Fig. 13c and Table 5) showed binding patterns similar to VRC01. Others, including 1B2530, and 8ANC195 could not be classified precisely based solely on ELISA.

As expected from earlier studies on HIV envelope-specific antibodies(Mouquet et al., 2010), $65 \%$ of the antibodies isolated using the 2CC-core were polyreactive (Fig. 14) compared to $22.7 \%$ polyreactivity in healthy control memory B cells(Tiller et al., 2007) and $17.3 \%$ in gp140 negative B cells from HIV positive controls(Mouquet et al., 2010). Somatic hypermutation was likely required for development of high affinity antigen binding and polyreactivity because reversion of 4 representative antibodies to the corresponding germline led to complete loss of binding to YU2-gp140(Yang et al., 2000) (Fig. 14b and Fig. 15a to c). 
a
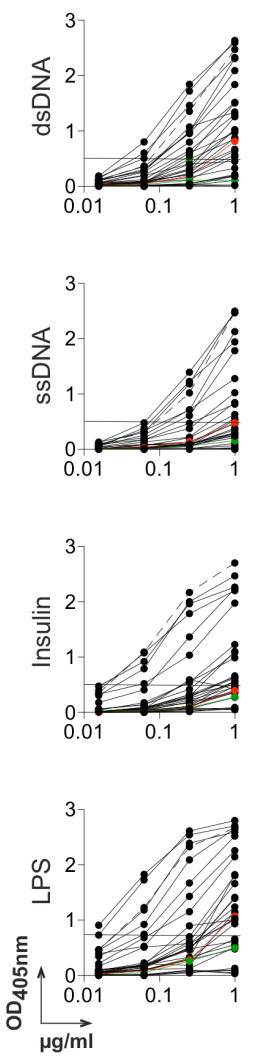

C
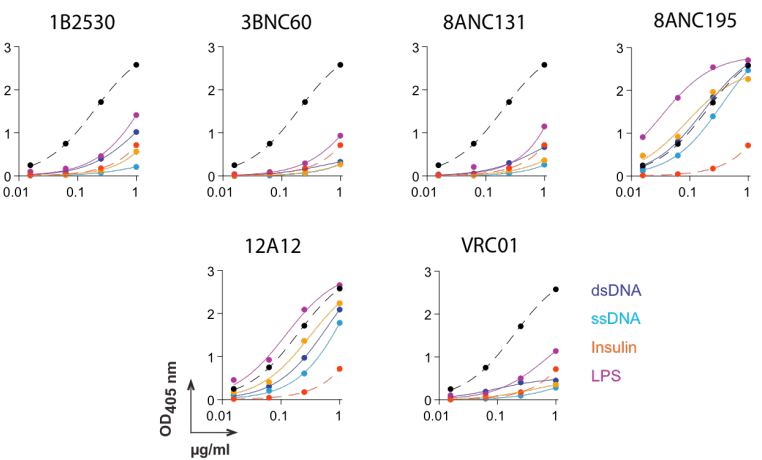

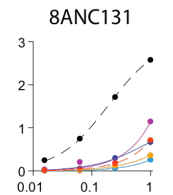

b

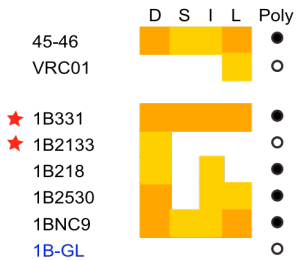

$\star 3 \mathrm{~B} 8$

3B 6

+ 3B46

+ 3B41

3B27

$3 \mathrm{ANC} 4$
3ANC38

3ANC38

3BNC58

$3 \mathrm{BNC117}$

3BNC60-GL

8ANC14

8 ANC57

8ANC5

8ANC195

8 ANC192

8 ANC182

$8 \mathrm{ANC} 134$

8ANC131

12A21

$12 \mathrm{~A} 12$

12A-GL

$\mathrm{OD}_{405 \mathrm{~nm}}$

\begin{tabular}{ll|l|l|l|}
$\mathbf{D}, \mathbf{S}, \mathbf{I}<0.5$ & $0.5-1$ & $1-2$
\end{tabular}

\begin{tabular}{ll|l|l|l|}
\hline & $<0.75$ & $0.75-1.5$ & $1.5-2.5$ & $>2.5$
\end{tabular}

VRC01

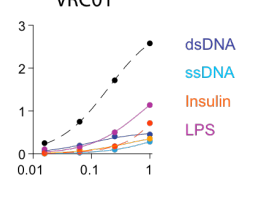

Figure 14; Polyreactivity of anti-HIV

antibodies. a, ELISAs measuring the reactivity of anti-HIV antibodies against double-stranded DNA (dsDNA), singlestranded DNA (ssDNA), insulin and lipopolysaccharide (LPS) were performed and evaluated as described(Mouquet et al., 2010; Wardemann et al., 2003). Dotted lines represent the positive control antibody ed38(Wardemann et al., 2003). Horizontal lines show cut-off OD405 $\mathrm{nm}$ for positive reactivity. Green and red lines show the negative (mGO53) and low positive (eiJB40) control antibodies, respectively(Wardemann et al., 2003). b, Table summarizes the reactivity against dsDNA, ssDNA, insulin and LPS (D, S, I and L, respectively) of all single tested antibodies and their germline counterparts. Colors indicate the different levels of antibody reactivity for each antigen. Open circles identify non polyreactive, closed circles polyreactive antibodies. Purple text and "GL" indicates antibodies reverted to germline. Red stars indicate antibodies from sort with YU2-gp140(Yang et al., 2000). c, Representative polyreactivity ELISAs(Mouquet et al., 2010; Wardemann et al., 2003) with positive control antibody ed38(Wardemann et al., 2003) shown in black dotted lines and low positive (eiJB40) control shown in red dotted lines. 
a

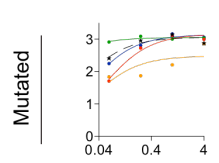

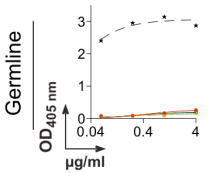

b
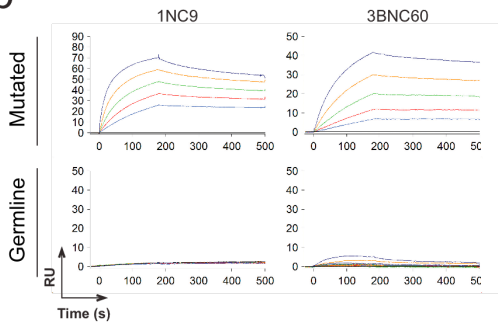

$3 B N C 60$
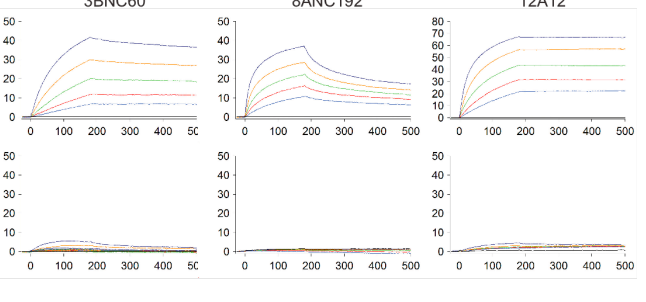

C
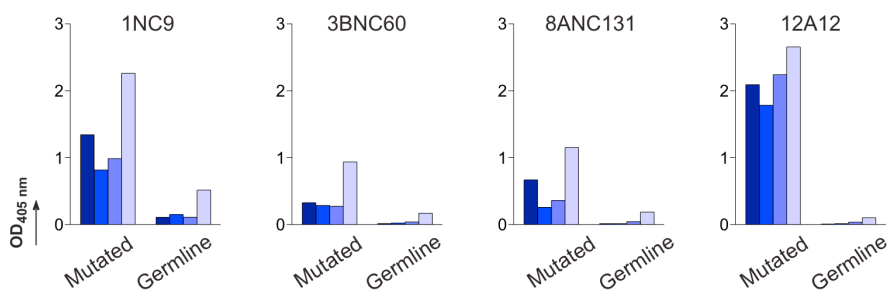

d
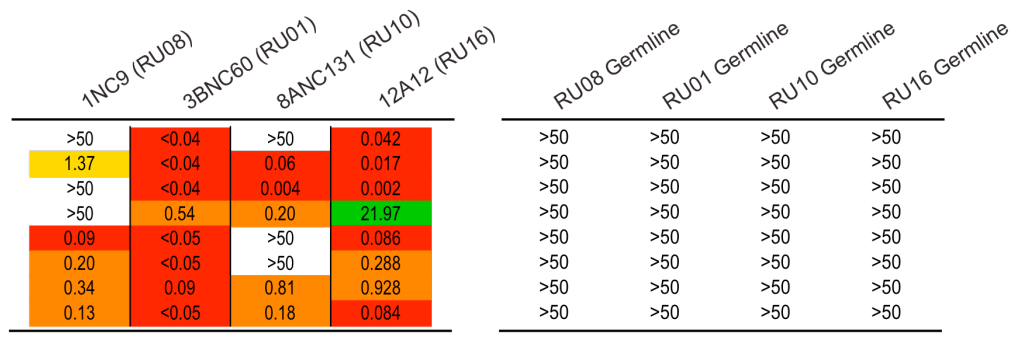

Figure 15; Binding and neutralization of mutated and germline antibodies. a, Binding of selected antibodies (Table 5) and their germline versions against YU2-gp140 as measured by ELISA. Dotted black line shows b12(Burton et al., 1991), solid blue line 3BNC60, green 8ANC192, orange 12A12 and red 1NC9 (Table 5). b, Antibody binding to YU2-gp140 measured by surface plasmon resonance (SPR). The SPR sensorgrams for antibody binding of the selected antibodies and their germline counterparts are shown. The antibodies were tested at concentrations ranging from $44.8 \mathrm{nM}$ (light blue curve) to $700 \mathrm{nM}$ (dark blue curve). $\mathrm{RU}$, response units. c, Bar graphs show the binding of the selected antibodies (Table 5) and their germline versions to ssDNA, dsDNA, Insulin and LPS (from dark to light blue) (OD405nm) at an antibody concentration of $1 \mu \mathrm{g} / \mathrm{ml}$. d, IC50 neutralization titers of the selected antibodies and germline versions against a basic virus panel (Table 6). Colors indicate concentration at IC50: red $\leq 0.1 \mu \mathrm{g} / \mathrm{ml}$; orange $0.1-1 \mu \mathrm{g} / \mathrm{ml}$; yellow $1-10 \mu \mathrm{g} / \mathrm{ml}$; green $\geq 10 \mu \mathrm{g} / \mathrm{ml}$; white not neutralized at any concentration tested. 


\section{HIV neutralizing activity}

HIV neutralizing activity was measured in vitro using an initial panel of 8 viruses including 3 tier 1 Clade A, B and C, and 5 tier 2 Clade B envelope (Env) pseudovirus variants(Li et al., 2005; Seaman et al., 2010). The neutralizing activity of the antibodies was compared to VRC01 and purified serum IgG from the donors (Fig. 16a)(Scheid et al., 2011b). A selection of 11 representative antibodies showing high levels of neutralizing activity were further tested on a panel of 15 additional tier 2 Env pseudovirus variants (Fig. 16b), including 5 viruses that are resistant to VRC01 (Fig. 16 b). 88\% of all of the antibodies tested showed some neutralizing activity and 6 clones (RU01, 08, 10, 12, 16 and NIH45-46) contained antibodies that were highly potent and broad (Fig. 16). These clones were also the most abundant among those captured by $2 \mathrm{CC}$-core in each of the four patients studied (Fig. $13 \mathrm{~A}$ and Table 5). Five antibodies representing four different broadly neutralizing founder B cell clones [Clone RU01 (3BNC117, 3BNC55) Clone RU16 (12A12) Clone RU12 (8ANC195) and NIH45-46], were tested against an expanded panel of 118 tier 2 viral isolates from all known clades including 32 transmitted founder viruses (Fig. 16c and Table 7) (VRC01 had previously been tested on 82 of these)(Wu et al., 2010). The most impressive of the new antibodies, 3BNC117 belonging to a clone with 85 members (RU01), showed an average $\mathrm{IC}_{80}$ on a combined group of 95 tier 2 viruses of $1.4 \mu \mathrm{g} / \mathrm{ml}$ (Table $7 \mathrm{~b})$.

When compared to the previously published VRC01 neutralization data only 17 of the viruses tested were more sensitive to VRC01 than 3BNC117 and 3BNC117 showed 
greater breadth (Fig. 16b, c and Table 7) (Wu et al., 2010). NIH45-46 a new variant of VRC01 is more potent than VRC01 on 62 of the viruses tested but still less potent than 3BNC117 (Fig. 16, B and C and Table 7)(Wu et al., 2010). Together the new antibodies neutralize $96 \%$ of the 118 viruses tested (Table 7). Finally, the best antibodies were highly hypermutated, and this was essential for their breadth and potency (Fig. 15 and Table 7).

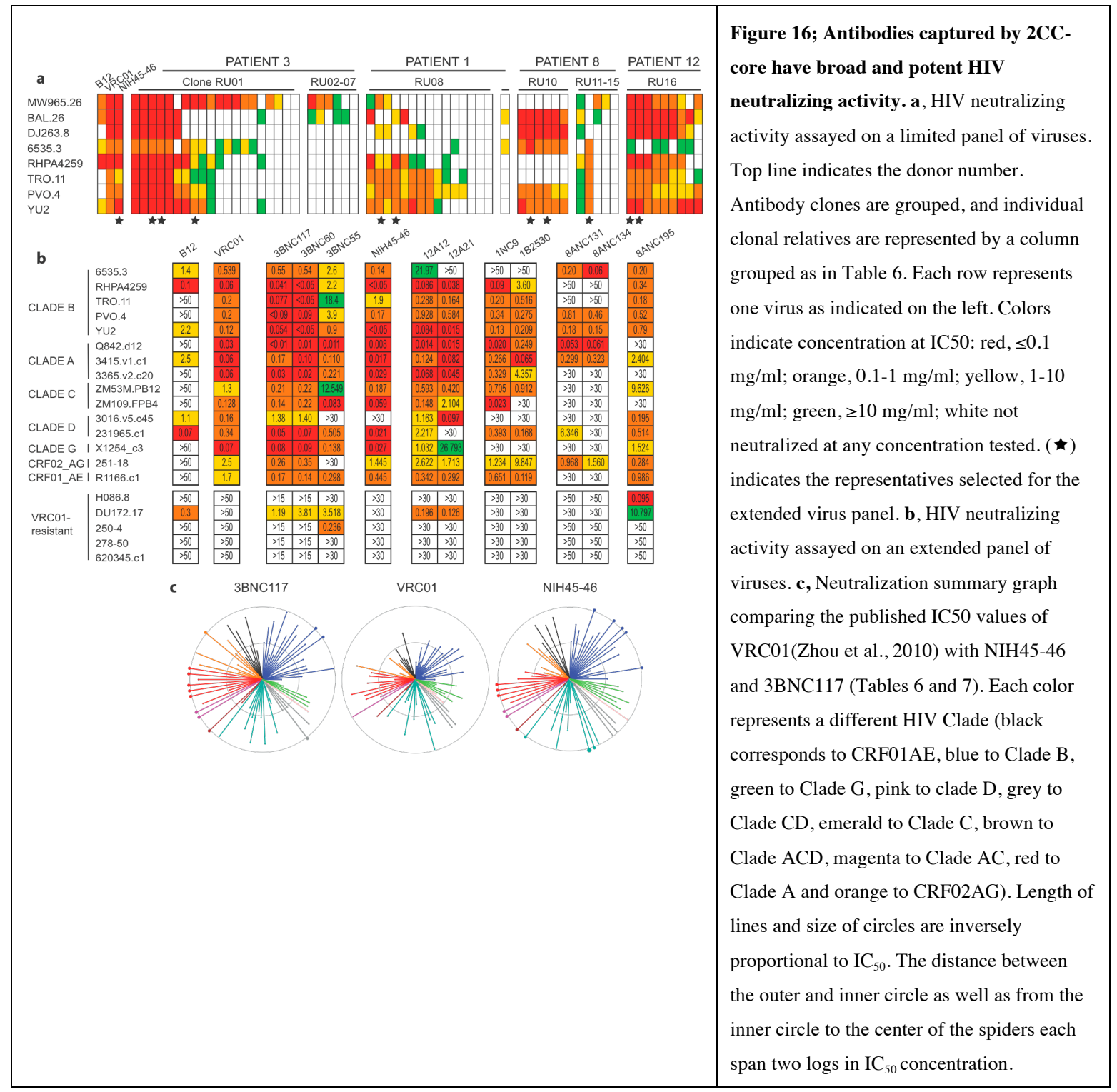




\section{Table 6; Neutralizing activity of 2CC-core binding antibodies against a basic virus panel of 3 Tier 1 (Clades A, B, C) and 5 Tier 2}

(Clade B) viruses. Each column represents one antibody and antibody clones are grouped for each source patient (Table 5). Tier 1 viruses are: MW965.26 (Clade C), BaL.26 (Clade B), DJ263.8 (Clade A); Tier 2 (Clade B) viruses are: 6535.3, RHPA4259.7, TRO.11, PVO.4, YU2.DG. Colors indicate concentration at IC50 (a-d) and IC80 (e-h): for monoclonal antibodies: red $\leq 0.1 \mu \mathrm{g} / \mathrm{ml}$; orange 0.1-1 $\mu \mathrm{g} / \mathrm{ml}$; yellow $1-10 \mu \mathrm{g} / \mathrm{ml}$; green $\geq 10 \mu \mathrm{g} / \mathrm{ml}$; white not neutralized at any concentration tested. Previously published data from antibodies B12(Burton et al., 1991; Scheid et al., 2009a; Zhou et al., 2010) and VRC01(Zhou et al., 2010) is added as control; for serum IgG: orange $10-100 \mu \mathrm{g} / \mathrm{ml}$; yellow $>100 \mu \mathrm{g} / \mathrm{ml}$; white not neutralized at any concentration tested

Table 6, In vitro Tzm-bl neutralization assay, basic panel IC50 values

a Patient 3, Clone RU01

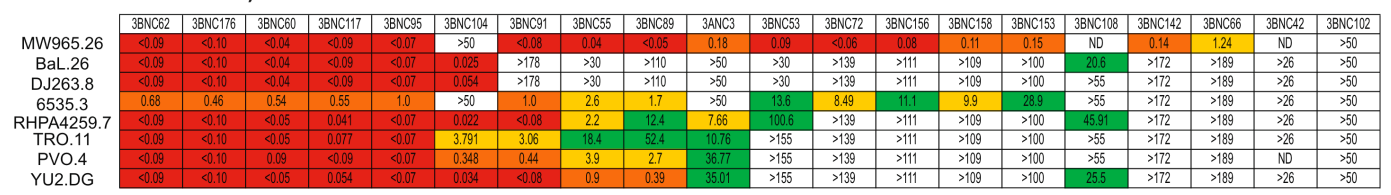

Patient 3, Clones RU02-07

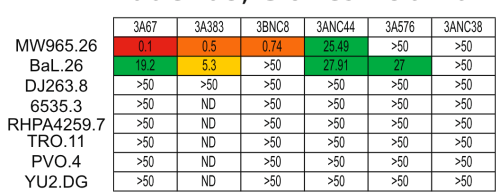

b Patient 1, Clone RU08

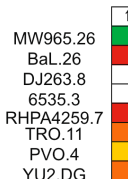

YU2.DG
B12 and NIH45 Clone
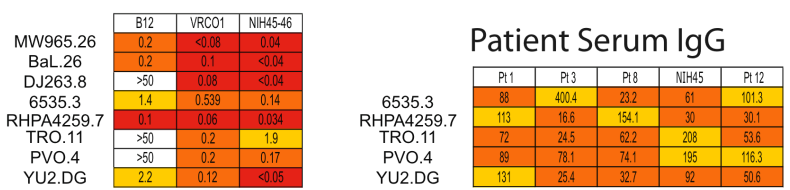

Clone RU09

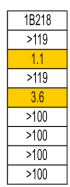


Table 6, In vitro Tzm-bl neutralization assay, basic panel IC50 values

c Patient 8 , Clone RU10

\begin{tabular}{|c|c|c|c|c|c|}
\hline 8ANC192 & 8ANC134 & 8ANC13 & 8ANC131 & 8ANC182 & 8ANC45 \\
\hline 773 & 250 & 250 & 25 & & 15 \\
\hline
\end{tabular}

MW965.26
BaL.26

BaL. 26
DJ263.8

6535.3

RHPA4259.7

PVO 4

YU2.DG

Patient 12, Clone RU16

\begin{tabular}{|l|l|l|l|l|l|l|l|l|}
\hline 12412 & 122421 & 12422 & 12416 & 12220 & 1246 & 12423 & 12446 & 12455 \\
\hline
\end{tabular}

MW965.26

BaL.26
DJ263.8

DJ263.8

RHPA4259

PVO 4

YU2.DG

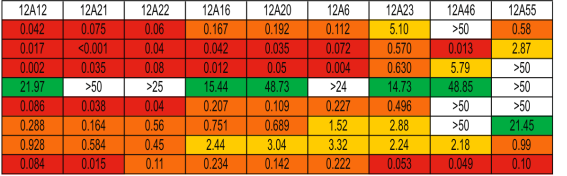

Patient 8, Clones RU11-15

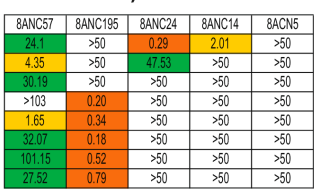

B12 and NIH45 Clone

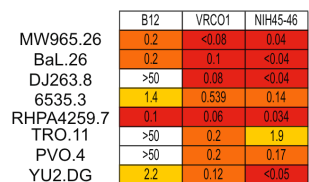

Table 6, In vitro Tzm-bl neutralization assay, basic panel IC80 values

e

Patient 3, Clone RU01

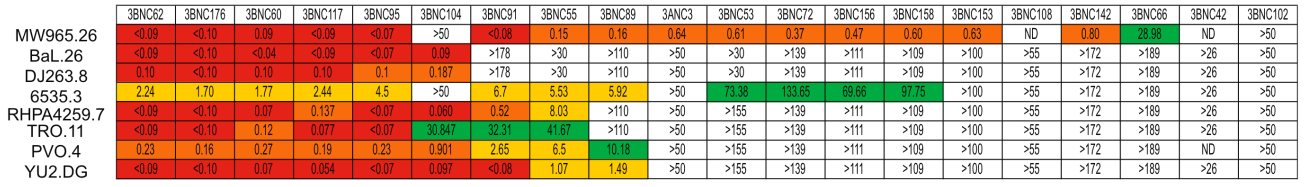

Patient 3, Clones RU02-07

B12 and NIH45 Clone
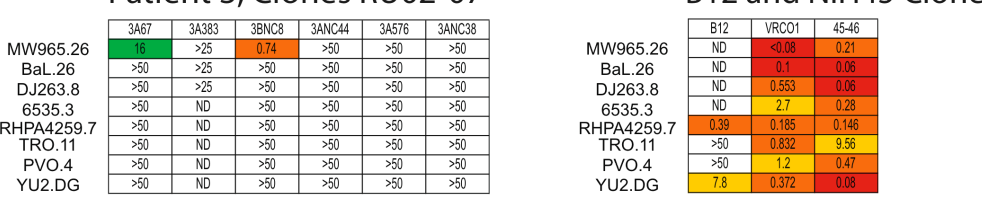

f Patient 1, Clone RU08

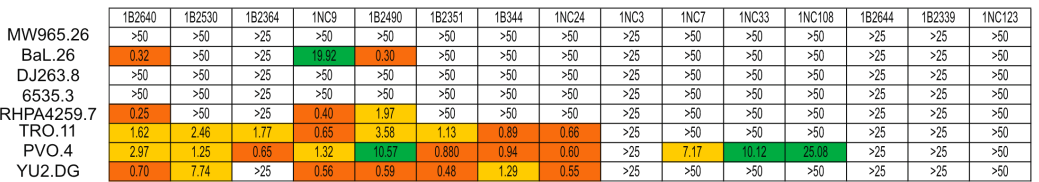

Clone RU09

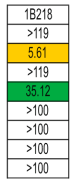


Table 6, In vitro Tzm-bl neutralization assay, basic panel IC80 values

g Patient 8, Clone RU10

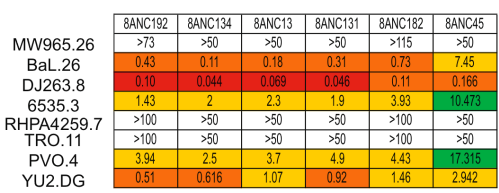

h

Patient 12, Clone RU16

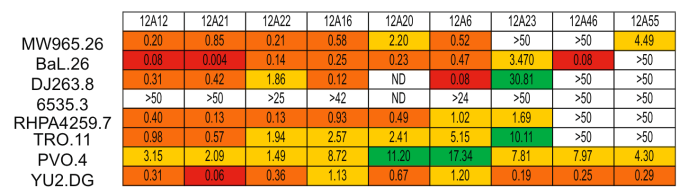

Patient 8, Clones RU11-15

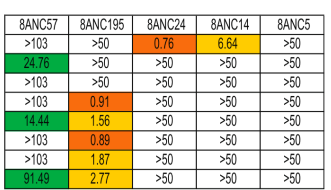

B12 and NIH45 Clone

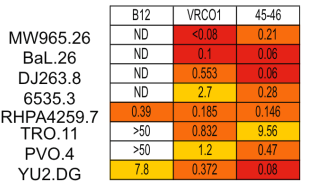




\section{Table 7; Neutralizing activity of selected antibodies against an extended Tier 2 virus panel.}

Colors indicate concentration at IC50 a and IC80 b: red $\leq 0.1 \mu \mathrm{g} / \mathrm{ml}$; orange $0.1-1 \mu \mathrm{g} / \mathrm{ml}$; yellow $1-10 \mu \mathrm{g} / \mathrm{ml}$; green $\geq 10 \mu \mathrm{g} / \mathrm{ml}$; white not neutralized at any concentration tested. Previously

published neutralization data from antibody VRC01 is added as control. c, Summary table of neutralizing activity shows the $\%$ of viruses from the indicated clades neutralized $<50$ and $<1 \mathrm{mg} / \mathrm{ml}$ respectively. The Average expresses the arithmetic mean concentrations needed to neutralize the viruses that are sensitive to the respective antibodies.

Table 7, IC50

a

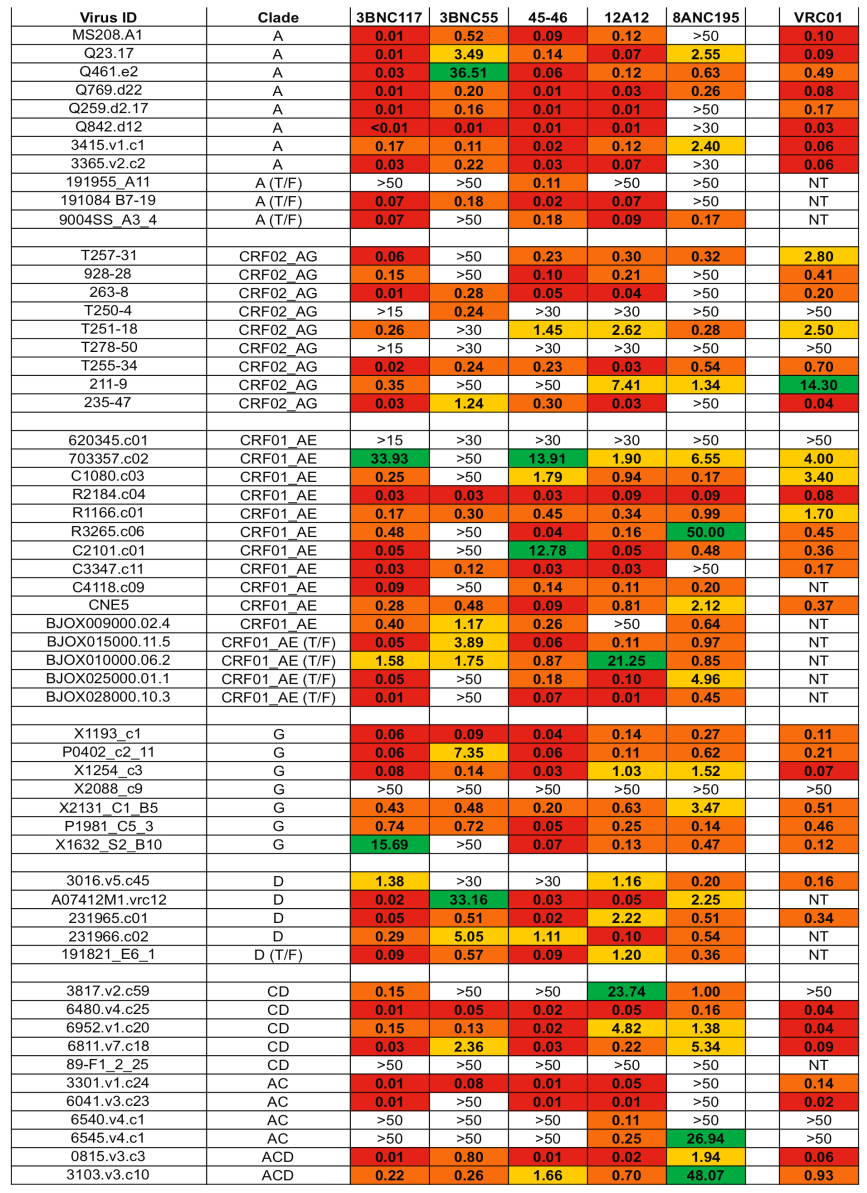


Table 7, IC50

a

\begin{tabular}{|c|c|c|c|c|c|c|c|}
\hline Virus ID & Clade & 3BNC117 & 3BNC55 & $45-46$ & 12A12 & 8ANC195 & VRC01 \\
\hline 6535.3 & $B$ & 0.55 & 2.60 & 0.14 & 21.97 & 0.20 & 0.54 \\
\hline QH0692.42 & $B$ & 0.13 & 2.45 & 0.55 & 1.92 & 2.71 & 1.50 \\
\hline SC422661.8 & $B$ & 0.02 & 0.26 & 0.01 & 0.24 & 0.29 & 0.08 \\
\hline PVO.4 & $B$ & $<0.09$ & 3.90 & 0.17 & 0.93 & 0.52 & 0.22 \\
\hline TRO.11 & $B$ & $<0.09$ & 18.40 & 1.90 & 0.29 & 0.18 & 0.21 \\
\hline AC10.0.29 & $\mathrm{B}$ & 13.84 & $>50$ & 0.42 & 1.15 & 0.88 & 2.20 \\
\hline RHPA4259.7 & $B$ & $<0.09$ & 2.20 & $<0.05$ & 0.09 & 0.34 & 0.06 \\
\hline THRO4156.18 & B & 1.76 & $>50$ & 1.59 & 3.05 & $>50$ & 2.30 \\
\hline REJO4541.67 & $B$ & 0.01 & 0.13 & $<0.05$ & 0.19 & 0.08 & 0.06 \\
\hline TRJO4551.58 & $B$ & 0.05 & 0.10 & 0.01 & 0.14 & 0.19 & 0.08 \\
\hline WITO4160.33 & $B$ & 0.01 & 1.71 & 0.01 & 0.06 & $>50$ & 0.15 \\
\hline CAAN5342.A2 & $B$ & 0.42 & 4.10 & 0.11 & 1.32 & $>50$ & 0.82 \\
\hline WEAU_d15_410_787 & $\mathrm{B}(\mathrm{T} / \mathrm{F})$ & 0.05 & 0.10 & 0.01 & 0.05 & $>50$ & 0.12 \\
\hline 1006_11_C3_1601 & $\mathrm{B}(\mathrm{T} / \mathrm{F})$ & 0.03 & $>50$ & 0.05 & 0.22 & 0.43 & 0.15 \\
\hline 1054_07_TC4_1499 & $\mathrm{B}(\mathrm{T} / \mathrm{F})$ & 0.07 & 4.05 & 0.07 & 2.55 & 1.02 & 0.71 \\
\hline 1056_10_TA11_1826 & $\mathrm{B}(\mathrm{T} / \mathrm{F})$ & 0.30 & 1.25 & 0.12 & 0.58 & $>50$ & 0.92 \\
\hline 1012_11_TC21_3257 & $B(T / F)$ & 0.02 & 0.22 & 0.01 & 0.27 & $>50$ & 0.12 \\
\hline 6240_08_TA5_4622 & $B(T / F)$ & 0.33 & 2.51 & 0.44 & 1.21 & $>50$ & 0.61 \\
\hline 6244_13_B5_4576 & $B(T / F)$ & 0.04 & 7.24 & 0.07 & 0.47 & $>50$ & 0.21 \\
\hline 62357_14_D3_4589 & $B(T / F)$ & 0.06 & $>50$ & 0.05 & 0.62 & $>50$ & 0.96 \\
\hline SC05_8C11_2344 & $B(T / F)$ & 0.15 & 1.93 & 0.14 & 2.03 & 0.47 & 0.64 \\
\hline Du156.12 & C & 0.02 & 0.07 & 0.01 & 0.04 & 0.22 & 0.09 \\
\hline Du172.17 & $C$ & 1.19 & 3.52 & $>30$ & 0.20 & 10.80 & $>50$ \\
\hline Du422.1 & $C$ & $>50$ & $>50$ & $>50$ & $>50$ & $>50$ & $>50$ \\
\hline ZM197M.PB7 & $\mathrm{C}$ & 0.22 & 0.53 & 0.14 & 1.24 & 23.45 & 0.36 \\
\hline ZM214M.PL15 & C & 0.06 & 3.10 & 0.05 & 0.37 & 0.91 & 0.44 \\
\hline ZM233M.PB6 & $\mathrm{C}$ & 0.13 & 0.64 & 1.86 & 39.19 & 7.39 & 2.00 \\
\hline ZM249M.PL1 & C & 0.03 & 0.06 & 0.02 & 0.06 & $>50$ & 0.05 \\
\hline ZM53M.PB12 & C & 0.21 & 12.55 & 0.19 & 0.59 & 9.63 & 1.30 \\
\hline ZM109F.PB4 & C & 0.14 & 0.08 & 0.06 & 0.15 & $>30$ & 0.13 \\
\hline ZM135M.PL10a & C & 0.03 & 0.29 & 0.36 & 1.35 & $>50$ & 0.35 \\
\hline CAP45.2.00.G3 & $\mathrm{C}$ & 3.88 & $>50$ & $>50$ & 1.83 & 28.30 & 2.30 \\
\hline CAP210.2.00.E8 & $C$ & 17.22 & $>50$ & $>50$ & $>50$ & $>50$ & $>50$ \\
\hline HIV-001428-2.42 & C & $<0.05$ & 0.03 & $<0.001$ & 0.02 & $>50$ & 0.02 \\
\hline HIV-0013095-2.11 & C & 0.33 & 0.57 & 0.01 & 0.20 & 0.32 & 0.11 \\
\hline HIV-16055-2.3 & C & 5.60 & $>50$ & 0.02 & 0.04 & 15.30 & 0.08 \\
\hline HIV-16845-2.22 & C & 27.46 & $>50$ & 2.05 & 1.93 & 3.30 & 2.80 \\
\hline Ce1086_B2 & $C(T / F)$ & 0.09 & $>50$ & 0.04 & 0.12 & 4.42 & NT \\
\hline Ce0393_C3 & $C(T / F)$ & 0.20 & 14.03 & 0.32 & 0.33 & 6.77 & NT \\
\hline Ce1176_A3 & $C(T / F)$ & 0.22 & $>50$ & 1.29 & 1.44 & 4.45 & NT \\
\hline Ce2010_F5 & $C(T / F)$ & 0.05 & 1.32 & 0.13 & 0.33 & $>50$ & NT \\
\hline Ce0682_E4 & $C(T / F)$ & 0.03 & 1.71 & 0.07 & 0.11 & 0.20 & NT \\
\hline Ce1172_H1 & $C(T / F)$ & $>50$ & $>50$ & $>50$ & $>50$ & 42.30 & NT \\
\hline Ce2060_G9 & $C(T / F)$ & 0.24 & 37.85 & 0.14 & 0.48 & 6.20 & NT \\
\hline Ce703010054_2A2 & $C(T / F)$ & 0.37 & 0.22 & 0.22 & 0.25 & 13.62 & NT \\
\hline BF1266.431a & $C(T / F)$ & 0.03 & 0.07 & 0.01 & 2.07 & $>50$ & NT \\
\hline $246 \mathrm{~F} \mathrm{C1G}$ & $C(T / F)$ & 19.32 & 0.28 & $>50$ & 0.37 & 12.81 & NT \\
\hline 249M B10 & $C(T / F)$ & 0.10 & 0.12 & 0.04 & 0.11 & $>50$ & NT \\
\hline ZM247v1(Rev-) & $C(T / F)$ & $>50$ & $>50$ & 1.64 & 0.27 & 3.41 & NT \\
\hline 7030102001E5(Rev-) & $C(T / F)$ & 0.29 & 1.08 & 0.14 & 0.60 & 0.86 & NT \\
\hline 1394C9G1(Rev-) & $C(T / F)$ & $>50$ & $>50$ & 0.09 & 0.32 & $>50$ & NT \\
\hline Ce704809221_1B3 & $C(T / F)$ & 0.08 & $>50$ & 0.15 & 0.36 & 0.48 & NT \\
\hline CNE19 & $B C$ & 0.02 & 10.38 & 0.07 & 0.13 & 0.29 & NT \\
\hline CNE20 & BC & $>50$ & $>50$ & 8.71 & 0.31 & 0.50 & NT \\
\hline CNE21 & $B C$ & 45.38 & $>50$ & 7.53 & 0.34 & 0.27 & NT \\
\hline CNE17 & $B C$ & 5.76 & 2.39 & 0.15 & 1.74 & 2.59 & NT \\
\hline CNE30 & BC & 0.26 & $>50$ & 0.34 & 0.68 & 7.52 & NT \\
\hline CNE52 & $B C$ & 0.02 & $>50$ & 0.03 & 0.08 & 5.59 & NT \\
\hline CNE53 & $B C$ & 0.08 & 3.54 & 0.01 & 0.09 & $>50$ & NT \\
\hline CNE58 & $B C$ & 0.25 & $>50$ & 0.25 & 0.07 & $>50$ & NT \\
\hline
\end{tabular}


Table 7, IC80

b

\begin{tabular}{|c|c|c|c|c|c|c|c|}
\hline Virus ID & Clade* & 3BNC117 & 3BNC55 & $45-46$ & 12A12 & 8ANC195 & VRC01 \\
\hline MS208.A1 & $\mathrm{A}$ & 0.09 & 2.41 & 0.60 & 0.44 & $>50$ & 0.462 \\
\hline Q23.17 & A & 0.02 & 32.12 & 0.60 & 0.18 & 2.55 & 0.261 \\
\hline Q461.e2 & $A$ & 0.09 & $>50$ & 0.32 & 0.45 & 2.51 & 1.6 \\
\hline Q769.d22 & $\mathrm{A}$ & 0.04 & 2.55 & 0.04 & 0.11 & 1.20 & 0.289 \\
\hline Q259.d2.17 & A & 0.05 & 2.16 & 0.06 & 0.06 & $>50$ & 0.543 \\
\hline Q842.d12 & A & 0.01 & 0.06 & 0.03 & 0.06 & $>30$ & 0.096 \\
\hline 3415.v1.c1 & A & 0.47 & 0.39 & 0.07 & 0.42 & 17.74 & 0.15 \\
\hline 3365.v2.c2 & A & 0.10 & 2.34 & 0.11 & 0.19 & $>30$ & 0.17 \\
\hline 191955_A11 & $\mathrm{A}(\mathrm{T} / \mathrm{F})$ & $>50$ & $>50$ & 0.43 & $>50$ & $>50$ & NT \\
\hline 191084 B7-19 & $\mathrm{A}(\mathrm{T} / \mathrm{F})$ & 0.23 & 0.55 & 0.07 & 0.22 & $>50$ & NT \\
\hline 9004SS_A3_4 & $A(T / F)$ & 0.18 & $>50$ & 0.65 & 0.30 & 0.81 & NT \\
\hline T257-31 & CRF02 AG & 0.37 & $>50$ & 1.11 & 1.63 & 3.89 & 8.7 \\
\hline $928-28$ & CRF02_AG & 0.55 & $>50$ & 0.39 & 0.79 & $>50$ & 1.7 \\
\hline $263-8$ & CRF02_AG & 0.04 & 2.22 & 0.10 & 0.23 & $>50$ & 0.55 \\
\hline T250-4 & CRF02_AG & $>15$ & 1.92 & $>30$ & $>30$ & $>50$ & $>50$ \\
\hline T251-18 & CRF02_AG & 0.82 & $>30$ & 5.26 & 9.39 & 1.51 & 11.2 \\
\hline T278-50 & CRF02_AG & $>15$ & $>30$ & $>30$ & $>30$ & $>50$ & $>50$ \\
\hline T255-34 & CRF02_AG & 0.14 & 1.58 & 2.38 & 0.26 & 8.09 & 2.7 \\
\hline $211-9$ & CRF02_AG & 1.28 & $>50$ & $>50$ & 47.27 & 8.43 & $>50$ \\
\hline $235-47$ & CRF02_AG & 0.12 & 14.94 & 1.49 & 0.12 & $>50$ & 0.17 \\
\hline $620345 . c 01$ & CRF01_AE & $>15$ & $>30$ & $>30$ & $>30$ & $>50$ & $>50$ \\
\hline $703357 . c 02$ & CRF01_AE & $>50$ & $>50$ & $>50$ & 9.62 & 30.52 & 11.1 \\
\hline C1080.c03 & CRF01_AE & 1.73 & $>50$ & 18.04 & 7.05 & 1.12 & 14.4 \\
\hline R2184.c04 & CRF01_AE & 0.10 & 0.16 & 0.12 & 0.37 & 12.98 & 0.32 \\
\hline R1166.c01 & CRF01_AE & 0.64 & 2.35 & 1.68 & 1.85 & 4.83 & 4.6 \\
\hline R3265.c06 & CRF01_AE & 13.04 & $>50$ & 0.44 & 1.61 & $>50$ & 1.9 \\
\hline C2101.c01 & CRF01_AE & 0.31 & $>50$ & $>50$ & 0.24 & 3.54 & 1.2 \\
\hline C3347.c11 & CRF01_AE & 0.13 & 1.16 & 0.18 & 0.19 & $>50$ & 0.58 \\
\hline C4118.c09 & CRF01_AE & 0.52 & $>50$ & 0.91 & 0.72 & 0.71 & $\mathrm{NT}$ \\
\hline CNE5 & CRF01_AE & 1.28 & 3.56 & 0.41 & 6.28 & 9.67 & 1.1 \\
\hline BJOX009000.02.4 & CRF01_AE & 1.79 & 5.58 & 1.16 & $>50$ & 3.09 & NT \\
\hline BJOX015000.11.5 & CRF01_AE (T/F) & 0.32 & $>50$ & 0.38 & 0.76 & 4.30 & NT \\
\hline BJOX010000.06.2 & CRF01_AE (T/F) & 10.45 & 10.75 & 6.37 & $>50$ & 5.84 & NT \\
\hline BJOX025000.01.1 & CRF01_AE (T/F) & 0.20 & $>50$ & 10.00 & 1.54 & $>50$ & NT \\
\hline BJOX028000.10.3 & CRF01_AE (T/F) & 0.05 & $>50$ & $>50$ & 0.06 & 2.83 & NT \\
\hline X1193_c1 & G & 0.25 & 0.54 & 0.16 & 0.87 & 1.66 & 0.32 \\
\hline $\mathrm{P} 0402$ c2 11 & G & 0.38 & $>50$ & 0.26 & 0.49 & 6.35 & 0.59 \\
\hline X1254_c3 & G & 0.27 & 0.57 & 0.08 & 5.78 & 6.95 & 0.19 \\
\hline X2088_c9 & G & $>50$ & $>50$ & $>50$ & $>50$ & $>50$ & $>50$ \\
\hline X2131_C1_B5 & G & 1.96 & 2.12 & 0.90 & 2.94 & $>50$ & 1.5 \\
\hline P1981_C5_3 & $\mathrm{G}$ & 3.62 & 3.26 & 0.22 & 1.18 & 1.15 & 1.3 \\
\hline X1632_S2_B10 & G & $>50$ & $>50$ & $>50$ & 0.87 & 4.11 & 0.74 \\
\hline & & & & & & & \\
\hline $3016 . v 5 . c 45$ & $\mathrm{D}$ & $>30$ & $>30$ & $>30$ & 11.86 & 0.87 & 0.42 \\
\hline A07412M1.vrc12 & $\mathrm{D}$ & 0.10 & $>50$ & 0.13 & 0.27 & 7.49 & NT \\
\hline $231965 . c 01$ & $\mathrm{D}$ & 0.22 & 2.78 & 0.10 & 15.10 & 2.36 & 1.2 \\
\hline $231966 . c 02$ & $\mathrm{D}$ & 2.37 & $>50$ & 11.36 & 0.51 & 2.98 & NT \\
\hline 191821_E6_1 & $\mathrm{D}(\mathrm{T} / \mathrm{F})$ & 0.51 & 3.17 & 0.46 & 6.66 & 1.61 & NT \\
\hline 3817.v2.c59 & CD & 0.52 & $>50$ & $>50$ & $>50$ & 5.30 & $>50$ \\
\hline 6480.v4.c25 & $C D$ & 0.04 & 0.18 & 0.08 & 0.18 & 1.13 & 0.09 \\
\hline 6952.v1.c20 & $C D$ & 0.75 & 0.46 & 0.07 & $>50$ & 7.22 & 0.12 \\
\hline 6811.v7.c18 & CD & 0.17 & 15.22 & 0.13 & 0.83 & 27.63 & 0.26 \\
\hline 89-F1_2_25 & $C D$ & $>50$ & $>50$ & $>50$ & $>50$ & $>50$ & NT \\
\hline $3301 . v 1 . c 24$ & $A C$ & 0.05 & 0.37 & 0.03 & 0.18 & $>50$ & 0.32 \\
\hline $6041 . v 3 . c 23$ & $\mathrm{AC}$ & 0.07 & $>50$ & 0.04 & 0.04 & $>50$ & 0.08 \\
\hline 6540.v4.c1 & $\mathrm{AC}$ & $>50$ & $>50$ & $>50$ & $>50$ & $>50$ & $>50$ \\
\hline 6545.v4.c1 & $\mathrm{AC}$ & $>50$ & $>50$ & $>50$ & 7.42 & $>50$ & $>50$ \\
\hline 0815.v3.c3 & $A C D$ & 0.02 & 34.86 & 0.03 & 0.05 & 1.94 & 0.13 \\
\hline $3103 . v 3 . c 10$ & $A C D$ & 0.85 & 0.78 & 6.57 & 2.49 & $>50$ & 2.5 \\
\hline
\end{tabular}


Table S7, IC80

b

\begin{tabular}{|c|c|c|c|c|c|c|c|}
\hline Virus ID & Clade* & 3BNC117 & 3BNC55 & $45-46$ & 12A12 & 8ANC195 & VRC01 \\
\hline 6535.3 & B & 2.44 & 22.70 & 0.28 & $>50$ & 0.91 & 2.7 \\
\hline QH0692.42 & $\mathrm{B}$ & 0.49 & 9.04 & 1.56 & 7.12 & 17.08 & 4.8 \\
\hline SC422661.8 & $B$ & 0.08 & 1.24 & 0.07 & 1.51 & 4.67 & 0.265 \\
\hline PVO.4 & $B$ & 0.19 & 14.70 & 0.47 & 3.15 & 1.87 & 1.2 \\
\hline TRO.11 & B & $<0.09$ & $>50$ & 9.56 & 0.98 & 0.89 & 0.832 \\
\hline AC10.0.29 & B & $>50$ & $>50$ & 1.49 & 5.08 & 7.00 & 6.5 \\
\hline RHPA4259.7 & B & $<0.09$ & 21.20 & $<0.05$ & 0.40 & 1.56 & 0.185 \\
\hline THRO4156.18 & $B$ & 10.14 & $>50$ & 6.02 & 12.79 & $>50$ & 23 \\
\hline REJO4541.67 & B & 0.05 & 1.34 & 0.010 & 1.13 & 0.68 & 0.251 \\
\hline TRJO4551.58 & $B$ & 0.19 & 0.41 & 0.05 & 0.44 & 1.17 & 0.207 \\
\hline WITO4160.33 & B & 0.04 & 26.55 & 0.08 & 0.33 & $>50$ & 0.412 \\
\hline CAAN5342.A2 & $B$ & 1.51 & 15.32 & 0.33 & 4.93 & $>50$ & 2.8 \\
\hline WEAU_d15_410_787 & $\mathrm{B}(\mathrm{T} / \mathrm{F})$ & 0.19 & 0.49 & 0.03 & 0.23 & $>50$ & 0.26 \\
\hline 1006_11_C3_1601 & $\mathrm{B}(\mathrm{T} / \mathrm{F})$ & 0.10 & $>50$ & 0.31 & 0.96 & 1.98 & 0.39 \\
\hline 1054_07_TC4_1499 & $\mathrm{B}(\mathrm{T} / \mathrm{F})$ & 0.49 & 23.30 & 0.61 & 9.64 & 6.75 & 2.9 \\
\hline 1056_10_TA11_1826 & $B(T / F)$ & 1.82 & 7.00 & 0.59 & 3.65 & $>50$ & 3.3 \\
\hline 1012_11_TC21_3257 & $B(T / F)$ & 0.07 & 1.58 & 0.04 & 1.19 & $>50$ & 0.32 \\
\hline 6240_08_TA5_4622 & $B(T / F)$ & 1.17 & 9.30 & 1.55 & 4.31 & $>50$ & 1.8 \\
\hline 6244_13_B5_4576 & $\mathrm{B}(\mathrm{T} / \mathrm{F})$ & 0.15 & 43.45 & 0.26 & 1.64 & $>50$ & 0.53 \\
\hline 62357_14_D3_4589 & $\mathrm{B}(\mathrm{T} / \mathrm{F})$ & 0.26 & $>50$ & 0.22 & 4.15 & $>50$ & 4.7 \\
\hline SC05_8C11_2344 & $B(T / F)$ & 0.51 & 6.83 & 0.38 & 7.00 & 3.06 & 1.9 \\
\hline Du156.12 & C & 0.08 & 0.24 & 0.05 & 0.16 & 1.56 & 0.193 \\
\hline Du172.17 & C & 8.90 & $>30$ & $>30$ & 0.99 & $>30$ & $>50$ \\
\hline Du422.1 & C & $>50$ & $>50$ & $>50$ & $>50$ & $>50$ & $>50$ \\
\hline ZM197M.PB7 & C & 1.03 & 2.64 & 0.64 & 6.16 & $>50$ & 1.6 \\
\hline ZM214M.PL15 & $C$ & 0.52 & $>50$ & 0.39 & 1.45 & 12.30 & 2.6 \\
\hline ZM233M.PB6 & $C$ & 0.85 & 4.18 & 16.52 & $>50$ & 43.45 & 9.3 \\
\hline ZM249M.PL1 & $\mathrm{C}$ & 0.11 & 0.27 & 0.06 & 0.22 & $>50$ & 0.232 \\
\hline ZM53M.PB12 & $\mathrm{C}$ & 0.85 & $>30$ & 0.65 & 2.07 & $>30$ & 4 \\
\hline ZM109F.PB4 & C & 0.88 & 0.40 & 0.22 & 0.70 & $>30$ & 0.754 \\
\hline ZM135M.PL10a & C & 0.13 & 1.37 & 3.11 & 6.45 & $>50$ & 2.7 \\
\hline CAP45.2.00.G3 & $\mathrm{C}$ & $>50$ & $>50$ & $>50$ & 36.51 & $>50$ & $>50$ \\
\hline CAP210.2.00.E8 & $\mathrm{C}$ & $>50$ & $>50$ & $>50$ & $>50$ & $>50$ & $>50$ \\
\hline HIV-001428-2.42 & $\mathrm{C}$ & 0.02 & 0.10 & 0.01 & 0.07 & $>50$ & 0.06 \\
\hline HIV-0013095-2.11 & C & 2.53 & 2.14 & 0.03 & 0.97 & 1.85 & 0.33 \\
\hline HIV-16055-2.3 & $C$ & $>50$ & $>50$ & 0.06 & 0.16 & $>50$ & 0.26 \\
\hline HIV-16845-2.22 & C & $>50$ & $>50$ & 12.10 & 10.02 & 20.06 & 12.7 \\
\hline Ce1086_B2 & $C(T / F)$ & 0.31 & $>50$ & 0.28 & 0.62 & 19.11 & NT \\
\hline Ce0393_C3 & $\mathrm{C}(\mathrm{T} / \mathrm{F})$ & 0.67 & $>50$ & 1.07 & 1.52 & $>50$ & NT \\
\hline Ce1176_A3 & $C(T / F)$ & 0.75 & $>50$ & 5.55 & 4.69 & 35.17 & NT \\
\hline Ce2010_F5 & $C(T / F)$ & 0.21 & 6.20 & 0.43 & 1.12 & $>50$ & NT \\
\hline Ce0682_E4 & $C(T / F)$ & 0.15 & 18.38 & 0.25 & 0.45 & 1.29 & NT \\
\hline Ce1172_H1 & $C(T / F)$ & $>50$ & $>50$ & $>50$ & $>50$ & $>50$ & NT \\
\hline Ce2060_G9 & $C(T / F)$ & 0.81 & $>50$ & 0.48 & 2.18 & $>50$ & NT \\
\hline Ce703010054_2A2 & $C(T / F)$ & 1.67 & 1.08 & 0.97 & 1.16 & $>50$ & NT \\
\hline BF1266.431a & $C(T / F)$ & 0.09 & 0.22 & 0.03 & 26.46 & $>50$ & NT \\
\hline $246 \mathrm{~F} \mathrm{C1G}$ & $C(T / F)$ & $>50$ & 1.00 & $>50$ & 1.81 & $>50$ & NT \\
\hline 249M B10 & $C(T / F)$ & 0.40 & 0.47 & 0.17 & 0.41 & $>50$ & NT \\
\hline ZM247v1(Rev-) & $C(T / F)$ & $>50$ & $>50$ & $>50$ & 1.73 & 25.12 & NT \\
\hline 7030102001E5(Rev-) & $C(T / F)$ & 1.44 & 5.78 & 0.63 & 4.40 & 8.32 & NT \\
\hline 1394C9G1(Rev-) & $C(T / F)$ & $>50$ & $>50$ & 0.38 & 2.51 & $>50$ & NT \\
\hline Ce704809221_1B3 & $C(T / F)$ & 0.31 & $<50$ & 0.88 & 2.39 & 3.52 & NT \\
\hline CNE19 & $\mathrm{BC}$ & 0.08 & $>50$ & 0.37 & 0.46 & 1.73 & NT \\
\hline CNE20 & $\mathrm{BC}$ & $>50$ & $>50$ & 47.01 & 1.94 & 3.19 & NT \\
\hline CNE21 & $\mathrm{BC}$ & $>50$ & $>50$ & $>50$ & 1.72 & 1.52 & NT \\
\hline CNE17 & $B C$ & 42.98 & 8.93 & 0.55 & 6.23 & 11.07 & NT \\
\hline CNE30 & $B C$ & 0.85 & $>50$ & 1.48 & 2.23 & 40.45 & NT \\
\hline CNE52 & $B C$ & 0.06 & $>50$ & 0.12 & 0.34 & 43.09 & NT \\
\hline CNE53 & $\mathrm{BC}$ & 0.99 & $>50$ & 0.04 & 0.32 & $>50$ & NT \\
\hline CNE58 & $\mathrm{BC}$ & 2.03 & $>50$ & 1.49 & 0.26 & $>50$ & NT \\
\hline
\end{tabular}




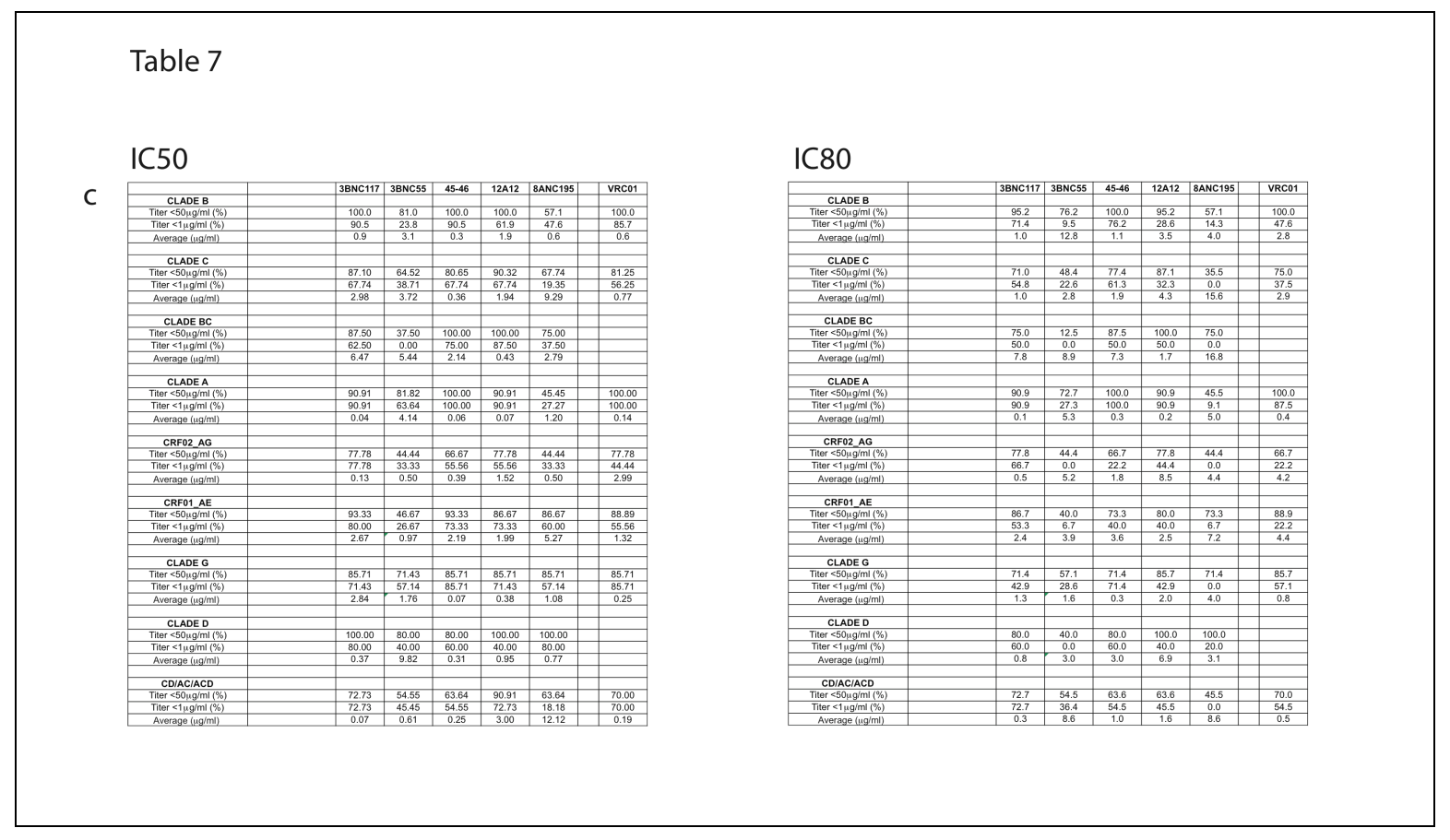




\section{Anti-2CC-core antibodies in the bone marrow plasma cell compartment}

Our cloning strategy captures antibodies produced by antigen binding memory B cells in the blood, but circulating antibodies are not produced by these cells, and originate instead from plasma cells in the bone marrow(Dorner and Radbruch, 2007). To determine whether the antibodies cloned from memory B cells are also found in the bone marrow plasma cell compartment, we purified plasma cells from paired bone marrow samples from patients 3 and 8 (Fig. 17) and used PCR to specifically amplify $\operatorname{Ig} V_{H}$ genes from the clones RU01 and RU10 from memory B cells in these individuals (Fig. 16a, Fig. 17a, and Table 5). Members of these clones and large numbers of additional variants were readily identified in the respective plasma cell samples (Fig. 17b and c). We also verified that antibodies from clones RU01, RU08 and RU10 (Fig. 16a and Table 5) are found in serum by mass spectrometry (Fig. 18 and Table 8 ). 
a

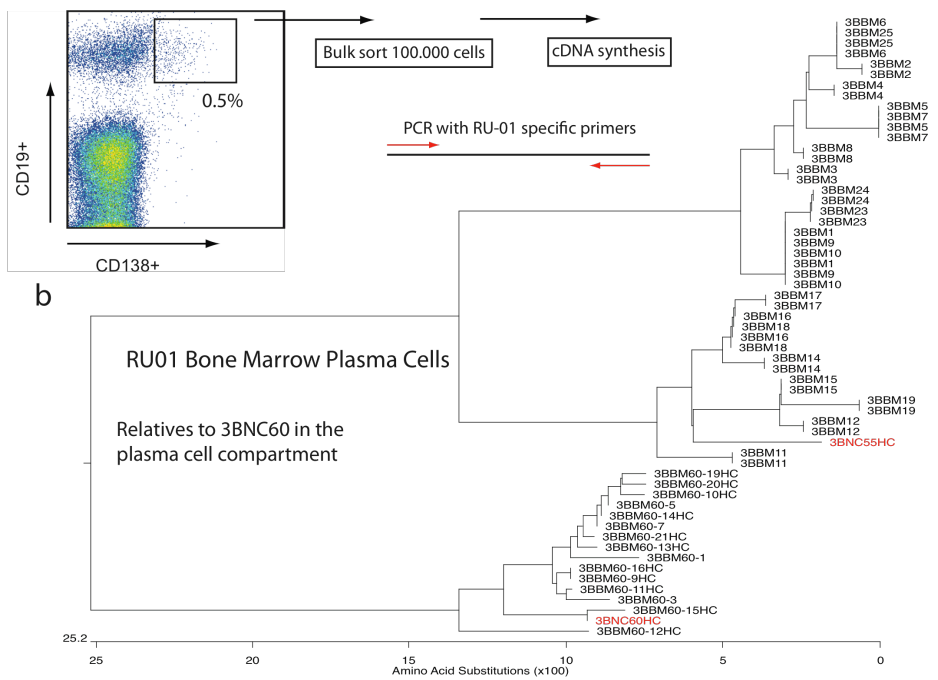

C

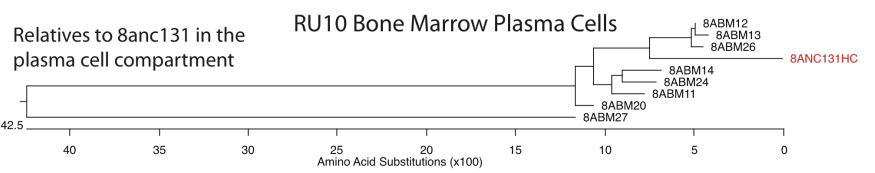

Figure 17; Clone specific amplification of IgG genes from CD138+ bone marrow plasma cells. a,

FACS plot showing sorting strategy for bulk sort of CD19+, CD138+ bone marrow plasma cells. (b and $\mathbf{c}$ ) Phylogenetic trees based on predicted amino acid sequences of members of the b, RU01 clone (Pt 3) and c, RU10 clone ( $\mathrm{Pt} 8)$. Antibodies that were also isolated from the peripheral memory B cell compartment are shown in red. Clone specific primers were: for RU01

CTGCAACCGGTGTACATTCTCAAGTGCAACTGGTGC (FWRD), CTGCAACCGGTGTACATTCTCAGGTCCATTTGTCACAG (FWRD), TGCGAAGTCGACGCTGACGAGACAGTGACCTGC (REV), TGCGAAGTCGACGCTGAAGAGACAATAATTTG (REV), TGCGAAGTCGACGCTGACGAGACAATAACT (REV) and for RU10: CTGCAACCGGTGTACATTTTCAGGGGCACTTGGTG (FWRD), TGCGAAGTCGACGCTGAGGTGACGATGACCGTG (REV). 
a

b

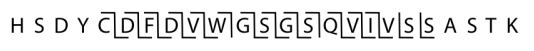

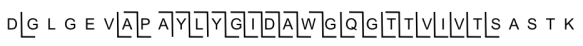
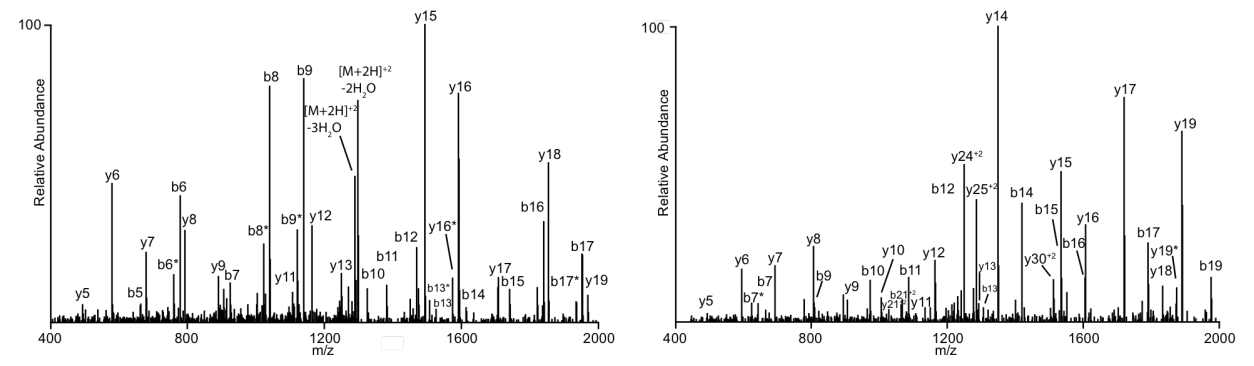

C $3 \mathrm{BNC60}$

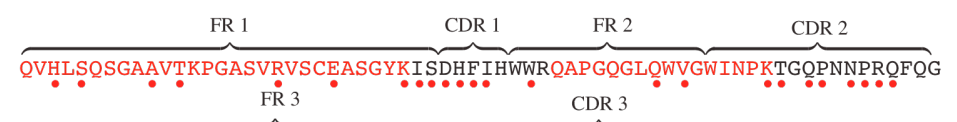

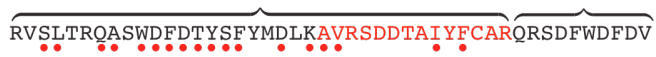

1B2530

$$
\text { FR } 1
$$

CDR 1

FR 2

CDR 2

$\overbrace{\text { QVQLEQSGTAVRKPGASVTLSCQASGYNFVKY I IHWVRQKPGLGFEWVGMIDPYRGRPWSAHKFQG }}^{C}$

$\overbrace{}^{\text {FR } 3} \overbrace{}^{\text {CDR } 3}$

$\overbrace{\text { RLSLSRDTSMEILYMTLTSLKSDDTATYFCARAEAASDSHSRPIMFDH }}$

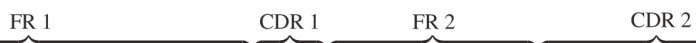

8ANC134 $\overbrace{\text { QGQLVQSGGGVKKPGTSVTISCLASEYTFNEFVIHWIRQAPGQGPVWLGLIKRSGRLMTSYKFQD }}^{\text {. }}$

FR 3 CDR 3

$\overbrace{\text { RLSLRRDRSTGTVFMELRGLRLDDTAVYYCARDGLGEVAPAYLYGIDAWGQGSTVIVTSASTK }}$

\section{Figure 18; Detection of antibodies by mass spectrometry.}

( $\mathbf{a}$ and $\mathbf{b}$ ) Two sample spectra of collision activated dissociation MS/MS recorded on the doubly charged peptides HSDYCDFDVWGSGSQVIVSSASTK from 3BNC153HC a, (Table 5) and DGLGEVAPAYLYGIDAWGQGTTVIVTSASTK from 8ANC134HC b, (Table 5). Observed b-type fragment ions (containing the $\mathrm{N}$-terminus) and y-type fragment ions (containing the $\mathrm{C}$-terminus) are labeled in the spectrum. Loss of water from fragment ions is indicated by *. Ions corresponding to the loss of water from the parent ion are labeled in the spectrum. The complete data set for the peptides detected is shown in Table 8. c, Amino acid sequences of 3BNC60,1B2530 and 8ANC134 heavy chains with peptides found by Mass Spec in red. Red dots indicate differences from respective germline sequences. 


\section{Table 8; Antibody sequences from one expanded neutralizing clone in each (a) Pt1, (b) Pt3 and (c)}

Pt8. Clone labeling as in Table 5. Peptides identified by mass spectrometry are indicated in color. The variants marked with an asterisk are uniquely defined by one or more mass spectrometrically observed peptides (shown in yellow). The remaining mass spectrometrically observed peptides map non-uniquely to multiple variants as shown in red. Underlined amino acids indicate non-tryptic cleavage sites in the variants shown. The cleavages are presumed to occur through chymotryptic cleavage or additional mutations (not observed among the cloned variants) that place a lysine or arginine residue at these sites.

\section{Table 8}

a

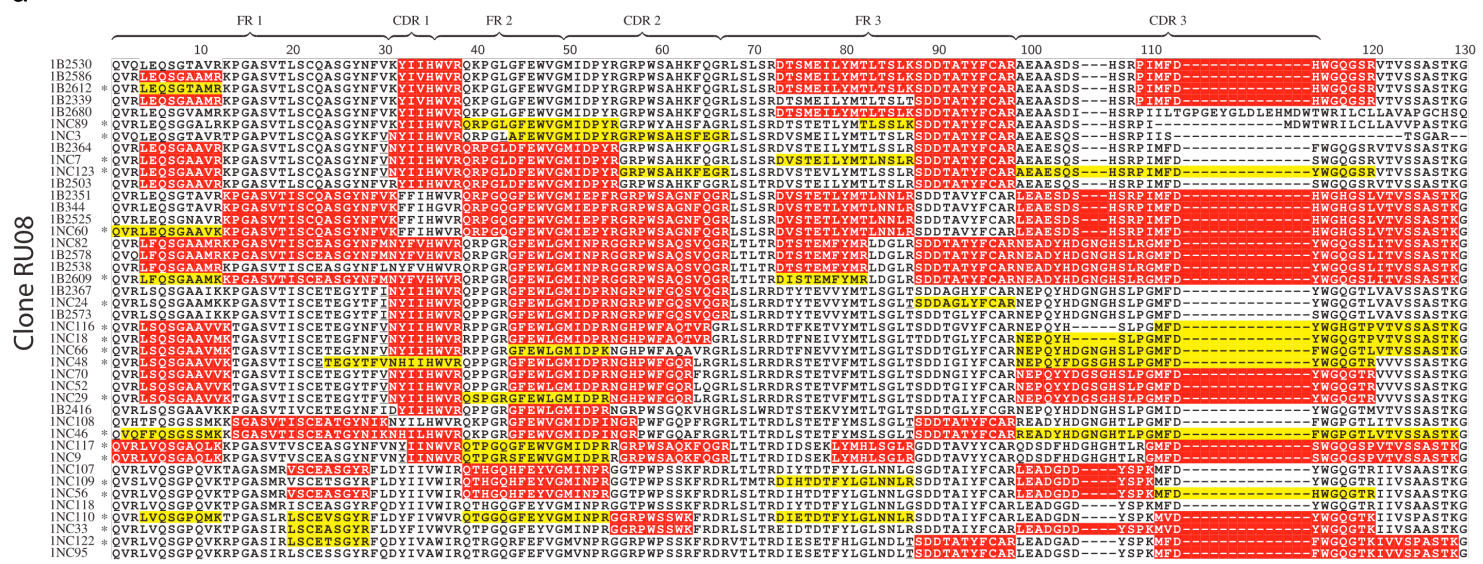

\section{Table 8}

b

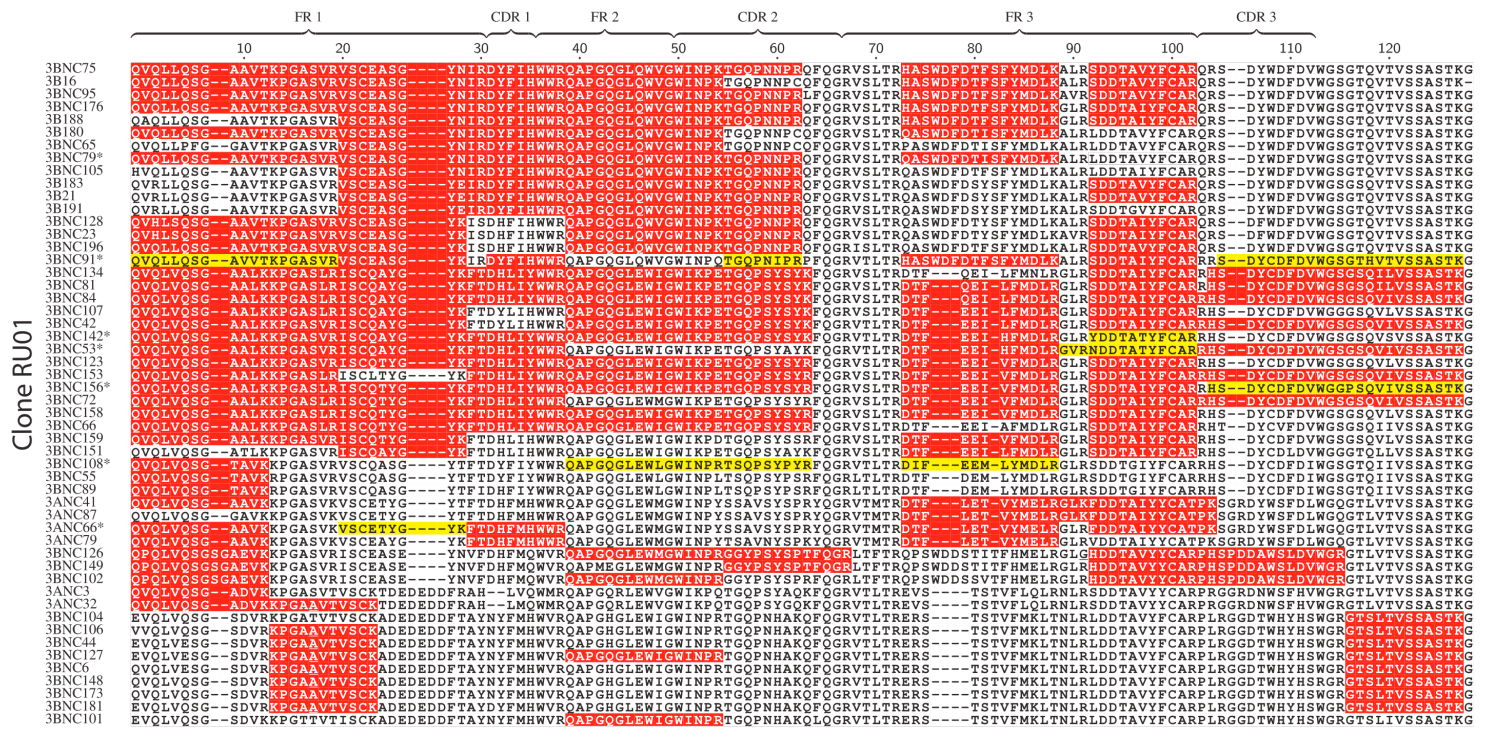




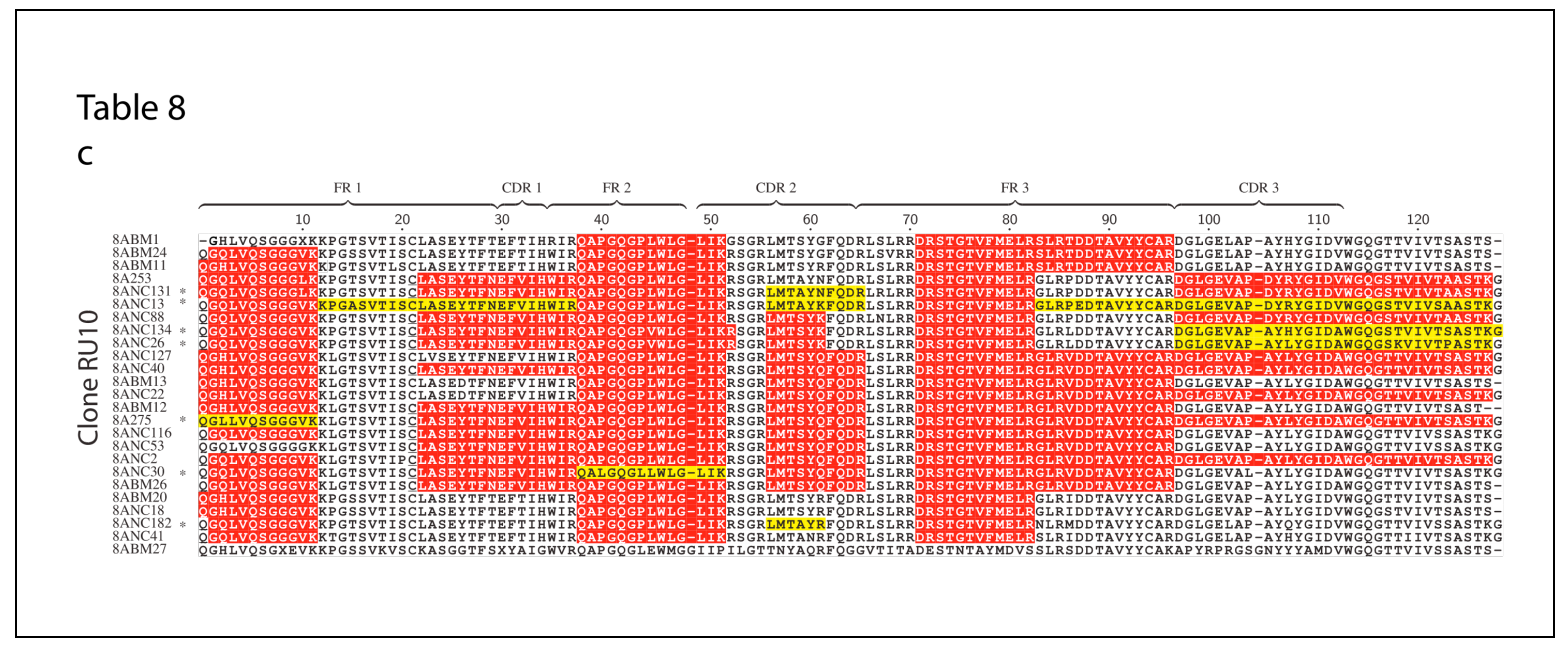




\section{Affinity of anti-2CC-core antibodies}

To determine whether antibody affinity to gp120 is related to neutralizing activity, we compared the binding of the highly active antibodies, selected clonal relatives and germline reverted progenitors using Surface Plasmon Resonance (SPR) (Figs. 15, 19a, b and 20; Table 9). The top neutralizing antibodies showed affinities $\left(\mathrm{K}_{\mathrm{A}}\right)$ ranging from $\cong 10^{7}-10^{12}\left(\mathrm{M}^{-1}\right)$ to $\mathrm{YU} 2$-gp140 trimers(Yang et al., 2000$)$ and $\cong 10^{7}-10^{11}\left(\mathrm{M}^{-1}\right)$ to the $2 \mathrm{CC}$ core(Dey et al., 2009b) (Fig. 16a, b and Table 9(Scheid et al., 2011b)). Consistent with their decreased neutralizing potency and breadth, 3BNC66, 3BNC156 and 3BNC55 displayed lower affinities to the YU2-gp140 trimer than 3BNC117, but surprisingly, the affinities of these antibodies to 2CC-core did not correlate with their neutralizing activity (Figs. 16, 20 and Tables 6 and 8). Finally, we were unable to detect binding by any of the germline reverted antibodies tested (Figs. 15b, 19b, and Table 9). We conclude that the antibodies captured by the 2CC-core tend to show higher affinity to the YU2- gp140 trimer than to the $2 \mathrm{CC}$-core. 


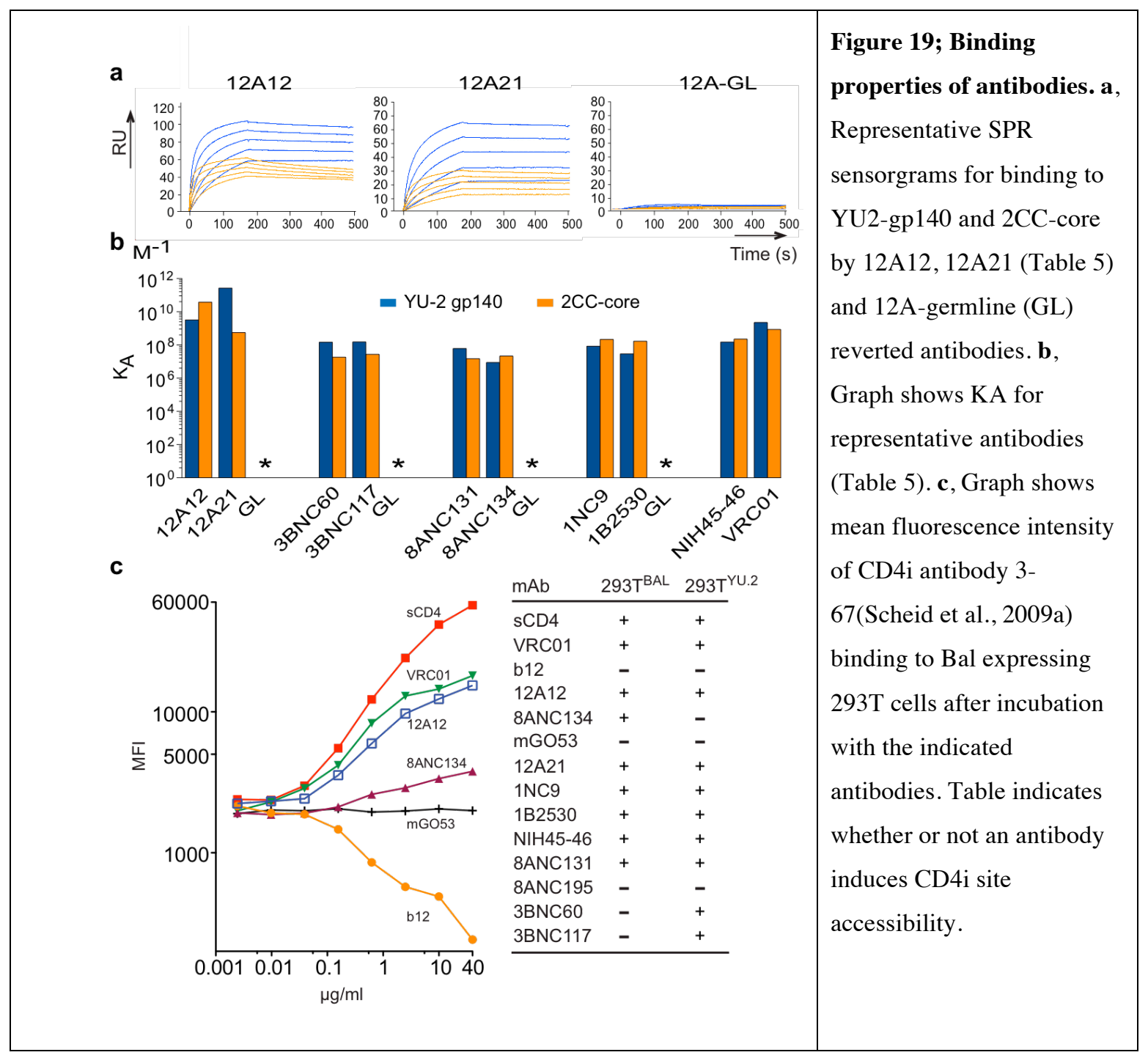


a

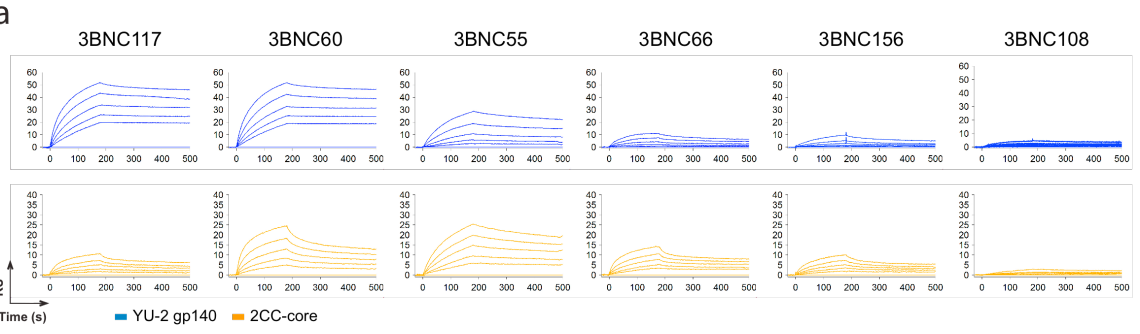

b

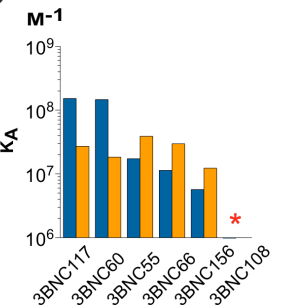

Figure 20; Affinity of RU01 clone members (Pt 3). a, Antibody binding to YU2-gp140(Yang et al., 2000) and 2CC-core(Dey et al., 2009b) measured by surface plasmon resonance (SPR). The SPR sensograms for antibody binding of the selected 3BNC-antibodies are shown over time. b, Bar graphs show the binding affinity (KA) for gp140 and 2CC-core antigens for the selected IgG antibodies shown in a, RU, response units.

Table 9; Affinity of IgG antibodies to YU2-gp140 and 2CC-core ligands measured by surface plasmon resonance.

\begin{tabular}{|c|c|c|c|c|c|c|c|c|c|c|}
\hline & \multicolumn{5}{|c|}{ gp140 } & \multicolumn{5}{|c|}{ 2CC-core } \\
\hline & $k_{\mathrm{a}}\left(\mathbf{M}^{-1} \mathbf{s}^{-1}\right)$ & $k_{d}\left(s^{-1}\right)$ & $\mathrm{K}_{\mathrm{D}}(\mathrm{M})$ & $\mathrm{K}_{\mathrm{A}}\left(\mathrm{M}^{-1}\right)$ & $x^{2}$ & $\mathbf{k}_{\mathrm{a}}\left(\mathbf{M}^{-1} \mathbf{s}^{-1}\right)$ & $k_{d}\left(s^{-1}\right)$ & $\mathrm{K}_{\mathrm{D}}(\mathrm{M})$ & $K_{A}\left(M^{-1}\right)$ & $\chi^{2}$ \\
\hline $12 \mathrm{~A} 12$ & $4.59 \mathrm{E}+04$ & $1.44 \mathrm{E}-05$ & $3.15 \mathrm{E}-10$ & $3.18 \mathrm{E}+09$ & 0.77 & $6.33 \mathrm{E}+04$ & $1.70 \mathrm{E}-06$ & $2.69 \mathrm{E}-11$ & $3.71 \mathrm{E}+10$ & 0.68 \\
\hline 12A21 & $9.18 \mathrm{E}+04$ & $3.44 \mathrm{E}-07$ & $3.75 \mathrm{E}-12$ & $2.67 E+11$ & 4.99 & $1.82 \mathrm{E}+05$ & $3.30 \mathrm{E}-04$ & 1.81E-09 & $5.53 \mathrm{E}+08$ & 3.06 \\
\hline $12 A G L$ & 1 & 1 & 1 & 1 & & 1 & I & I & 1 & 1 \\
\hline $3 B N C 60$ & $2.73 E+04$ & $1.86 \mathrm{E}-04$ & 6.81E-09 & $1.47 \mathrm{E}+08$ & 0.32 & $3.02 E+04$ & 1.64E-03 & $5.45 \mathrm{E}-08$ & $1.84 \mathrm{E}+07$ & 0.38 \\
\hline 3BNC117 & $3.04 \mathrm{E}+04$ & 1.99E-04 & $6.54 \mathrm{E}-09$ & $1.53 E+08$ & 0.48 & $4.05 E+04$ & 1.49E-03 & $3.68 \mathrm{E}-08$ & $2.72 E+07$ & 0.33 \\
\hline 3BNC55 & $1.31 \mathrm{E}+04$ & $7.55 \mathrm{E}-04$ & $5.78 \mathrm{E}-08$ & $1.73 E+07$ & 0.19 & $3.16 \mathrm{E}+04$ & $8.15 \mathrm{E}-04$ & $2.57 \mathrm{E}-08$ & $3.88 \mathrm{E}+07$ & 0.55 \\
\hline $3 B N C 66$ & $1.60 \mathrm{E}+04$ & $1.41 \mathrm{E}-03$ & 8.81E-08 & $1.14 \mathrm{E}+07$ & 0.10 & $3.96 \mathrm{E}+04$ & 1.33E-03 & $3.36 \mathrm{E}-08$ & $2.98 \mathrm{E}+07$ & 0.12 \\
\hline 3BNC156 & $1.13 \mathrm{E}+04$ & $1.98 \mathrm{E}-03$ & 1.75E-07 & $5.70 \mathrm{E}+06$ & 0.07 & $1.88 \mathrm{E}+04$ & $1.53 \mathrm{E}-03$ & 8.12E-08 & $1.23 \mathrm{E}+07$ & 0.12 \\
\hline 3BNC108 & 1 & 1 & 1 & 1 & I & 1 & 1 & I & 1 & I \\
\hline 3BNC60GI & 1 & I & I & I & I & I & I & 1 & I & I \\
\hline 8ANC131 & $6.59 \mathrm{E}+04$ & 1.09E-03 & $1.65 \mathrm{E}-08$ & $6.05 E+07$ & 2.64 & $4.88 \mathrm{E}+04$ & $3.23 E-03$ & 6.61E-08 & $1.51 \mathrm{E}+07$ & 0.31 \\
\hline 8ANC134 & $1.55 \mathrm{E}+04$ & $1.74 \mathrm{E}-03$ & 1.13E-07 & $8.86 \mathrm{E}+06$ & 0.07 & $2.08 \mathrm{E}+04$ & 9.57E-04 & 4.61E-08 & 2.17E+07 & 0.09 \\
\hline $8 A G L$ & 1 & I & I & I & & 1 & 1 & 1 & 1 & I \\
\hline 8ANC195 & $4.88 \mathrm{E}+04$ & $1.67 \mathrm{E}-03$ & $3.43 \mathrm{E}-08$ & $2.92 E+07$ & 0.24 & $2.41 E+04$ & $1.32 \mathrm{E}-03$ & $5.47 \mathrm{E}-08$ & $1.83 E+07$ & 0.17 \\
\hline LSSNEC9 & $4.83 \mathrm{E}+04$ & $5.81 \mathrm{E}-04$ & $1.20 \mathrm{E}-08$ & 8.31E+07 & 1.19 & $5.11 \mathrm{E}+04$ & 2.36E-04 & 4.61E-09 & 2.17E+08 & 0.29 \\
\hline LSSB2530 & $4.74 \mathrm{E}+04$ & $1.62 \mathrm{E}-03$ & $3.42 E-08$ & $2.93 E+07$ & 0.61 & $6.83 E+04$ & 4.02E-04 & 5.90 E-09 & $1.70 \mathrm{E}+08$ & 0.36 \\
\hline LSSGL & 1 & I & I & I & & I & 1 & 1 & 1 & I \\
\hline $45-46$ & $4.26 \mathrm{E}+04$ & 2.87E-04 & $6.75 \mathrm{E}-09$ & $1.48 \mathrm{E}+08$ & 0.88 & $1.12 \mathrm{E}+05$ & 4.94E-04 & $4.40 \mathrm{E}-09$ & $2.27 E+08$ & 0.94 \\
\hline VRC01 & $1.83 \mathrm{E}+04$ & 8.08E-06 & 4.41E-10 & $2.27 E+09$ & 0.08 & $2.84 \mathrm{E}+04$ & $3.25 \mathrm{E}-05$ & 1.15E-09 & $8.73 E+08$ & 0.10 \\
\hline
\end{tabular}




\section{CD4 agonistic function of 2CC-core antibodies}

WhenVRC01 binds to the HIV spike it produces large conformational changes that mimic CD4 binding and expose the CD4i site(Wu et al., 2010). By contrast, the broadly neutralizing antibody b12(Burton et al., 1991) and many other known CD4bs antibodies do not(Moore and Sodroski, 1996). To determine whether the ability to mimic CD4 is a shared feature of the most potent antibodies (Tables 6 and 7), we expressed two different HIV spikes(Pietzsch et al., 2010a) on the surface of HEK 293T cells and measured CD4i antibody binding in the presence or absence of CD4 or CD4bs antibodies (Fig. 19c). With one exception, all of the antibodies tested resemble CD4 and VRC01 in that they facilitate CD4i-antibody binding to one or both viral spikes (Figs. 19c and 21). The only antibody tested that did not share this characteristic, 8ANC195, was not a traditional CD4bs antibody in that it was equally sensitive to the D368R and I420R mutations (Fig.

$13 \mathrm{c}$ and Table 5), and it differed from the others in its neutralization pattern (Fig. 16a and b; and Tables 6 and 7). 
a
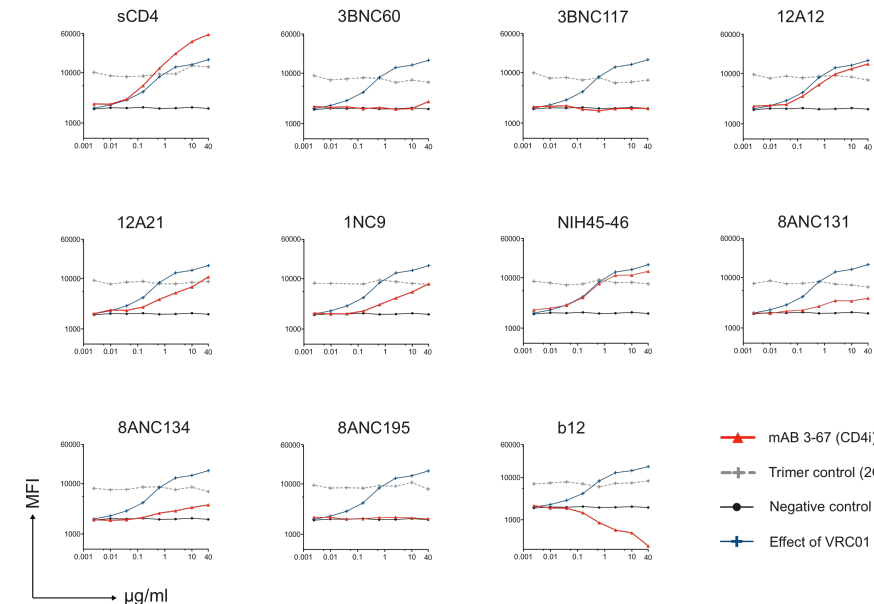

$\simeq$ mAB 3-67 (CD4i)

-+- Trimer control (2G12)

- Negative control (mGO)

+ Effect of VRC01 on 3-67

b
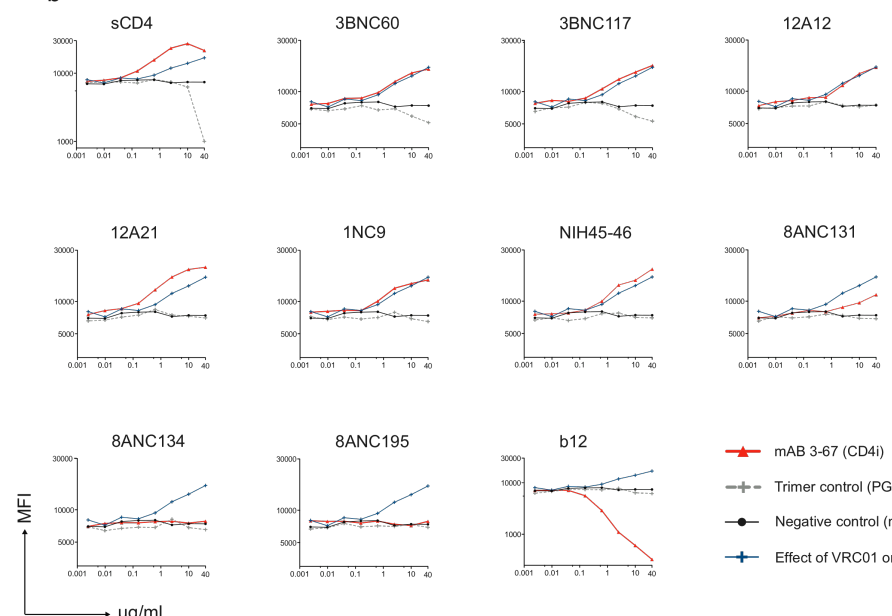

- mAB 3-67 (CD4i)
-+- Trimer control (PG16)
- Negative control (mGO)
+ Effect of VRC01 on 3-67

Figure 21; Effect of sCD4 or monoclonal antibodies on binding of a CD4i antibody (3-67(Scheid et al., 2009a)) to 293T cells expressing two different HIV spikes. To characterize the newly identified antibodies we measured changes in binding of the CD4i antibody (3-67(Scheid et al., 2009a)) in the presence of soluble CD4 or the selected antibodies (Table 5). sCD4 or antibodies of interest were added to

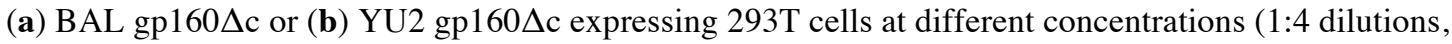
starting with $40 \mu \mathrm{g} / \mathrm{ml}$ ), followed by incubation with an Alexa647-labeled CD4-induced-site antibody (3-67, red line). In addition, surface expression of gp160 $\Delta \mathrm{c}$ was tested with Alexa-647-labeled 2G12(Trkola et al., 1996) or PG16(Walker et al., 2009)(grey lines). As a reference the binding curves of 3-67(Scheid et al., 2009a) in the presence of the CD4bs antibody VRC01(Wu et al., 2010)(blue line) and the non-HIV reactive antibody mGO (black line(Wardemann et al., 2003)) is illustrated in all graphs. 


\section{Sequence Conservation of CD4bs Antibodies}

To determine whether highly active CD4bs antibodies share common sequence features, we aligned the 10 best antibodies: 2 variants each from independently derived antibody clones arising in each of the 4 patients studied and from NIH45 (Fig. 12, Fig. 22a and b)(Wu et al., 2010). Comparison of the $I g V_{H}$ regions revealed a conserved consensus sequence covering $68 \operatorname{Ig} V_{H}$ residues (Fig. 22A). Interestingly, the $\operatorname{Ig} V_{H}$ consensus contains 7 VRC01-gp120 contact residues, including Arg 71 $1_{\mathrm{VRC} 01}$, which mimics the key interaction of $\operatorname{Arg} 59_{\mathrm{CD} 4}$ and Asp368 ${ }_{\text {gp120 }}$ (Fig. 22a) (Kwong et al., 1998; Zhou et al., 2010). All 10 antibodies arise from only two closely related germline $\operatorname{Ig} V_{H}$ genes that conserve 6 contact residues (Figs. 22a, 23a, and Table 5). The codons of the consensus residues are highly somatically mutated in the 10 selected antibodies, however, the ratio of replacement to silent mutations in the consensus residues ranges from 0.7 to 1.7 , whereas it is 3.5-22 in the non-consensus residues indicating that conservation of the consensus is strongly selected (Fig. 24 and Table 10). The light chain of VRC01 makes fewer contacts with gp120(Zhou et al., 2010). Consistent with its more limited role, comparison of the light chain sequences of the same antibodies uncovers a less extensive consensus covering 53 IgVL residues, which includes 3 VRC01-gp120 contact residues (Figs. 12b and 22b). Finally, like the heavy chains, the light chains arise from a limited set of germline genes: 2 are derived from IgK1D-33, 2 from IgK3-11, and one from IgL1-47 (Figs. 22b, 23b, and Table 5)(Zhou et al., 2010). Interestingly, antibody 8ANC195, which differed from the others in several important respects (Figs. 13c, 16b, and 19c, 21 and Tables 6 and 7) did not entirely conform to the consensus and did not 
arise from related heavy or light chains (Fig. 22a and b and Table 5). Thus, there is significant sequence convergence among highly active agonistic CD4bs antibodies (HAADs). 
Figure 22; Sequence and structural conservation of HAADs. a, Amino acid alignment of 10 selected HAADs (Table 5), their germline genes, and 8ANC195. Residues are numbered according to the 3BNC60 structure. Framework (FR) and CDR regions are indicated. Red shading shows amino acid identity, yellow shows biochemical similarity. $70 \%$ similarity between the 10 selected HAADs defined the consensus. The consensus sequence is shown above, dashes in this sequence indicate non-conserved residues. Contact residues between VRC01 and gp120 are shown above the consensus as closed circles for main and side chain interactions, open circles main chain only, and stars side chains only(Zhou et al., 2010). (b) As in (a) for light chains. (c, d, and e) Crystal structure of 3BNC60 Fab. c, Superimposed C $\alpha$ traces of the two Fab molecules in the 3BNC60 asymmetric unit are shown in green and red. Semi-transparent surfaces are used to outline the heavy (cyan) and light (grey) chains. d, Superimposition of the 3BNC60 VH (red C $\alpha$ trace) and VRC01 VH (cyan C $\alpha$ trace) shown with a ribbon representation of the CD4 binding loop. The salt bridge between Arg71 ${ }_{\mathrm{VRC} 01}$ and Asp368 $8_{\mathrm{gp} 120}$ is shown as dashed lines. e, Superimposition of the 3BNC60 VL (red C $\alpha$ trace). Hydrogen bonds between VRC01 and gp120 are shown as dashed lines. 
Figure 22

a

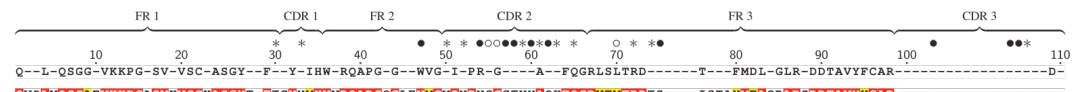

Consensus

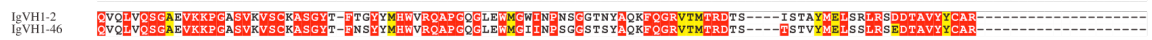

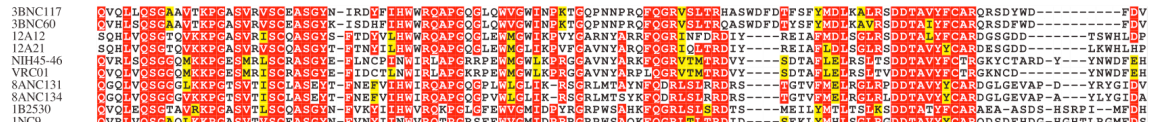

b

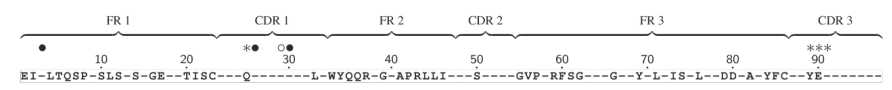

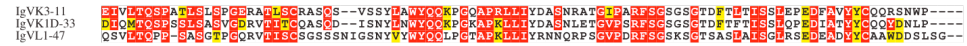

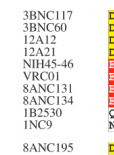

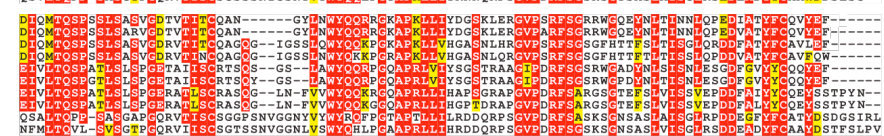

c

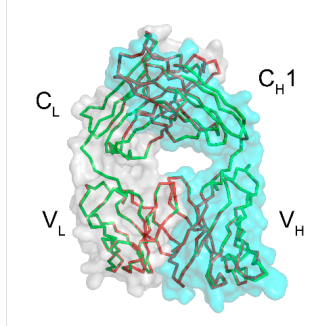

d
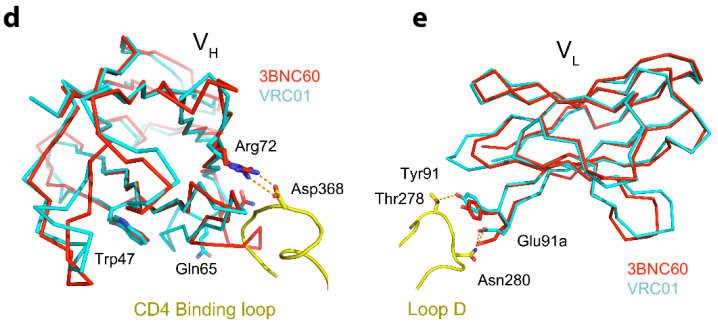
a

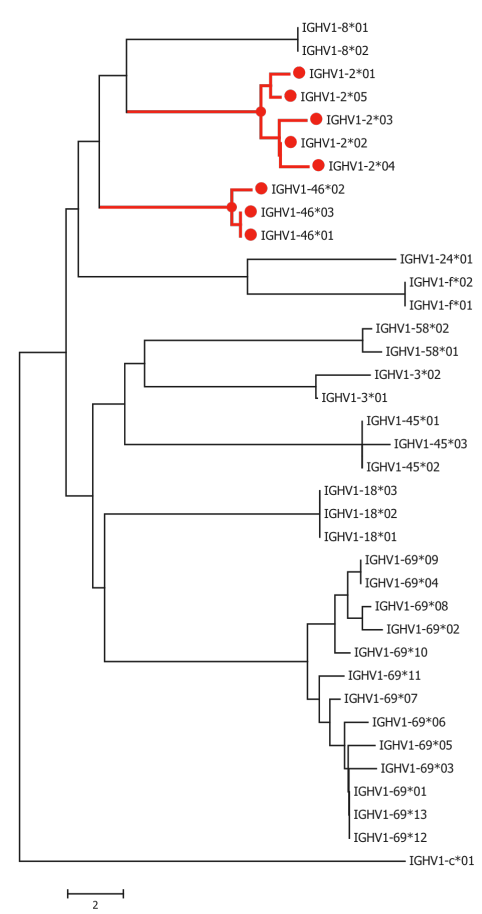

b

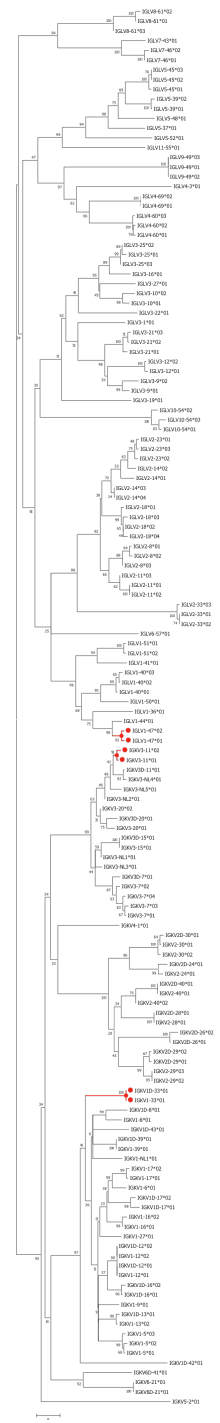

Figure 23; Phylogenetic tree of (a) IgVH and (b) Ig light chain germline sequences. Red shows position of germline genes used by highly active agonistic anti-CD4bs antibodies. 
Figure 24; Somatic hypermutation analysis of selected antibodies for (a) immunoglobulin heavy chain gene, (b) light chain kappa and (c) light chain lambda gene sequences. Sequences are aligned with their respective germline nucleotide sequences. Somatic mutations are shown in red letters, additionally gray boxes designate replacement mutations. Germline amino acid sequences with star indicating consensus residues are shown above the nucleotide alignment. 


\section{Figure 24}

a

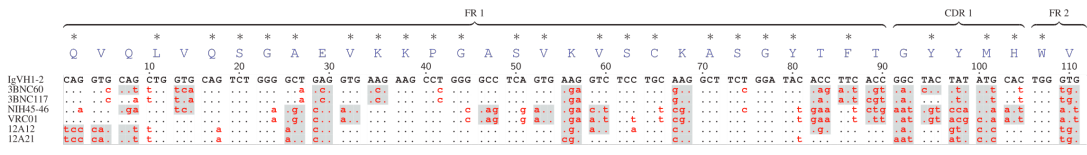

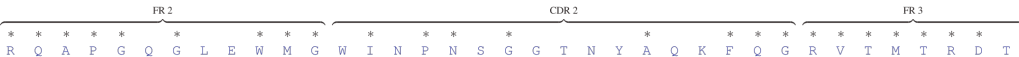

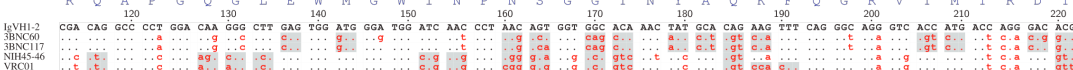

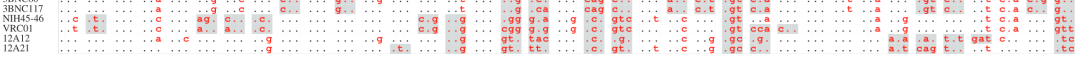

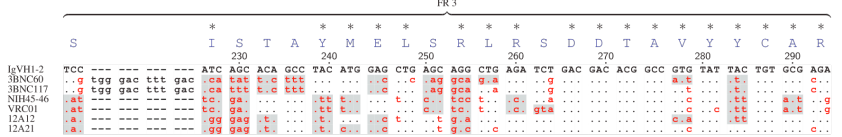

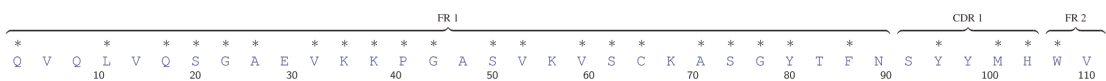

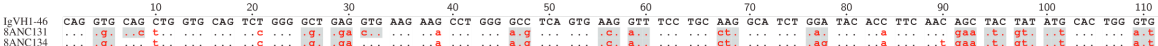

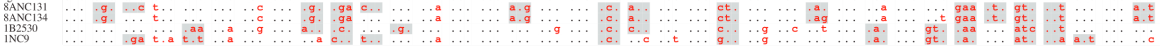

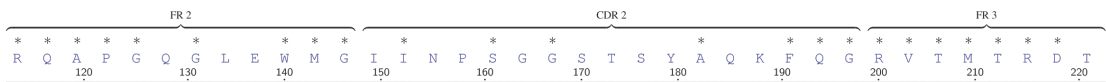

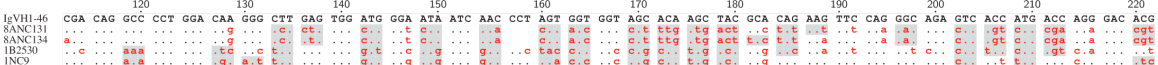

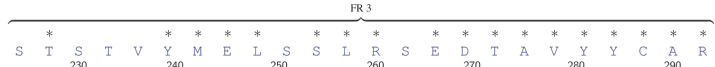

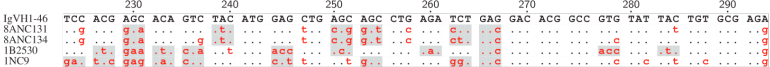




\section{Figure 24}

b

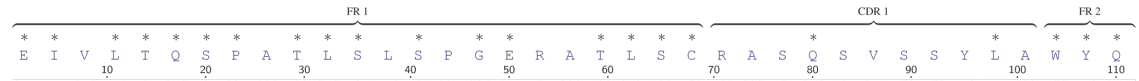

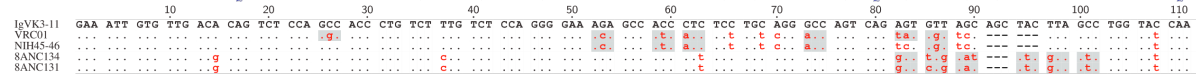

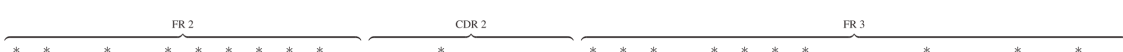

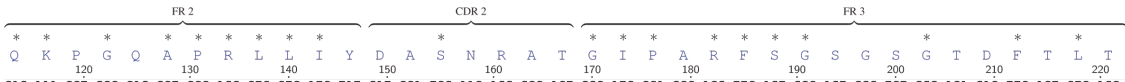

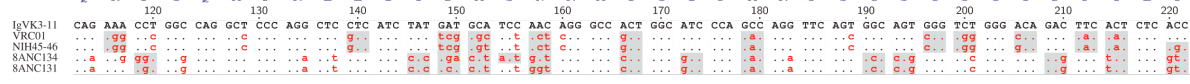

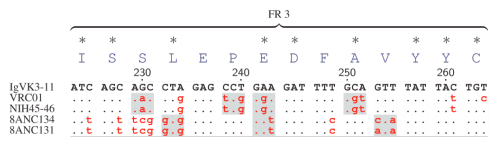

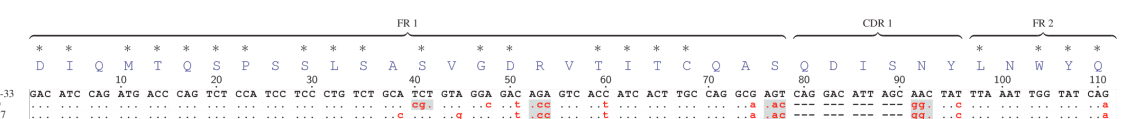

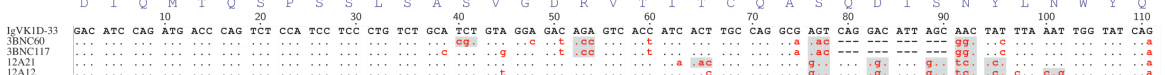

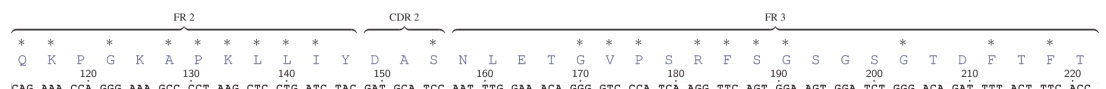

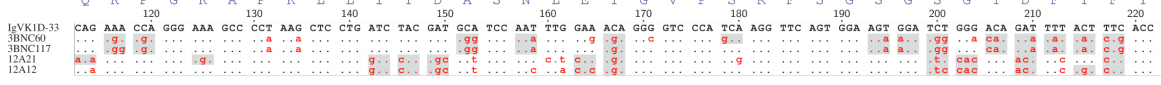

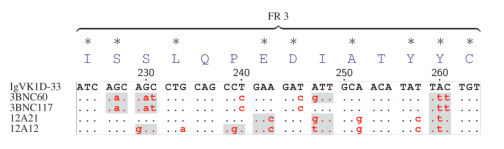

\section{Figure 24}

C

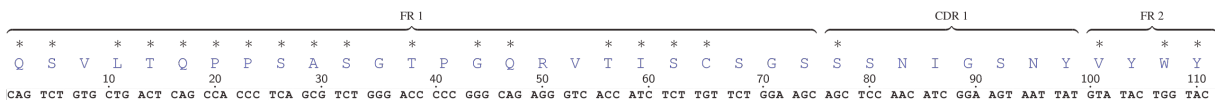
$\begin{array}{llllllllllllll}10 & \end{array}$

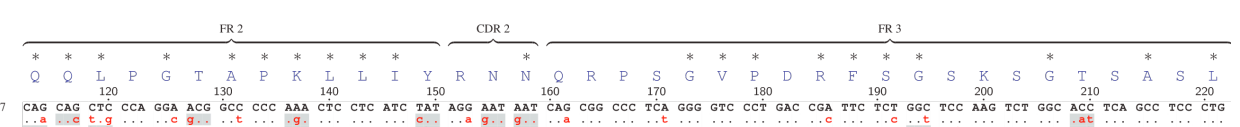

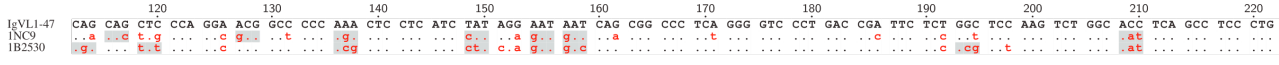

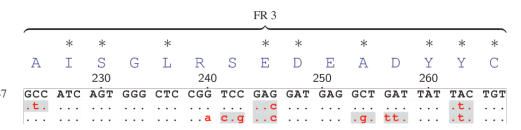

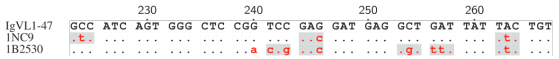




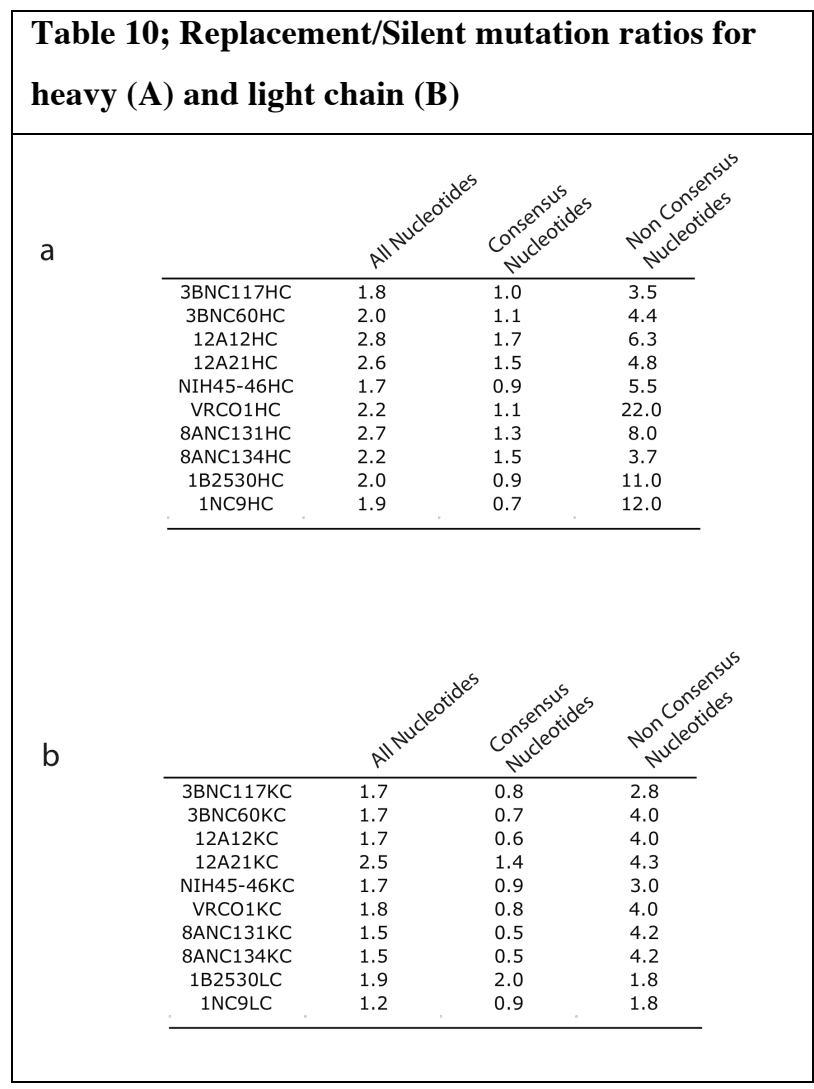




\section{Structural conservation of HAADs}

To determine whether the structure of the antibodies in different patients is also conserved, we solved the crystal structure of the 3BNC60 Fab to $2.65 \AA$ A resolution and compared it to VRC01 (Fig. 22c, d and e). Superimposition of the $V_{H}$ domains from 3BNC60 and VRC01 in the VRC01-gp120 co-crystal structure(Zhou et al., 2010) yields a root mean square deviation (rmsd) of $1.3 \AA$ (calculated for $111 \mathrm{C} \alpha$ atoms) with major differences confined to CDR2 residues 58-65 (3BNC60 numbering). Superimposing the structures suggests conservation of the recognition interface with gp120 (Fig. 22d). For example, Arg72 ${ }_{3 \mathrm{BNC} 60}$ adopts a similar conformation as Arg71 $1_{\mathrm{VRC} C 1}$, which mimics an important salt bridge normally formed between $\operatorname{Arg} 59_{\mathrm{CD} 4}$ and $\operatorname{Asp} 368_{\mathrm{gp} 120}(5,25)$. Gln65 $5_{3 \mathrm{BNC} 60}$, which corresponds to Gln64 $4_{\mathrm{VRC} 01}$, is within the residue segment (residues 5865) that differs in structure from VRC01. The conformation of this region of 3BNC60, which is involved in a lattice contact in the crystals, is likely to change upon binding gp120, as it would clash with the CD4-binding loop on gp120. Superimposing the 3BNC60 and VRC01 VL domains yields a rmsd of $0.9 \AA \AA$ (calculated for $95 \mathrm{C} \alpha$ atoms) and shows that some of gp120-contacting residues are structurally conserved (Fig. 22e); $\operatorname{Tyr} 91_{3 \mathrm{BNC} 60}$ and Glu90 ${ }_{3 \mathrm{BNC} 60}$ adopt similar conformations as Tyr91 $1_{\mathrm{VRC} C 1}$ and Glu96 $6_{\mathrm{vRC} C 1}$, which engage loop D of gp120 via polar interactions (Fig. 22e). The $V_{H}$ and $V_{L}$ domains of the two Fabs show similar interdomain interactions and overall orientation, as superimposition of the $\mathrm{V}_{\mathrm{H}}$ and $\mathrm{V}_{\mathrm{L}}$ domains of 3BNC60 and VRC01 yields an rmsd of $1.4 \AA$ (calculated for $206 \mathrm{C} \alpha$ atoms). Overall, these structural comparisons suggest that 
3BNC60 binds gp120 with the same architecture as observed for the binding of VRC01(Zhou et al., 2010). 


\section{Discussion}

Our experiments define a class of agonistic CD4bs antibodies, HAADs, that shares IgVH and $I g V L$ consensus sequences including 10 of the contact residues between VRC01 and the HIV spike (Fig. 22a and b). In five different donors, these antibodies originate from only 2 closely related $I g V H$ and $3 \operatorname{IgVL}$ genes (Fig 22a and b). Although we cannot exclude the possibility that using the 2CC-core as bait for single cell sorting might introduce a selection bias, gp140 sorts performed on two of the donors did not reveal additional broadly neutralizing antibodies (Table 5 and 6 ), suggesting that a significant fraction of the CD4 binding site-directed repertoire was captured in our experiments. Thus, the repertoire of antibodies that are available to solve the problem of broad and potent HIV neutralization by binding to the CD4bs appears to be somewhat restricted. Despite this restriction, HAADs account for a significant fraction of the memory B cell, and plasma cell compartments, and the circulating IgGs in the patients tested. Therefore HAADs are not rare, and once elicited, they contribute to the circulating antibody pool in patients that neutralize the virus broadly. However, HAADs are not found in all patients with high titers of broad neutralizing activity(Dhillon et al., 2007; Li et al., 2007; Walker et al., 2009). Moreover, broad neutralization can be achieved by targeting epitopes other than the CD4bs(Buchacher et al., 1994; Muster et al., 1993; Purtscher et al., 1994; Trkola et al., 1996; Walker et al., 2011; Walker et al., 2009; Zwick et al., 2001a) or by combinations of antibodies to different epitopes (Scheid et al., 2009a; Zwick et al., 2001b), or even combination of different CD4bs antibodies (Table 7). 
The high levels of neutralizing activity displayed by HAADs appears to be correlated with binding to a specific surface, which is similar, but not identical, to that contacted by CD4(McClure et al., 1987; Zhou et al., 2010). Why a specific type of binding that mimics CD4 appears to be required is not known(Wu et al., 2010); however, it has been suggested that binding of soluble CD4, or CD4 mimetic compounds, to the HIV envelope trimer leads to the formation of a meta-stable intermediate that decays rapidly and loses the ability to fuse(Haim et al., 2009). We speculate that HAAD binding mimics soluble CD4, and destabilizes the trimer. Irrespective of their mechanism of action, HAADs might contribute to viremic control in a subset of HIV infected individuals, and may be useful in HIV prevention or possibly even therapy because of the low concentrations required for viral neutralization. 


\section{Chapter 4}

\section{Discussion}

Until recently our understanding of broadly neutralizing activity against HIV was very limited. We have pioneered a new technique to investigate such responses efficiently and with unprecedented resolution. Together with others this has given us the opportunity to transform our understanding of HIV neutralization. This chapter will discuss improvements of our structural view of neutralization before focusing on other features of the neutralizing HIV B cell response.

\section{Neutralizing Epitopes}

In contrast to previous assumptions broad neutralization targets a diversity of different epitopes on the HIV envelope. On gp120 even variable regions such as the loops V1/2 and V3 are targeted by broad neutralization. The identification of neutralizing epitopes is far from complete and extensive analysis of more patients is required.

\section{CD4 binding site}

The CD4bs is a frequent target of highly potent broadly neutralizing responses. For HAADs, there is a striking conservation of the immunological pathway to this activity (Falkowska et al., 2012; Lynch et al., 2012; Scheid et al., 2011b; Wu et al., 2010; Wu et al., 2011; Zhou et al., 2010). Remarkably, this conservation includes the repertoire of germline sequences, which seems to be restricted to 2 heavy chain genes. We speculate, 
that specifically targeting this germline repertoire might help in vaccine design. This could be achieved by selecting antigens with high affinity to the germline version of HAADs.

Not all CD4bs directed broad neutralizers can be classified as HAADs. Several recently identified broadly neutralizing CD4bs antibody clones do not act as CD4 agonists on the surface trimer and show a different pattern of neutralization in large pseudovirus screens(Falkowska et al., 2012; Liao et al., 2013; Scheid et al., 2011b). Not all of these have been co-crystallized with gp120 yet and the structural definition of their epitopes will provide insight into alternative ways of approaching the CD4bs. However, these antibodies share with HAADs a high affinity to gp120 stabilized in the CD4 bound conformation.

\section{Variable loops $1 / 2$}

Single cell analysis of B cells that were selected based on their neutralizing activity rather than their binding characteristics(Walker et al., 2009) revealed new broadly neutralizing epitopes. Two of these antibodies, PG9 and PG16 are directed to an epitope that includes the base of variable loops $1 / 2$. Co-crystals of PG9 with a V1/2 scaffold proves that most of the antibody epitope consists of a $\mathrm{Man}_{5} \mathrm{GlcNAc}_{2}$ residue at position 160 of gp120 (strains CAP45 and ZM109), as well as glycan residues 156 (CAP45) or 173 (ZM109)(McLellan et al., 2011). With its CDR3, antibody PG9 penetrates the glycan shield of the envelope at position 160 and grasps the entire glycan up to the protein proximal $\mathrm{N}$-acetylglucosamine(McLellan et al., 2011). In addition to these glycan sites 
PG9 also forms hydrogen bonds as well as electrostatic interactions with strand C of V1/V2. Other representatives of this class of antibodies were identified recently (PG16(Walker et al., 2009), CH01-04(Bonsignori et al., 2011), PGT141-145(Walker et al., 2011)). These antibodies compete with each other in binding assays. Also, binding as well as neutralization of this group of antibodies depends on the N160 residue, confirming that they target an overlapping region on the HIV envelope.

\section{Variable loop 3}

Another group of broadly neutralizing antibodies (PGT127 and PGT128(Walker et al., 2011)) was also found to mainly interact with glycan residues. These antibodies have a primary binding site at the $\mathrm{Man}_{8 / 9} \mathrm{GlcNAc}_{2}$ of position N332 of the gp120 outer domain(Pejchal et al., 2011). The secondary binding site is focused on the core pentasaccharide attached to N301 on the V3 loop(Pejchal et al., 2011). The importance of these residues was confirmed functionally by decreased binding and neutralization sensitivity of point mutants(Pejchal et al., 2011). In addition to the two independent glycan binding sites, the antibodies also interact with the $\mathrm{C}$ terminal V3 stem, supporting a model of heteroligation(Mouquet et al., 2010) within one combined antibody binding site.

\section{Further neutralizing epitopes}

As mentioned above, we and other groups are currently investigating further patients and selection methods for single B cell analysis. These attempts will very likely uncover further neutralizing epitopes on the envelope surface. Follow up studies on patient 3 , 
from which highly potent CD4bs antibodies were isolated(Scheid et al., 2011b) have yielded two different antibodies directed to a new epitope in the vicinity of the V3 loop and the CD4i site (Klein et al., 2012a). Although far not as broad and potent as the CD4bs antibodies from this donor, their activity seems to complement the CD4bs directed neutralizing activity. In addition to introducing a further new neutralizing epitope, this study most importantly emphasizes complementary activity of diverse neutralizing antibodies within one patient (Bonsignori et al., 2012; Klein et al., 2012a)).

\section{Characteristics of the $B$ cell response}

\section{Mutations and Clone Evolution}

Single cell analysis revealed characteristic molecular features of the HIV neutralizing B cell repertoire. High levels of somatic hypermutation are required for neutralization, because reversion leads to loss of binding and neutralizing activity in broad neutralizers(Mouquet et al., 2010; Scheid et al., 2011b; Zhou et al., 2010) (Bonsignori et al., 2011; Scheid et al., 2011b; Walker et al., 2011; Walker et al., 2009; Wu et al., 2010). This is true even when only non-contact sites in the scaffolding framework regions are reverted (Klein et al., 2013).

At the same time extensive somatic hypermutation carries the risk of a non-functional immunoglobulin or introducing AID mediated translocations(Muschen et al., 2000; Nussenzweig and Nussenzweig, 2010; Odegard and Schatz, 2006; Pasqualucci et al., 2001; Shen et al., 1998). In most immune responses somatic hypermutation is limited, because there is no selection advantage for an antigen off rate beyond the speed of 
antibody internalization $\left(10^{-3}-10^{-4} \mathrm{~s}^{-1}\right)($ Batista and Neuberger, 1998; Foote and Eisen, 1995).

It is not clear, why so many somatic mutations are required in HIV infection and if similar levels of mutations are achieved in other chronic infections. However, the diversity of epitope versions in the course of chronic HIV infection (Wei et al., 2003) might play a role. We speculate that broadly neutralizing epitopes such as the CD4bs represent functionally conserved regions on the envelope that nevertheless undergo constant changes. These changes might lead to recall of B cell clones into germinal centers for further rounds of affinity maturation. It is possible that over time these recalls lead to neutralization breadth and therefore should be copied in a sequential vaccine approach.

In supportof of this model of "chronic" affinity maturation a recent study has tracked one evolving CD4bs B cell clone for over 100 weeks of infection (Liao et al., 2013). Most importantly, the authors were able to isolate several intermediate viral envelopes with their respective binding antibody intermediates and characterized both structurally. This is particularly exciting as combining the recently developed techniques for monoclonal antibody investigations with viral isolation in this fashion might be a very valuable tool in the near future to portrait numerous "maps to neutralizing serum activity".

\section{CDR3 length and polyreactivity}

Long CDR3 regions(Bonsignori et al., 2011; Cardoso et al., 2005; McLellan et al., 2011;

Ofek et al., 2004; Scheid et al., 2011b; Walker et al., 2011)as well as polyreactivity 
(Haynes et al., 2005; Mouquet et al., 2010; Scheid et al., 2011b)are further common features of several broad neutralizers.

Extended CDR3 regions are generated during V(D)J recombination (Tonegawa, 1983)and nucleotide addition early in B cell development and to a lesser extent during somatic hypermutation(Scheid et al., 2011b; Wilson et al., 1998).

Increased CDR3 length is associated with polyreactivity(Ichiyoshi and Casali, 1994) and extensive single cell analysis of B cell compartments has shown that both features are selected against during B cell maturation(Wardemann et al., 2003). This selection is achieved by developmental checkpoints that reduce the risk of autoimmunity(Yurasov et al., 2005). Nevertheless, long CDR3 regions are functionally important elements of several broad neutralizers. This was shown in particular for broadly neutralizing gp41(Cardoso et al., 2005; Ofek et al., 2004) and variable loop (McLellan et al., 2011; Pejchal et al., 2011)directed antibodies. In addition, 45-46, one of the most broad and potent CD4bs antibodies is a clonal member of VRC01 and acquired its additional activity through a 4 residue insertion in the CDR3 region. The insertion leads to increased contact with the gp120 inner domain. Overall, a large fraction of broad neutralizers require long CDR3 regions for their activity and vaccine efforts might have to specifically target this fraction of the B cell compartment.

Similarly, polyreactivity is selected against throughout B cell development(Scheid et al., 2011a; Tiller et al., 2007; Wardemann et al., 2003). However, a large fraction of broadly neutralizing antibodies are polyreactive, which might be an efficient means to address 
low antigen density on the viral surface of HIV because it allows simultaneous binding of both Fab arms(Mouquet et al., 2010). In "heteroligation", one arm binds specifically with high affinity to the cognate antigen, whereas the second arm binds unspecifically with a polyreactive interaction, thereby increasing the overall binding avidity(Mouquet et al., 2010). It is not clear, which role heteroligation plays in vivo. However, vaccine design might attempt to mimic low density interactions in order to elicit polyreactive antibodies with higher avidity.

Broadly neutralizing HIV antibodies can protect against infection and are produced frequently in immune responses against this virus. Our single cell analysis has provided valuable and long-sought insight into structural and developmental features of broad HIV neutralization. Using the methods and antibodies described in this work, we will hopefully be able to address how to phenocopy such a response with a vaccine. Of note, never before has a vaccine been designed "reversely" by starting with neutralizing antibody epitopes and generating footprints of these targets. One of the main challenges in this approach will be the differentiation between binding and neutralizing antibodies. Neutralization is not selected for in an immune response. Therefore, it will be necessary to find reagents that selectively bind to and elicit neutralizing antibodies.

Another challenge will be the generation of neutralization breadth. Antigen diversity and numerous rounds of somatic hypermutation might be involved in the generation of breadth(Liao et al., 2013). In support of this idea, recent $\mathrm{T}$ cell based vaccine approaches have successfully incorporated viral diversity(Barouch et al., 2010; Santra et al., 2010). 
Finally, in addition to providing new possible vaccine targets and maps to develop broadly neutralizing serum activity, the growing number of broadly neutralizing antibodies might provide us with new tools in HIV antibody therapy.

As mentioned above, early studies using the antibodies 2F5, 4E10 and 2G12 had met with limited success. Recent experiments in humanized mouse models however suggest that a combination of several highly potent broadly neutralizing antibodies is able to rapidly reduce and durably control viral loads at undetectable levels without antiretroviral treatment(Klein et al., 2012b). The prospect of transferring these findings to different clinical settings is an additional exciting door that the investigation of broadly neutralizing B cell responses has opened to us. 


\section{Chapter 5}

\section{Materials and Methods}

Samples. Human samples were collected after signed informed consent in accordance with Institutional Review Board (IRB)-reviewed protocols by all participating institutions. Patient 1 was selected from a cohort of long term non progressors followed at the Aaron Diamond Aids Research Center, New York. Patients 2, 3, 5 and 8 were selected from a group of elite controllers that were followed at the Ragon Institute in Boston. Patients 1, 2, 3, 5 and 8 were selected based on their broad neutralizing serum activity against a standard panel of HIV isolates(Li et al., 2005). Patient 12 was selected from the Protocol G Cohort of the "International Aids Vaccine Initiative" and patients 4 and 6 from the cohort of the National Institute of Allergy and Infectious Diseases based on broad serum neutralizing activity(Walker et al., 2010).

Staining, single-cell sorting and antibody cloning. Staining and single cell sorting of 2CC-core and gp140 specific Ig+ memory B cells was performed as previously described(Scheid et al., 2009a; Scheid et al., 2009b; Wardemann et al., 2003). Briefly,

CD19+ B cells were enriched from peripheral blood mononuclear cells using anti human CD19 magnetic MACS beads (Miltenyi Biotec) and subsequently stained with anti human CD20 and anti human IgG antibodies (Becton Dickinson) as well as biotinylated 2CC-core(Dey et al., 2009b) or YU2-gp140 trimer(Yang et al., 2000) followed by detection with streptavidin coupled phycoerythrin (PE, Beckton Dickinson). Single cells 
were sorted on a FACSAria III cell sorter (Becton Dickinson), excluding cell doublets, into 96-well PCR plates (Denville) containing $4 \mu \mathrm{l} /$ well of ice-cold $0.5 \times$ phosphatebuffered saline (PBS) containing 10 mM DTT, 8 U RNAsin ${ }^{\circledR}$ (Promega), 0.4 U 5'-3'

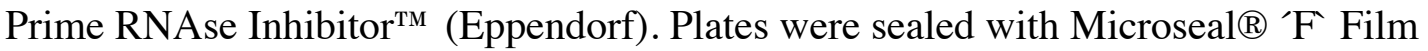
(BioRad), immediately frozen on dry ice before storage at $-80{ }^{\circ} \mathrm{C}$. cDNA synthesis and Ig amplification were performed as previously described(Wardemann et al., 2003) and with following modifications: Instead of using the original primer sets(Wardemann et al., 2003), first and second immunoglobulin specific PCRs were also carried out using the primers described in Table 4 in a semi-nested approach. In order to amplify immunoglobulin genes that are highly somatically mutated the 5 ' primers are set further upstream in the leader region to avoid the potentially mutated region. These 5' primers (Table 4) are used in both PCR steps with different constant region primers in each step (Fig. 10, Table 4). The cloning of heavy and light chain PCR products into their respective expression vectors was performed as previously described(Wardemann et al., 2003) and 100\% identity of cloned expression plasmids with the original PCR product confirmed by sequencing before expression of the antibodies in HEK 293 cells as previously described(Wardemann et al., 2003). Clonal relationships are identified by immunoglobulin sequence analysis. Antibodies with shared $\mathrm{V}$ and $\mathrm{J}$ genes for heavy and light chains as well as shared CDR3 region characteristics and somatic hypermutations are considered members of an expanded clone. 
Deglycosylation of gp120 For deglycosylation 150ug of GP120 was treated with PNGase F (New England Biolabs) and O-glycosidase (QA Bio) in $50 \mathrm{mM}$ sodium phosphate without denaturing agents and incubated overnight at $37^{\circ} \mathrm{C}$ to ensue maximal deglycosylation. Lectin blots were preformed to verify glycan removal as previously described(Kaneko et al., 2006).

ELISAs. High-binding 96-well ELISA plates (Costar) were coated overnight with 100 ng/well of purified antigens (gp140, gp120, gp41, gp120 core and 2CC-core)(Dey et al., 2009b; Kwong et al., 1998; Yang et al., 2000) and mutant proteins (gp120 D368R, gp120 I420R) (Olshevsky et al., 1990; Pantophlet et al., 2003; Thali et al., 1993; Thali et al., 1991)in PBS. After washing, plates were blocked $2 \mathrm{~h}$ with $2 \%$ BSA, $1 \mu \mathrm{M}$ EDTA, $0.05 \%$ Tween-PBS (blocking buffer) and then incubated for 2 hours with IgG antibodies diluted at $4 \mu \mathrm{g} / \mathrm{ml}$ and several consecutive 1:4 dilutions in PBS. After washing, the plates were developed by incubation for $1 \mathrm{~h}$ with goat HRP-conjugated anti-human IgG (Jackson ImmunoReseach) (at $0.8 \mu \mathrm{g} / \mathrm{ml}$ in blocking buffer) and by adding $100 \mu 1$ of HRP chromogenic substrate (ABTS solution, Invitrogen). Optical densities were measured at 405nm $\left(\mathrm{OD}_{405 \mathrm{~nm}}\right)$ using an ELISA microplate reader (Molecular Devices). Background values given by incubation of PBS alone in coated wells were subtracted. IgG Antibodies were tested for polyreactivity as previously described (Mouquet et al., 2010) and considered polyreactive when they recognized at least two structurally different antigens out of the four tested; ssDNA, dsDNA, insulin, and LPS. Threshold values for reactivity were determined by using control antibodies mGO53 (negative), eiJB40 (low positive), and ED38 (high positive)(Mouquet et al., 2010; Wardemann et al., 2003). 
Neutralization assays. Neutralization screens were performed as described(Montefiori, 2005). In brief, neutralization was detected as reduction in luciferase reporter gene expression after single round infection in Tzm-bl cells. In order to rule out unspecific antiviral activity in antibody samples MuLV (murine leukemia virus) was used as a negative control.

Clone specific identification of bone marrow plasma cells. Bone marrow plasma cells were stained with anti human CD138 and anti CD19 antibodies (Becton Dickinson) after Ficoll purification of mononuclear cells from bone marrow aspirates using Ficoll-Paque (GE Healthcare). CD138+CD19+ human plasma cells were bulk sorted on a FACSArialII cell sorter (Becton Dickinson) and RNA isolation performed on 100,000 cells using Trizol LS reagent (Invitrogen) according to the manufacturers instructions. RNA was reverse transcribed using Superscript III reverse transcriptase (Invitrogen) according to manufacturers instructions. cDNA was then subjected to Immunoglobulin specific PCR as previously described(Wardemann et al., 2003) with following modifications: $1 \mathrm{ml}$ of cDNA was amplified in 2 rounds of nested immunoglobulin heavy chain clone specific PCR using first round forward leader and constant region reverse primers (Table 4) followed by clone specific forward and reverse primers, designed based on sequencing results from single cell analysis. PCR products were gel purified and cloned into TOPO TA vectors (Invitrogen) according to the manufacturers instructions. Colonies were screened by PCR with clone specific primers and sequenced. 
Surface plasmon resonance. All experiments were performed with a Biacore T100 (Biacore, Inc) in HBS-EP+ running buffer (Biacore, Inc) at $25^{\circ} \mathrm{C}$ as described previously(Mouquet et al., 2010). YU2-gp140 and 2CC-core proteins at $12.5 \mu \mathrm{g} / \mathrm{mL}$ were immobilized on CM5 chips (Biacore, Inc.) by amine coupling at $\mathrm{pH} 4.5$ resulting in an immobilization level of 100 RUs. For kinetic measurements on the gp140- and 2CC-corederivatized chips, IgGs were injected through flow cells at $700 \mathrm{nM}$ and 4 successive 1:2dilutions in HBS-EP+ running buffer (Biacore, Inc.) at flow rates of $40 \mu \mathrm{L} / \mathrm{min}$ with 3 min association and 5 min dissociation. The sensor surface was regenerated between each experiment with a 30 second injection of $10 \mathrm{mM}$ glycine- $\mathrm{HCl} \mathrm{pH} 2.5$ at a flow rate of 50 $\mu \mathrm{L} / \mathrm{min}$. Off rate $\left(\mathrm{k}_{\mathrm{d}}\left(\mathrm{s}^{-1}\right)\right)$, on rate $\left(k_{\mathrm{a}}\left(\mathrm{M}^{-1} \mathrm{~s}^{-1}\right)\right.$ and binding constants $\left(K_{\mathrm{D}}(\mathrm{M})\right.$ or $K_{\mathrm{A}}\left(\mathrm{M}^{-1}\right)$ were calculated after subtraction of backgrounds (binding to control flow cells and signal of the HBS-EP+ running buffer) using Biacore T100 Evaluation software using the kinetic analysis and the 1:1 binding model.

CD4i site induction. 293T cells were transfected with gp $160^{\mathrm{BAL}} \Delta \mathrm{c}$ or gp $160^{\mathrm{YU} .2} \Delta \mathrm{c}$ in a pMX-IRES-GFP construct(Pietzsch et al., 2010a) using Fugene ${ }^{\mathrm{TM}} 6$ (Roche) at a 1:2 plasmid/Fugene ratio. After 48 hours 293T cells were washed with PBS, detached with trypsin-free cell dissociation buffer (Gibco) and resuspended at a concentration of $10^{7}$ cells/ml in FACS buffer (PBS, $2 \%$ fetal bovine serum (FBS), 2 mM EDTA). sCD4 (Progenics Pharmaceuticals, Inc.) and monoclonal antibodies were added to gp160expressing 293T cells in a 1:4 dilution series starting with a concentration of $40 \mu \mathrm{g} / \mathrm{ml}$. mGO53(Mouquet et al., 2010; Wardemann et al., 2003)is a non-polyreactive negative control antibody that does not bind to gp $160 \Delta \mathrm{c}$. After incubation for $15 \mathrm{~min}$ on ice cells 
were stained for 25 min on ice with an Alexa647-labeled CD4-induced site antibody (367;(Scheid et al., 2009a)) or an Alexa647-labeled control antibody (i.e. PG16(Walker et al., 2009) or 2G12(Trkola et al., 1996) for gp160 ${ }^{\mathrm{YU} .2}$ and 2G12(Trkola et al., 1996) for gp160 $\left.{ }^{\mathrm{BAL}}\right)$. Antibody labeling was performed by using Alexa Fluor® 647 Microscale Protein Labeling Kit (Invitrogen). Cells were analyzed on an LSRFortessa cell analyzer (BD Bioscience).

Crystallization. The 3BNC60 IgG was expressed by transient expression in HEK293-6E cells and the Fab fragment was prepared by papain cleavage as described(Diskin et al., 2010). Crystallization screens were conducted at $20^{\circ} \mathrm{C}$ by vapor diffusion in $\mathrm{nL}$ sitting drops using a Mosquito ${ }^{\mathrm{TM}}$ (TTP LabTech) crystallization robot on MRC crystallization plates (Jena Bioscience). We combined 3BNC60 Fab at a concentration of $9.5 \mathrm{mg} / \mathrm{ml}$ with reservoir solution in a 1:1 ratio to create $400 \mathrm{~nL}$ drops. Initial crystallization hits were obtained using the PEGRx HT ${ }^{\mathrm{TM}}$ (Hampton Research) crystallization screen and further optimized manually. Crystals suitable for data collection grew after several weeks in $11.7 \%$ polyethylene glycol 20,000,0.1 M sodium acetate $\mathrm{pH} 5.0,100 \mathrm{mM}$ potassium/sodium tartrate, $20 \mathrm{mM}$ lithium sulfate, $10 \mathrm{mM} \mathrm{N}$-Cyclohexyl-2aminoethanesulfonic acid (CHES) pH 9.5 in the monoclinic space group $\mathrm{P} 2{ }_{1}$ with two Fabs in the asymmetric unit. Crystals were soaked in reservoir solution supplemented with $15 \%$ glycerol for 2 hours before immersing in reservoir solution supplemented with $30 \%$ glycerol and flash cooling in liquid nitrogen. Diffraction data were collected at the Stanford Synchrotron Radiation Lightsource (SSRL) beam-line 12-2 at $100 \mathrm{~K}$ using a Pilatus 6M detector. Data were indexed, integrated, and scaled using XDS(Kabsch, 
2010). Molecular replacement was conducted using Phaser(McCoy et al., 2007) with the $\mathrm{V}_{\mathrm{H}}$ and $\mathrm{C}_{\mathrm{H}} 1$ domains from the anti-tumor antibody CTM01 (PDB code 1AD9) and with the $\mathrm{V}_{\mathrm{L}}$ and $\mathrm{C}_{\mathrm{L}}$ domains of the gp120 b13 antibody (PDB code 3IDX) as search models. Model building and refinement to $2.65 \AA$ Å resolution was done iteratively using Phenix(Adams et al., 2010)and $\operatorname{Coot(Emsley~et~al.,~2010).~The~structure~was~refined~}$ using a maximum-likelihood target function and non-crystallographic symmetry restraints. The final model $\left(\mathrm{R}_{\text {work }}=20.7 \% ; \mathrm{R}_{\text {free }}=25.7 \%\right)$ includes 6478 protein atoms, 146 water molecules and 28 sugar atoms. $91.9 \%, 7.6 \%$ and $0.5 \%$ of the residues were in the favored, allowed, and disallowed regions, respectively, of the Ramachandran plot. Structural analyses and visualization were done using PyMol (The PyMOL Molecular Graphics System, Version 1.3, Schrödinger, LLC). The 3BNC60 structure consists of residues 3-205 for the light chain (including the first $\mathrm{N}$-acetylglucosamine within an $\mathrm{N}$ linked carbohydrate attached to Asn72) and 2-217 for the heavy-chain. Residues at the termini residues and residues $133-140$ within the $\mathrm{C}_{\mathrm{H}} 1$ domain are disordered. Mass Spectrometry. IgG was purified from serum using Protein G Sepharose (GE Healthcare) according to the manufacturers instructions. IgGs were then digested with immobilized papain (Pierce) and digested Fab-Fc fragment mixes incubated with saturating quantities of biotinylated 2CC-core protein(Dey et al., 2009a). Streptavidin coupled Dynabeads (Invitrogen) were added after incubation for 15 minutes at room temperature and subjected to 10 rounds of washing with Phosphate Buffered Saline (Gibco). Bound Fab fragments were eluted with lithium dodecyl sulfate buffer (Invitrogen) at $95^{\circ} \mathrm{C}$ and sample purity confirmed with SDS-polyacrylamide gel 
electrophoresis followed by silver stain or coomassie staining before analysis by mass spectrometry.

Isolated Fab fragments were reduced with dithiothreitol, alkylated using iodoacetamide, resolved by $1 \mathrm{D}$ gel electrophoresis on a 4-12\% NuPAGE Novex Bis-Tris gel (Invitrogen), and stained with Coomassie Blue (Thermo Fisher). The Fab fragments were excised from the gel, and digested using 200ng of trypsin (Promega). The resulting peptides were isolated using reverse phase resin (PORS 20 R2, Applied Biosystem)(Krutchinsky et al., 2001) and eluted using an aliquot of $40 \%$ acetonitrile in $0.5 \%$ acetic acid and a second aliquot of $80 \%$ acetonitrile in $0.5 \%$ acetic acid. Acetonitrile was removed using a speedvac (Thermo Fisher Scientific) and aliquots of the remaining solution pressure loaded onto self-packed PicoFrit ${ }^{\circledR}$ column (New Objective,

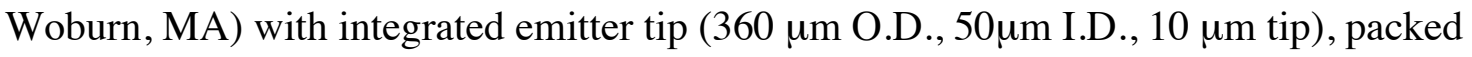
with $6 \mathrm{~cm}$ of reverse-phase C18 material (ReproSil-Pur C18-AQ, $3 \mu \mathrm{m}$ beads from Dr. Maisch $\mathrm{GmbH}$ ) and interfaced to a Agilent 1200 series HPLC system (Agilent) with either a LTQ Orbitrap ${ }^{\mathrm{TM}}$ XL mass spectrometer or a LTQ Orbitrap Velos ${ }^{\mathrm{TM}}$ mass spectrometer (Thermo Fisher Scientific) using a home-built micro electrospray source. The peptides were eluted into the mass spectrometer with the following gradient: 0 to $5 \%$ $\mathrm{B}$ in $5 \mathrm{~min}, 40 \% \mathrm{~B}$ in $125 \mathrm{~min}, 60 \% \mathrm{~B}$ in $150 \mathrm{~min}, 100 \% \mathrm{~B}$ in $165 \min (\mathrm{A}=0.1 \mathrm{M}$ acetic acid, $\mathrm{B}=70 \%$ acetonitrile in $0.1 \mathrm{M}$ acetic acid, flow rate $90 \mathrm{~nL} / \mathrm{min}$ ). Both instruments were operated in the data dependent mode and for both mass spectrometers the target value was set to $5 \mathrm{e} 5$ ions and a resolution of $60,000($ at $400 \mathrm{~m} / \mathrm{z}$ ). For analysis on the LTQ Orbitrap ${ }^{\mathrm{TM}}$ XL a full scan was followed by 8 MS/MS scans on the 8 most abundant 
ions from that full scan. The peptides (only charge states $>1$ ) were isolated with a $2 \mathrm{Da}$ window, target window of 1e4 ions, dissociated via CAD (normalized collision energy $=$ 35 , activation $\mathrm{Q}=0.25$, activation time $30 \mathrm{msec}$ ) and mass analyzed in the LTQ. For analysis on the LTQ Orbitrap ${ }^{\mathrm{TM}}$ Velos a full scan was followed by $10 \mathrm{MS} / \mathrm{MS}$ scans at 7,500 resolution on the 10 most abundant ions from the immediate preceding full scan. The peptides (only charge state $>2$ ) were isolated with a 3 Da window, target window of 2e5 ions, dissociated via HCD (normalized collision energy $=40$, activation time 0.100 msec) and mass analyzed in the Orbitrap. For either instrument the ions selected for MS/MS were set on an exclusion list for 30 seconds. The resulting MS/MS spectra were searched against the Human IPI and in-house patient specific IgG database using Xtandem!(Craig and Beavis, 2004). Peptides were automatically compared to tryptic peptides in the human IPI and our in-house patient specific database. Peptide hits corresponding to patient specific IgG were manually confirmed.

Multiple sequence alignments. All multiple sequence alignments were conducted using CLUSTALW2 with default parameters (weight matrix: GONNET for proteins and UIB for DNA, gap open= 10, gap extension 0.1). Alignment shadings were generated using TeXshade package.

Alignment consensus. The consensus sequences for multiple alignments were generated based on identity and similarity between residues $(\geq 70 \%)$. The amino acids were grouped based on biochemical similarity as: FYW, ILVM, RK, DE, GA, ST and NQ. Phylogenetic Germline Trees. The relationship between sequences was generated using the Neighbor-Joining method(Saitou and Nei, 1987). The bootstrap consensus tree 
inferred from 1,000 replicates(Felsenstein, 1988) was taken to represent the relationship. Branches corresponding to partitions reproduced in less than $50 \%$ bootstrap replicates are collapsed. The percentage of replicate trees in which the associated sequence clustered together in the bootstrap test $(1,000$ replicates $)$ are shown next to the branches(Felsenstein, 1988). The tree is drawn to scale, with branch lengths in the same units as those of the evolutionary distances used to infer the phylogenetic tree. The evolutionary distances were computed using the number of differences method(Kumar et al., 1994) and are in the units of the number of amino acid differences per sequence. All ambiguous positions were removed for each sequence pair. Evolutionary analyses were conducted in MEGA5(Tamura et al., 2007).

R/S Ratio Calculation. DNA sequences were superposed over the protein alignments for replacement/substitution calculation. All gap positions were removed from the analysis. The R/S ratio analysis was conducted using Perl scripts.

Statistical analysis. P value for mutation analysis was calculated using an unpaired twotailed students t-test. 


\section{References}

Abrahams, M.R., Anderson, J.A., Giorgi, E.E., Seoighe, C., Mlisana, K., Ping, L.H., Athreya, G.S., Treurnicht, F.K., Keele, B.F., Wood, N., et al. (2009). Quantitating the multiplicity of infection with human immunodeficiency virus type 1 subtype $C$ reveals a non-poisson distribution of transmitted variants. Journal of virology 83, 3556-3567.

Adams, P.D., Afonine, P.V., Bunkoczi, G., Chen, V.B., Davis, I.W., Echols, N., Headd, J.J., Hung, L.W., Kapral, G.J., Grosse-Kunstleve, R.W., et al. (2010). PHENIX: a comprehensive Python-based system for macromolecular structure solution. Acta Crystallogr D Biol Crystallogr 66, 213-221.

Allen, C.D., Okada, T., and Cyster, J.G. (2007a). Germinal-center organization and cellular dynamics. Immunity 27, 190-202.

Allen, C.D., Okada, T., Tang, H.L., and Cyster, J.G. (2007b). Imaging of germinal center selection events during affinity maturation. Science (New York, NY 315, 528-531.

Balazs, A.B., Chen, J., Hong, C.M., Rao, D.S., Yang, L., and Baltimore, D. (2012). Antibody-based protection against HIV infection by vectored immunoprophylaxis. Nature 481, 81-84.

Bar, K.J., Tsao, C.Y., Iyer, S.S., Decker, J.M., Yang, Y., Bonsignori, M., Chen, X., Hwang, K.K., Montefiori, D.C., Liao, H.X., et al. (2012). Early Low-Titer Neutralizing Antibodies Impede HIV-1 Replication and Select for Virus Escape. PLoS Pathog 8, e1002721.

Barouch, D.H., O'Brien, K.L., Simmons, N.L., King, S.L., Abbink, P., Maxfield, L.F., Sun, Y.H., La Porte, A., Riggs, A.M., Lynch, D.M., et al. (2010). Mosaic HIV-1 vaccines expand the breadth and depth of cellular immune responses in rhesus monkeys. Nature medicine 16, 319-323.

Batista, F.D., and Neuberger, M.S. (1998). Affinity dependence of the B cell response to antigen: a threshold, a ceiling, and the importance of off-rate. Immunity 8, 751-759.

Bende, R.J., van Maldegem, F., Triesscheijn, M., Wormhoudt, T.A., Guijt, R., and van Noesel, C.J. (2007). Germinal centers in human lymph nodes contain reactivated memory B cells. The Journal of experimental medicine 204, 2655-2665.

Berek, C., Berger, A., and Apel, M. (1991). Maturation of the immune response in germinal centers. Cell 67, 1121-1129. 
Berek, C., and Milstein, C. (1987). Mutation drift and repertoire shift in the maturation of the immune response. Immunol Rev 96, 23-41.

Binley, J.M., Lybarger, E.A., Crooks, E.T., Seaman, M.S., Gray, E., Davis, K.L., Decker, J.M., Wycuff, D., Harris, L., Hawkins, N., et al. (2008). Profiling the specificity of neutralizing antibodies in a large panel of plasmas from patients chronically infected with human immunodeficiency virus type 1 subtypes B and C. Journal of virology 82, 1165111668.

Binley, J.M., Wrin, T., Korber, B., Zwick, M.B., Wang, M., Chappey, C., Stiegler, G., Kunert, R., Zolla-Pazner, S., Katinger, H., et al. (2004). Comprehensive cross-clade neutralization analysis of a panel of anti-human immunodeficiency virus type 1 monoclonal antibodies. Journal of virology 78, 13232-13252.

Blink, E.J., Light, A., Kallies, A., Nutt, S.L., Hodgkin, P.D., and Tarlinton, D.M. (2005). Early appearance of germinal center-derived memory B cells and plasma cells in blood after primary immunization. The Journal of experimental medicine 201, 545-554.

Bonsignori, M., Hwang, K.K., Chen, X., Tsao, C.Y., Morris, L., Gray, E., Marshall, D.J., Crump, J.A., Kapiga, S.H., Sam, N.E., et al. (2011). Analysis of a clonal lineage of HIV1 envelope V2/V3 conformational epitope-specific broadly neutralizing antibodies and their inferred unmutated common ancestors. Journal of virology 85, 9998-10009.

Bonsignori, M., Montefiori, D.C., Wu, X., Chen, X., Hwang, K.K., Tsao, C.Y., Kozink, D.M., Parks, R.J., Tomaras, G.D., Crump, J.A., et al. (2012). Two distinct broadly neutralizing antibody specificities of different clonal lineages in a single HIV-1-infected donor: implications for vaccine design. Journal of virology 86, 4688-4692.

Buchacher, A., Predl, R., Strutzenberger, K., Steinfellner, W., Trkola, A., Purtscher, M., Gruber, G., Tauer, C., Steindl, F., Jungbauer, A., et al. (1994). Generation of human monoclonal antibodies against HIV-1 proteins; electrofusion and Epstein-Barr virus transformation for peripheral blood lymphocyte immortalization. AIDS Res Hum Retroviruses 10, 359-369.

Burton, D.R., Barbas, C.F., 3rd, Persson, M.A., Koenig, S., Chanock, R.M., and Lerner, R.A. (1991). A large array of human monoclonal antibodies to type 1 human immunodeficiency virus from combinatorial libraries of asymptomatic seropositive individuals. Proceedings of the National Academy of Sciences of the United States of America 88, 10134-10137.

Burton, D.R., Pyati, J., Koduri, R., Sharp, S.J., Thornton, G.B., Parren, P.W., Sawyer, L.S., Hendry, R.M., Dunlop, N., Nara, P.L., et al. (1994). Efficient neutralization of primary isolates of HIV-1 by a recombinant human monoclonal antibody. Science (New York, NY 266, 1024-1027. 
Burton, D.R., Stanfield, R.L., and Wilson, I.A. (2005). Antibody vs. HIV in a clash of evolutionary titans. Proceedings of the National Academy of Sciences of the United States of America 102, 14943-14948.

Buzon, V., Natrajan, G., Schibli, D., Campelo, F., Kozlov, M.M., and Weissenhorn, W. (2010). Crystal structure of HIV-1 gp41 including both fusion peptide and membrane proximal external regions. PLoS Pathog 6, e1000880.

Calarese, D.A., Scanlan, C.N., Zwick, M.B., Deechongkit, S., Mimura, Y., Kunert, R., Zhu, P., Wormald, M.R., Stanfield, R.L., Roux, K.H., et al. (2003). Antibody domain exchange is an immunological solution to carbohydrate cluster recognition. Science (New York, NY 300, 2065-2071.

Cao, J., Sullivan, N., Desjardin, E., Parolin, C., Robinson, J., Wyatt, R., and Sodroski, J. (1997). Replication and neutralization of human immunodeficiency virus type 1 lacking the V1 and V2 variable loops of the gp120 envelope glycoprotein. Journal of virology 71, 9808-9812.

Cao, Y., Qin, L., Zhang, L., Safrit, J., and Ho, D.D. (1995). Virologic and immunologic characterization of long-term survivors of human immunodeficiency virus type 1 infection. The New England journal of medicine 332, 201-208.

Cardoso, R.M., Zwick, M.B., Stanfield, R.L., Kunert, R., Binley, J.M., Katinger, H., Burton, D.R., and Wilson, I.A. (2005). Broadly neutralizing anti-HIV antibody 4E10 recognizes a helical conformation of a highly conserved fusion-associated motif in gp41. Immunity 22, 163-173.

Chan, D.C., Fass, D., Berger, J.M., and Kim, P.S. (1997). Core structure of gp41 from the HIV envelope glycoprotein. Cell 89, 263-273.

Chan, D.C., and Kim, P.S. (1998). HIV entry and its inhibition. Cell 93, 681-684.

Chen, B., Vogan, E.M., Gong, H., Skehel, J.J., Wiley, D.C., and Harrison, S.C. (2005). Structure of an unliganded simian immunodeficiency virus gp120 core. Nature 433, 834841.

Chen, L., Kwon, Y.D., Zhou, T., Wu, X., O'Dell, S., Cavacini, L., Hessell, A.J., Pancera, M., Tang, M., Xu, L., et al. (2009). Structural basis of immune evasion at the site of CD4 attachment on HIV-1 gp120. Science (New York, NY 326, 1123-1127.

Cohen, M.S., Shaw, G.M., McMichael, A.J., and Haynes, B.F. (2011). Acute HIV-1 Infection. The New England journal of medicine 364, 1943-1954.

Craig, R., and Beavis, R.C. (2004). TANDEM: matching proteins with tandem mass spectra. Bioinformatics 20, 1466-1467. 
Dalgleish, A.G., Beverley, P.C., Clapham, P.R., Crawford, D.H., Greaves, M.F., and Weiss, R.A. (1984). The CD4 (T4) antigen is an essential component of the receptor for the AIDS retrovirus. Nature 312, 763-767.

Davis, K.L., Gray, E.S., Moore, P.L., Decker, J.M., Salomon, A., Montefiori, D.C., Graham, B.S., Keefer, M.C., Pinter, A., Morris, L., et al. (2009). High titer HIV-1 V3specific antibodies with broad reactivity but low neutralizing potency in acute infection and following vaccination. Virology 387, 414-426.

Decker, J.M., Bibollet-Ruche, F., Wei, X., Wang, S., Levy, D.N., Wang, W., Delaporte, E., Peeters, M., Derdeyn, C.A., Allen, S., et al. (2005). Antigenic conservation and immunogenicity of the HIV coreceptor binding site. The Journal of experimental medicine 201, 1407-1419.

Deeks, S.G., and Walker, B.D. (2007). Human immunodeficiency virus controllers: mechanisms of durable virus control in the absence of antiretroviral therapy. Immunity $27,406-416$.

Dennison, S.M., Stewart, S.M., Stempel, K.C., Liao, H.X., Haynes, B.F., and Alam, S.M. (2009). Stable docking of neutralizing human immunodeficiency virus type 1 gp41 membrane-proximal external region monoclonal antibodies 2F5 and 4E10 is dependent on the membrane immersion depth of their epitope regions. Journal of virology 83 , 10211-10223.

Dennison, S.M., Sutherland, L.L., Jaeger, F.H., Anasti, K.M., Parks, R., Stewart, S., Bowman, C., Xia, S.M., Zhang, R., Shen, X., et al. (2011). Induction of antibodies in rhesus macaques that recognize a fusion-intermediate conformation of HIV-1 gp41. PLoS One $6, \mathrm{e} 27824$.

Derdeyn, C.A., Decker, J.M., Bibollet-Ruche, F., Mokili, J.L., Muldoon, M., Denham, S.A., Heil, M.L., Kasolo, F., Musonda, R., Hahn, B.H., et al. (2004). Envelopeconstrained neutralization-sensitive HIV-1 after heterosexual transmission. Science (New York, NY 303, 2019-2022.

Dey, A.K., David, K.B., Lu, M., and Moore, J.P. (2009a). Biochemical and biophysical comparison of cleaved and uncleaved soluble, trimeric HIV-1 envelope glycoproteins. Virology 385, 275-281.

Dey, B., Pancera, M., Svehla, K., Shu, Y., Xiang, S.H., Vainshtein, J., Li, Y., Sodroski, J., Kwong, P.D., Mascola, J.R., et al. (2007). Characterization of human immunodeficiency virus type 1 monomeric and trimeric gp120 glycoproteins stabilized in the CD4-bound state: antigenicity, biophysics, and immunogenicity. Journal of virology 81, 5579-5593. 
Dey, B., Svehla, K., Xu, L., Wycuff, D., Zhou, T., Voss, G., Phogat, A., Chakrabarti, B.K., Li, Y., Shaw, G., et al. (2009b). Structure-based stabilization of HIV-1 gp120 enhances humoral immune responses to the induced co-receptor binding site. PLoS Pathog 5, e1000445.

Dhillon, A.K., Donners, H., Pantophlet, R., Johnson, W.E., Decker, J.M., Shaw, G.M., Lee, F.H., Richman, D.D., Doms, R.W., Vanham, G., et al. (2007). Dissecting the neutralizing antibody specificities of broadly neutralizing sera from human immunodeficiency virus type 1-infected donors. Journal of virology 81, 6548-6562.

Diskin, R., Marcovecchio, P.M., and Bjorkman, P.J. (2010). Structure of a clade C HIV-1 gp120 bound to CD4 and CD4-induced antibody reveals anti-CD4 polyreactivity. Nat Struct Mol Biol 17, 608-613.

Doria-Rose, N.A. (2010). HIV neutralizing antibodies: clinical correlates and implications for vaccines. The Journal of infectious diseases 201, 981-983.

Doria-Rose, N.A., Klein, R.M., Manion, M.M., O'Dell, S., Phogat, A., Chakrabarti, B., Hallahan, C.W., Migueles, S.A., Wrammert, J., Ahmed, R., et al. (2009). Frequency and phenotype of human immunodeficiency virus envelope-specific B cells from patients with broadly cross-neutralizing antibodies. Journal of virology 83, 188-199.

Dorner, T., and Radbruch, A. (2005). Selecting B cells and plasma cells to memory. The Journal of experimental medicine 201, 497-499.

Dorner, T., and Radbruch, A. (2007). Antibodies and B cell memory in viral immunity. Immunity 27, 384-392.

Eisen, H.N., and Siskind, G.W. (1964). Variations in Affinities of Antibodies during the Immune Response. Biochemistry 3, 996-1008.

Emsley, P., Lohkamp, B., Scott, W.G., and Cowtan, K. (2010). Features and development of Coot. Acta Crystallogr D Biol Crystallogr 66, 486-501.

Euler, Z., van den Kerkhof, T.L., van Gils, M.J., Burger, J.A., Edo-Matas, D., Phung, P., Wrin, T., and Schuitemaker, H. (2012). Longitudinal analysis of early HIV-1-specific neutralizing activity in an elite neutralizer and in five patients who developed crossreactive neutralizing activity. Journal of virology 86, 2045-2055.

Euler, Z., van Gils, M.J., Bunnik, E.M., Phung, P., Schweighardt, B., Wrin, T., and Schuitemaker, H. (2010). Cross-reactive neutralizing humoral immunity does not protect from HIV type 1 disease progression. The Journal of infectious diseases 201, 1045-1053.

Falkowska, E., Ramos, A., Feng, Y., Zhou, T., Moquin, S., Walker, L.M., Wu, X., Seaman, M.S., Wrin, T., Kwong, P.D., et al. (2012). PGV04, an HIV-1 gp120 CD4 
binding site antibody, is broad and potent in neutralization but does not induce conformational changes characteristic of CD4. Journal of virology 86, 4394-4403.

Farzan, M., Choe, H., Desjardins, E., Sun, Y., Kuhn, J., Cao, J., Archambault, D., Kolchinsky, P., Koch, M., Wyatt, R., et al. (1998). Stabilization of human immunodeficiency virus type 1 envelope glycoprotein trimers by disulfide bonds introduced into the gp41 glycoprotein ectodomain. Journal of virology 72, 7620-7625.

Felsenstein, J. (1988). Phylogenies from molecular sequences: inference and reliability. Annu Rev Genet 22, 521-565.

Finnegan, C.M., Berg, W., Lewis, G.K., and DeVico, A.L. (2002). Antigenic properties of the human immunodeficiency virus transmembrane glycoprotein during cell-cell fusion. Journal of virology 76, 12123-12134.

Fischer, W., Ganusov, V.V., Giorgi, E.E., Hraber, P.T., Keele, B.F., Leitner, T., Han, C.S., Gleasner, C.D., Green, L., Lo, C.C., et al. (2010). Transmission of single HIV-1 genomes and dynamics of early immune escape revealed by ultra-deep sequencing. PLoS One 5, e12303.

Foote, J., and Eisen, H.N. (1995). Kinetic and affinity limits on antibodies produced during immune responses. Proceedings of the National Academy of Sciences of the United States of America 92, 1254-1256.

Frey, G., Chen, J., Rits-Volloch, S., Freeman, M.M., Zolla-Pazner, S., and Chen, B. (2010). Distinct conformational states of HIV-1 gp41 are recognized by neutralizing and non-neutralizing antibodies. Nat Struct Mol Biol 17, 1486-1491.

Frey, G., Peng, H., Rits-Volloch, S., Morelli, M., Cheng, Y., and Chen, B. (2008). A fusion-intermediate state of HIV-1 gp41 targeted by broadly neutralizing antibodies. Proceedings of the National Academy of Sciences of the United States of America 105, 3739-3744.

Gaidano, G., Pasqualucci, L., Capello, D., Berra, E., Deambrogi, C., Rossi, D., Maria Larocca, L., Gloghini, A., Carbone, A., and Dalla-Favera, R. (2003). Aberrant somatic hypermutation in multiple subtypes of AIDS-associated non-Hodgkin lymphoma. Blood $102,1833-1841$.

Gnanakaran, S., Bhattacharya, T., Daniels, M., Keele, B.F., Hraber, P.T., Lapedes, A.S., Shen, T., Gaschen, B., Krishnamoorthy, M., Li, H., et al. (2011). Recurrent signature patterns in HIV-1 B clade envelope glycoproteins associated with either early or chronic infections. PLoS Pathog 7, e1002209.

Gnanakaran, S., Daniels, M.G., Bhattacharya, T., Lapedes, A.S., Sethi, A., Li, M., Tang, H., Greene, K., Gao, H., Haynes, B.F., et al. (2010). Genetic signatures in the envelope 
glycoproteins of HIV-1 that associate with broadly neutralizing antibodies. PLoS Comput Biol 6, e1000955.

Gorny, M.K., Conley, A.J., Karwowska, S., Buchbinder, A., Xu, J.Y., Emini, E.A., Koenig, S., and Zolla-Pazner, S. (1992). Neutralization of diverse human immunodeficiency virus type 1 variants by an anti-V3 human monoclonal antibody. Journal of virology $66,7538-7542$.

Gorny, M.K., Revesz, K., Williams, C., Volsky, B., Louder, M.K., Anyangwe, C.A., Krachmarov, C., Kayman, S.C., Pinter, A., Nadas, A., et al. (2004). The v3 loop is accessible on the surface of most human immunodeficiency virus type 1 primary isolates and serves as a neutralization epitope. Journal of virology 78, 2394-2404.

Goudsmit, J., Debouck, C., Meloen, R.H., Smit, L., Bakker, M., Asher, D.M., Wolff, A.V., Gibbs, C.J., Jr., and Gajdusek, D.C. (1988). Human immunodeficiency virus type 1 neutralization epitope with conserved architecture elicits early type-specific antibodies in experimentally infected chimpanzees. Proceedings of the National Academy of Sciences of the United States of America 85, 4478-4482.

Gray, E.S., Madiga, M.C., Hermanus, T., Moore, P.L., Wibmer, C.K., Tumba, N.L., Werner, L., Mlisana, K., Sibeko, S., Williamson, C., et al. (2011). The neutralization breadth of HIV-1 develops incrementally over four years and is associated with CD4+ T cell decline and high viral load during acute infection. Journal of virology 85, 4828-4840.

Gray, E.S., Madiga, M.C., Moore, P.L., Mlisana, K., Abdool Karim, S.S., Binley, J.M., Shaw, G.M., Mascola, J.R., and Morris, L. (2009). Broad neutralization of human immunodeficiency virus type 1 mediated by plasma antibodies against the gp41 membrane proximal external region. Journal of virology 83, 11265-11274.

Gray, E.S., Moore, P.L., Choge, I.A., Decker, J.M., Bibollet-Ruche, F., Li, H., Leseka, N., Treurnicht, F., Mlisana, K., Shaw, G.M., et al. (2007). Neutralizing antibody responses in acute human immunodeficiency virus type 1 subtype $\mathrm{C}$ infection. Journal of virology $81,6187-6196$.

Greenstein, J.L., Leary, J., Horan, P., Kappler, J.W., and Marrack, P. (1980). Flow sorting of antigen-binding B cell subsets. J Immunol 124, 1472-1481.

Haaland, R.E., Hawkins, P.A., Salazar-Gonzalez, J., Johnson, A., Tichacek, A., Karita, E., Manigart, O., Mulenga, J., Keele, B.F., Shaw, G.M., et al. (2009). Inflammatory genital infections mitigate a severe genetic bottleneck in heterosexual transmission of subtype A and C HIV-1. PLoS Pathog 5, e1000274.

Haim, H., Si, Z., Madani, N., Wang, L., Courter, J.R., Princiotto, A., Kassa, A., DeGrace, M., McGee-Estrada, K., Mefford, M., et al. (2009). Soluble CD4 and CD4-mimetic 
compounds inhibit HIV-1 infection by induction of a short-lived activated state. PLoS Pathog 5, e1000360.

Hartley, O., Klasse, P.J., Sattentau, Q.J., and Moore, J.P. (2005). V3: HIV's switch-hitter. AIDS Res Hum Retroviruses 21, 171-189.

Hauser, A.E., Junt, T., Mempel, T.R., Sneddon, M.W., Kleinstein, S.H., Henrickson, S.E., von Andrian, U.H., Shlomchik, M.J., and Haberman, A.M. (2007). Definition of germinal-center B cell migration in vivo reveals predominant intrazonal circulation patterns. Immunity 26, 655-667.

Hayakawa, K., Ishii, R., Yamasaki, K., Kishimoto, T., and Hardy, R.R. (1987). Isolation of high-affinity memory B cells: phycoerythrin as a probe for antigen-binding cells. Proceedings of the National Academy of Sciences of the United States of America 84, 1379-1383.

Haynes, B.F., Fleming, J., St Clair, E.W., Katinger, H., Stiegler, G., Kunert, R., Robinson, J., Scearce, R.M., Plonk, K., Staats, H.F., et al. (2005). Cardiolipin polyspecific autoreactivity in two broadly neutralizing HIV-1 antibodies. Science (New York, NY 308, 1906-1908.

Hu, G., Liu, J., Taylor, K.A., and Roux, K.H. (2011). Structural comparison of HIV-1 envelope spikes with and without the V1/V2 loop. Journal of virology 85, 2741-2750.

Huang, C.C., Tang, M., Zhang, M.Y., Majeed, S., Montabana, E., Stanfield, R.L., Dimitrov, D.S., Korber, B., Sodroski, J., Wilson, I.A., et al. (2005). Structure of a V3containing HIV-1 gp120 core. Science (New York, NY 310, 1025-1028.

Huang, C.C., Venturi, M., Majeed, S., Moore, M.J., Phogat, S., Zhang, M.Y., Dimitrov, D.S., Hendrickson, W.A., Robinson, J., Sodroski, J., et al. (2004). Structural basis of tyrosine sulfation and VH-gene usage in antibodies that recognize the HIV type 1 coreceptor-binding site on gp120. Proceedings of the National Academy of Sciences of the United States of America 101, 2706-2711.

Huang, J., Ofek, G., Laub, L., Louder, M.K., Doria-Rose, N.A., Longo, N.S., Imamichi, H., Bailer, R.T., Chakrabarti, B., Sharma, S.K., et al. (2012). Broad and potent neutralization of HIV-1 by a gp41-specific human antibody. Nature 491, 406-412.

Hwang, S.S., Boyle, T.J., Lyerly, H.K., and Cullen, B.R. (1991). Identification of the envelope V3 loop as the primary determinant of cell tropism in HIV-1. Science (New York, NY 253, 71-74.

Ichiyoshi, Y., and Casali, P. (1994). Analysis of the structural correlates for antibody polyreactivity by multiple reassortments of chimeric human immunoglobulin heavy and light chain V segments. The Journal of experimental medicine 180, 885-895. 
Jacob, J., Kassir, R., and Kelsoe, G. (1991a). In situ studies of the primary immune response to (4-hydroxy-3-nitrophenyl)acetyl. I. The architecture and dynamics of responding cell populations. The Journal of experimental medicine 173, 1165-1175.

Jacob, J., Kelsoe, G., Rajewsky, K., and Weiss, U. (1991b). Intraclonal generation of antibody mutants in germinal centres. Nature 354, 389-392.

Javaherian, K., Langlois, A.J., LaRosa, G.J., Profy, A.T., Bolognesi, D.P., Herlihy, W.C., Putney, S.D., and Matthews, T.J. (1990). Broadly neutralizing antibodies elicited by the hypervariable neutralizing determinant of HIV-1. Science (New York, NY 250, 15901593.

Javaherian, K., Langlois, A.J., McDanal, C., Ross, K.L., Eckler, L.I., Jellis, C.L., Profy, A.T., Rusche, J.R., Bolognesi, D.P., Putney, S.D., et al. (1989). Principal neutralizing domain of the human immunodeficiency virus type 1 envelope protein. Proceedings of the National Academy of Sciences of the United States of America 86, 6768-6772.

Jerne, N.K. (1951). A study of avidity based on rabbit skin responses to diphtheria toxinantitoxin mixtures. Acta Pathol Microbiol Scand Suppl 87, 1-183.

Kabsch, W. (2010). Integration, scaling, space-group assignment and post-refinement. Acta Crystallogr D Biol Crystallogr 66, 133-144.

Kaneko, Y., Nimmerjahn, F., and Ravetch, J.V. (2006). Anti-inflammatory activity of immunoglobulin G resulting from Fc sialylation. Science (New York, NY 313, 670-673.

Karlsson Hedestam, G.B., Fouchier, R.A., Phogat, S., Burton, D.R., Sodroski, J., and Wyatt, R.T. (2008). The challenges of eliciting neutralizing antibodies to HIV-1 and to influenza virus. Nat Rev Microbiol 6, 143-155.

Keele, B.F., Giorgi, E.E., Salazar-Gonzalez, J.F., Decker, J.M., Pham, K.T., Salazar, M.G., Sun, C., Grayson, T., Wang, S., Li, H., et al. (2008). Identification and characterization of transmitted and early founder virus envelopes in primary HIV-1 infection. Proceedings of the National Academy of Sciences of the United States of America 105, 7552-7557.

Keulen, W., Nijhuis, M., Schuurman, R., Berkhout, B., and Boucher, C. (1997). Reverse transcriptase fidelity and HIV-1 variation. Science (New York, NY 275, 229; author reply $230-221$.

Kim, M., Qiao, Z., Yu, J., Montefiori, D., and Reinherz, E.L. (2007). Immunogenicity of recombinant human immunodeficiency virus type 1-like particles expressing gp41 derivatives in a pre-fusion state. Vaccine 25, 5102-5114. 
Klein, F., Diskin, R., Scheid, J.F., Gaebler, C., Mouquet, H., Georgiev, I.S., Pancera, M., Zhou, T., Incesu, R.B., Fu, B.Z., et al. (2013). Somatic mutations of the immunoglobulin framework are generally required for broad and potent HIV-1 neutralization. Cell 153, 126-138.

Klein, F., Gaebler, C., Mouquet, H., Sather, D.N., Lehmann, C., Scheid, J.F., Kraft, Z., Liu, Y., Pietzsch, J., Hurley, A., et al. (2012a). Broad neutralization by a combination of antibodies recognizing the CD4 binding site and a new conformational epitope on the HIV-1 envelope protein. The Journal of experimental medicine 209, 1469-1479.

Klein, F., Halper-Stromberg, A., Horwitz, J.A., Gruell, H., Scheid, J.F., Bournazos, S., Mouquet, H., Spatz, L.A., Diskin, R., Abadir, A., et al. (2012b). HIV therapy by a combination of broadly neutralizing antibodies in humanized mice. Nature 492, 118-122.

Kolchinsky, P., Kiprilov, E., and Sodroski, J. (2001). Increased neutralization sensitivity of CD4-independent human immunodeficiency virus variants. Journal of virology 75 , 2041-2050.

Krutchinsky, A.N., Kalkum, M., and Chait, B.T. (2001). Automatic identification of proteins with a MALDI-quadrupole ion trap mass spectrometer. Anal Chem 73, 50665077.

Kumar, S., Tamura, K., and Nei, M. (1994). MEGA: Molecular Evolutionary Genetics Analysis software for microcomputers. Comput Appl Biosci 10, 189-191.

Kwon, Y.D., Finzi, A., Wu, X., Dogo-Isonagie, C., Lee, L.K., Moore, L.R., Schmidt, S.D., Stuckey, J., Yang, Y., Zhou, T., et al. (2012). Unliganded HIV-1 gp120 core structures assume the CD4-bound conformation with regulation by quaternary interactions and variable loops. Proceedings of the National Academy of Sciences of the United States of America 109, 5663-5668.

Kwong, P.D., Wyatt, R., Majeed, S., Robinson, J., Sweet, R.W., Sodroski, J., and Hendrickson, W.A. (2000). Structures of HIV-1 gp120 envelope glycoproteins from laboratory-adapted and primary isolates. Structure 8, 1329-1339.

Kwong, P.D., Wyatt, R., Robinson, J., Sweet, R.W., Sodroski, J., and Hendrickson, W.A. (1998). Structure of an HIV gp120 envelope glycoprotein in complex with the CD4 receptor and a neutralizing human antibody. Nature 393, 648-659.

Li, H., Bar, K.J., Wang, S., Decker, J.M., Chen, Y., Sun, C., Salazar-Gonzalez, J.F., Salazar, M.G., Learn, G.H., Morgan, C.J., et al. (2010). High Multiplicity Infection by HIV-1 in Men Who Have Sex with Men. PLoS Pathog 6, e1000890.

Li, M., Gao, F., Mascola, J.R., Stamatatos, L., Polonis, V.R., Koutsoukos, M., Voss, G., Goepfert, P., Gilbert, P., Greene, K.M., et al. (2005). Human immunodeficiency virus 
type 1 env clones from acute and early subtype B infections for standardized assessments of vaccine-elicited neutralizing antibodies. Journal of virology 79, 10108-10125.

Li, M., Salazar-Gonzalez, J.F., Derdeyn, C.A., Morris, L., Williamson, C., Robinson, J.E., Decker, J.M., Li, Y., Salazar, M.G., Polonis, V.R., et al. (2006). Genetic and neutralization properties of subtype $C$ human immunodeficiency virus type 1 molecular env clones from acute and early heterosexually acquired infections in Southern Africa. Journal of virology $80,11776-11790$.

Li, Y., Migueles, S.A., Welcher, B., Svehla, K., Phogat, A., Louder, M.K., Wu, X., Shaw, G.M., Connors, M., Wyatt, R.T., et al. (2007). Broad HIV-1 neutralization mediated by CD4-binding site antibodies. Nature medicine 13, 1032-1034.

Li, Y., Svehla, K., Louder, M.K., Wycuff, D., Phogat, S., Tang, M., Migueles, S.A., Wu, X., Phogat, A., Shaw, G.M., et al. (2008). Analysis of the Neutralization Specificities in Polyclonal Sera Derived from Human Immunodeficiency Virus Type-1 Infected Individuals. Journal of virology.

Li, Y., Svehla, K., Louder, M.K., Wycuff, D., Phogat, S., Tang, M., Migueles, S.A., Wu, X., Phogat, A., Shaw, G.M., et al. (2009). Analysis of neutralization specificities in polyclonal sera derived from human immunodeficiency virus type 1-infected individuals. Journal of virology 83, 1045-1059.

Liao, H.X., Lynch, R., Zhou, T., Gao, F., Alam, S.M., Boyd, S.D., Fire, A.Z., Roskin, K.M., Schramm, C.A., Zhang, Z., et al. (2013). Co-evolution of a broadly neutralizing HIV-1 antibody and founder virus. Nature 496, 469-476.

Liu, J., Bartesaghi, A., Borgnia, M.J., Sapiro, G., and Subramaniam, S. (2008). Molecular architecture of native HIV-1 gp120 trimers. Nature 455, 109-113.

Liu, L., Cimbro, R., Lusso, P., and Berger, E.A. (2011). Intraprotomer masking of third variable loop (V3) epitopes by the first and second variable loops (V1V2) within the native HIV-1 envelope glycoprotein trimer. Proceedings of the National Academy of Sciences of the United States of America 108, 20148-20153.

Lynch, R.M., Tran, L., Louder, M.K., Schmidt, S.D., Cohen, M., Dersimonian, R., Euler, Z., Gray, E.S., Abdool Karim, S., Kirchherr, J., et al. (2012). The Development of CD4 Binding Site Antibodies During HIV-1 Infection. Journal of virology.

Manrique, A., Rusert, P., Joos, B., Fischer, M., Kuster, H., Leemann, C., Niederost, B., Weber, R., Stiegler, G., Katinger, H., et al. (2007). In vivo and in vitro escape from neutralizing antibodies 2G12, 2F5, and 4E10. Journal of virology 81, 8793-8808. 
Mao, Y., Wang, L., Gu, C., Herschhorn, A., Xiang, S.H., Haim, H., Yang, X., and Sodroski, J. (2012). Subunit organization of the membrane-bound HIV-1 envelope glycoprotein trimer. Nat Struct Mol Biol 19, 893-899.

Markosyan, R.M., Leung, M.Y., and Cohen, F.S. (2009). The six-helix bundle of human immunodeficiency virus Env controls pore formation and enlargement and is initiated at residues proximal to the hairpin turn. Journal of virology $83,10048-10057$.

Maruyama, M., Lam, K.P., and Rajewsky, K. (2000). Memory B-cell persistence is independent of persisting immunizing antigen. Nature 407, 636-642.

Mascola, J.R. (2007). HIV/AIDS: allied responses. Nature 449, 29-30.

Mascola, J.R., Lewis, M.G., Stiegler, G., Harris, D., VanCott, T.C., Hayes, D., Louder, M.K., Brown, C.R., Sapan, C.V., Frankel, S.S., et al. (1999). Protection of Macaques against pathogenic simian/human immunodeficiency virus $89.6 \mathrm{PD}$ by passive transfer of neutralizing antibodies. Journal of virology 73, 4009-4018.

Mascola, J.R., and Nabel, G.J. (2001). Vaccines for the prevention of HIV-1 disease. Curr Opin Immunol 13, 489-495.

Mascola, J.R., Stiegler, G., VanCott, T.C., Katinger, H., Carpenter, C.B., Hanson, C.E., Beary, H., Hayes, D., Frankel, S.S., Birx, D.L., et al. (2000). Protection of macaques against vaginal transmission of a pathogenic HIV-1/SIV chimeric virus by passive infusion of neutralizing antibodies. Nature medicine 6, 207-210.

McClure, M.O., Sattentau, Q.J., Beverley, P.C., Hearn, J.P., Fitzgerald, A.K., Zuckerman, A.J., and Weiss, R.A. (1987). HIV infection of primate lymphocytes and conservation of the CD4 receptor. Nature 330, 487-489.

McCoy, A.J., Grosse-Kunstleve, R.W., Adams, P.D., Winn, M.D., Storoni, L.C., and Read, R.J. (2007). Phaser crystallographic software. J Appl Crystallogr 40, 658-674.

McElrath, M.J., and Haynes, B.F. (2010). Induction of immunity to human immunodeficiency virus type-1 by vaccination. Immunity $33,542-554$.

McHeyzer-Williams, M.G., Nossal, G.J., and Lalor, P.A. (1991). Molecular characterization of single memory B cells. Nature 350, 502-505.

McKean, D., Huppi, K., Bell, M., Staudt, L., Gerhard, W., and Weigert, M. (1984). Generation of antibody diversity in the immune response of BALB/c mice to influenza virus hemagglutinin. Proceedings of the National Academy of Sciences of the United States of America 81, 3180-3184. 
McLellan, J.S., Pancera, M., Carrico, C., Gorman, J., Julien, J.P., Khayat, R., Louder, R., Pejchal, R., Sastry, M., Dai, K., et al. (2011). Structure of HIV-1 gp120 V1/V2 domain with broadly neutralizing antibody PG9. Nature 480, 336-343.

McMichael, A.J., Borrow, P., Tomaras, G.D., Goonetilleke, N., and Haynes, B.F. (2010). The immune response during acute HIV-1 infection: clues for vaccine development. Nature reviews 10,11-23.

Mietzner, B., Tsuiji, M., Scheid, J., Velinzon, K., Tiller, T., Abraham, K., Gonzalez, J.B., Pascual, V., Stichweh, D., Wardemann, H., et al. (2008). Autoreactive IgG memory antibodies in patients with systemic lupus erythematosus arise from nonreactive and polyreactive precursors. Proceedings of the National Academy of Sciences of the United States of America 105, 9727-9732.

Mikell, I., Sather, D.N., Kalams, S.A., Altfeld, M., Alter, G., and Stamatatos, L. (2011). Characteristics of the earliest cross-neutralizing antibody response to HIV-1. PLoS Pathog 7, e1001251.

Moir, S., Malaspina, A., and Fauci, A.S. (2011). Prospects for an HIV vaccine: leading B cells down the right path. Nat Struct Mol Biol 18, 1317-1321.

Montefiori, D.C. (2005). Evaluating neutralizing antibodies against HIV, SIV, and SHIV in luciferase reporter gene assays. Curr Protoc Immunol Chapter 12, Unit 1211.

Moore, J.P., and Sodroski, J. (1996). Antibody cross-competition analysis of the human immunodeficiency virus type $1 \mathrm{gp} 120$ exterior envelope glycoprotein. Journal of virology 70, 1863-1872.

Moore, P.L., Ranchobe, N., Lambson, B.E., Gray, E.S., Cave, E., Abrahams, M.R., Bandawe, G., Mlisana, K., Abdool Karim, S.S., Williamson, C., et al. (2009). Limited neutralizing antibody specificities drive neutralization escape in early HIV-1 subtype C infection. PLoS Pathog 5, e1000598.

Mouquet, H., Scheid, J.F., Zoller, M.J., Krogsgaard, M., Ott, R.G., Shukair, S., Artyomov, M.N., Pietzsch, J., Connors, M., Pereyra, F., et al. (2010). Polyreactivity increases the apparent affinity of anti-HIV antibodies by heteroligation. Nature 467, 591595.

Muschen, M., Re, D., Jungnickel, B., Diehl, V., Rajewsky, K., and Kuppers, R. (2000). Somatic mutation of the CD95 gene in human B cells as a side-effect of the germinal center reaction. The Journal of experimental medicine 192, 1833-1840.

Muster, T., Steindl, F., Purtscher, M., Trkola, A., Klima, A., Himmler, G., Ruker, F., and Katinger, H. (1993). A conserved neutralizing epitope on gp41 of human immunodeficiency virus type 1 . Journal of virology 67, 6642-6647. 
Neuberger, M.S., Lanoue, A., Ehrenstein, M.R., Batista, F.D., Sale, J.E., and Williams, G.T. (1999). Antibody diversification and selection in the mature B-cell compartment. Cold Spring Harb Symp Quant Biol 64, 211-216.

Nieuwenhuis, P., and Opstelten, D. (1984). Functional anatomy of germinal centers. Am J Anat 170, 421-435.

Nussenzweig, A., and Nussenzweig, M.C. (2010). Origin of chromosomal translocations in lymphoid cancer. Cell 141, 27-38.

Odegard, V.H., and Schatz, D.G. (2006). Targeting of somatic hypermutation. Nature reviews $6,573-583$.

Ofek, G., McKee, K., Yang, Y., Yang, Z.Y., Skinner, J., Guenaga, F.J., Wyatt, R., Zwick, M.B., Nabel, G.J., Mascola, J.R., et al. (2010). Relationship between antibody 2F5 neutralization of HIV-1 and hydrophobicity of its heavy chain third complementaritydetermining region. Journal of virology 84, 2955-2962.

Ofek, G., Tang, M., Sambor, A., Katinger, H., Mascola, J.R., Wyatt, R., and Kwong, P.D. (2004). Structure and mechanistic analysis of the anti-human immunodeficiency virus type 1 antibody 2F5 in complex with its gp41 epitope. Journal of virology 78, 1072410737.

Olshevsky, U., Helseth, E., Furman, C., Li, J., Haseltine, W., and Sodroski, J. (1990). Identification of individual human immunodeficiency virus type 1 gp120 amino acids important for CD4 receptor binding. Journal of virology 64, 5701-5707.

Pancera, M., Lebowitz, J., Schon, A., Zhu, P., Freire, E., Kwong, P.D., Roux, K.H., Sodroski, J., and Wyatt, R. (2005). Soluble mimetics of human immunodeficiency virus type 1 viral spikes produced by replacement of the native trimerization domain with a heterologous trimerization motif: characterization and ligand binding analysis. Journal of virology 79, 9954-9969.

Pancera, M., Majeed, S., Ban, Y.E., Chen, L., Huang, C.C., Kong, L., Kwon, Y.D., Stuckey, J., Zhou, T., Robinson, J.E., et al. (2010). Structure of HIV-1 gp120 with gp41interactive region reveals layered envelope architecture and basis of conformational mobility. Proceedings of the National Academy of Sciences of the United States of America 107, 1166-1171.

Pantophlet, R., and Burton, D.R. (2006). GP120: target for neutralizing HIV-1 antibodies. Annu Rev Immunol 24, 739-769.

Pantophlet, R., Ollmann Saphire, E., Poignard, P., Parren, P.W., Wilson, I.A., and Burton, D.R. (2003). Fine mapping of the interaction of neutralizing and nonneutralizing 
monoclonal antibodies with the CD4 binding site of human immunodeficiency virus type 1 gp120. Journal of virology 77, 642-658.

Parren, P.W., Marx, P.A., Hessell, A.J., Luckay, A., Harouse, J., Cheng-Mayer, C., Moore, J.P., and Burton, D.R. (2001). Antibody protects macaques against vaginal challenge with a pathogenic R5 simian/human immunodeficiency virus at serum levels giving complete neutralization in vitro. Journal of virology $75,8340-8347$.

Pasqualucci, L., Neumeister, P., Goossens, T., Nanjangud, G., Chaganti, R.S., Kuppers, R., and Dalla-Favera, R. (2001). Hypermutation of multiple proto-oncogenes in B-cell diffuse large-cell lymphomas. Nature 412, 341-346.

Pavri, R., and Nussenzweig, M.C. (2011). AID targeting in antibody diversity. Adv Immunol 110, 1-26.

Pejchal, R., Doores, K.J., Walker, L.M., Khayat, R., Huang, P.S., Wang, S.K., Stanfield, R.L., Julien, J.P., Ramos, A., Crispin, M., et al. (2011). A potent and broad neutralizing antibody recognizes and penetrates the HIV glycan shield. Science (New York, NY 334, 1097-1103.

Pejchal, R., Gach, J.S., Brunel, F.M., Cardoso, R.M., Stanfield, R.L., Dawson, P.E., Burton, D.R., Zwick, M.B., and Wilson, I.A. (2009). A conformational switch in human immunodeficiency virus gp41 revealed by the structures of overlapping epitopes recognized by neutralizing antibodies. Journal of virology $83,8451-8462$.

Pereyra, F., Addo, M.M., Kaufmann, D.E., Liu, Y., Miura, T., Rathod, A., Baker, B., Trocha, A., Rosenberg, R., Mackey, E., et al. (2008). Genetic and immunologic heterogeneity among persons who control HIV infection in the absence of therapy. The Journal of infectious diseases 197, 563-571.

Phan, T.G., Paus, D., Chan, T.D., Turner, M.L., Nutt, S.L., Basten, A., and Brink, R. (2006). High affinity germinal center B cells are actively selected into the plasma cell compartment. The Journal of experimental medicine 203, 2419-2424.

Pietzsch, J., Scheid, J.F., Mouquet, H., Klein, F., Seaman, M.S., Jankovic, M., Corti, D., Lanzavecchia, A., and Nussenzweig, M.C. (2010a). Human anti-HIV-neutralizing antibodies frequently target a conserved epitope essential for viral fitness. The Journal of experimental medicine 207, 1995-2002.

Pietzsch, J., Scheid, J.F., Mouquet, H., Seaman, M.S., Broder, C.C., and Nussenzweig, M.C. (2010b). Anti-gp41 antibodies cloned from HIV-infected patients with broadly neutralizing serologic activity. Journal of virology 84, 5032-5042.

Poignard, P., Saphire, E.O., Parren, P.W., and Burton, D.R. (2001). gp120: Biologic aspects of structural features. Annu Rev Immunol 19, 253-274. 
Purtscher, M., Trkola, A., Gruber, G., Buchacher, A., Predl, R., Steindl, F., Tauer, C., Berger, R., Barrett, N., Jungbauer, A., et al. (1994). A broadly neutralizing human monoclonal antibody against gp41 of human immunodeficiency virus type 1. AIDS Res Hum Retroviruses 10, 1651-1658.

Richman, D.D., Wrin, T., Little, S.J., and Petropoulos, C.J. (2003). Rapid evolution of the neutralizing antibody response to HIV type 1 infection. Proceedings of the National Academy of Sciences of the United States of America 100, 4144-4149.

Rizzuto, C.D., Wyatt, R., Hernandez-Ramos, N., Sun, Y., Kwong, P.D., Hendrickson, W.A., and Sodroski, J. (1998). A conserved HIV gp120 glycoprotein structure involved in chemokine receptor binding. Science (New York, NY 280, 1949-1953.

Roben, P., Moore, J.P., Thali, M., Sodroski, J., Barbas, C.F., 3rd, and Burton, D.R. (1994). Recognition properties of a panel of human recombinant Fab fragments to the CD4 binding site of gp120 that show differing abilities to neutralize human immunodeficiency virus type 1 . Journal of virology $68,4821-4828$.

Roberts, J.D., Bebenek, K., and Kunkel, T.A. (1988). The accuracy of reverse transcriptase from HIV-1. Science (New York, NY 242, 1171-1173.

Rong, R., Li, B., Lynch, R.M., Haaland, R.E., Murphy, M.K., Mulenga, J., Allen, S.A., Pinter, A., Shaw, G.M., Hunter, E., et al. (2009). Escape from autologous neutralizing antibodies in acute/early subtype $\mathrm{C} \mathrm{HIV}-1$ infection requires multiple pathways. PLoS Pathog 5, e1000594.

Rose, P.P., and Korber, B.T. (2000). Detecting hypermutations in viral sequences with an emphasis on $\mathrm{G}-->$ A hypermutation. Bioinformatics 16, 400-401.

Saitou, N., and Nei, M. (1987). The neighbor-joining method: a new method for reconstructing phylogenetic trees. Mol Biol Evol 4, 406-425.

Salazar-Gonzalez, J.F., Salazar, M.G., Keele, B.F., Learn, G.H., Giorgi, E.E., Li, H., Decker, J.M., Wang, S., Baalwa, J., Kraus, M.H., et al. (2009). Genetic identity, biological phenotype, and evolutionary pathways of transmitted/founder viruses in acute and early HIV-1 infection. The Journal of experimental medicine 206, 1273-1289.

Santra, S., Liao, H.X., Zhang, R., Muldoon, M., Watson, S., Fischer, W., Theiler, J., Szinger, J., Balachandran, H., Buzby, A., et al. (2010). Mosaic vaccines elicit CD8+ T lymphocyte responses that confer enhanced immune coverage of diverse HIV strains in monkeys. Nature medicine 16, 324-328.

Saphire, E.O., Parren, P.W., Pantophlet, R., Zwick, M.B., Morris, G.M., Rudd, P.M., Dwek, R.A., Stanfield, R.L., Burton, D.R., and Wilson, I.A. (2001). Crystal structure of a 
neutralizing human IGG against HIV-1: a template for vaccine design. Science (New York, NY 293, 1155-1159.

Sather, D.N., Armann, J., Ching, L.K., Mavrantoni, A., Sellhorn, G., Caldwell, Z., Yu, X., Wood, B., Self, S., Kalams, S., et al. (2008). Factors Associated with the Development of Cross-Reactive Neutralizing Antibodies during HIV-1 Infection. Journal of virology.

Sather, D.N., Armann, J., Ching, L.K., Mavrantoni, A., Sellhorn, G., Caldwell, Z., Yu, X., Wood, B., Self, S., Kalams, S., et al. (2009). Factors associated with the development of cross-reactive neutralizing antibodies during human immunodeficiency virus type 1 infection. Journal of virology 83, 757-769.

Sattentau, Q.J., Dalgleish, A.G., Weiss, R.A., and Beverley, P.C. (1986). Epitopes of the CD4 antigen and HIV infection. Science (New York, NY 234, 1120-1123.

Sattentau, Q.J., Moore, J.P., Vignaux, F., Traincard, F., and Poignard, P. (1993). Conformational changes induced in the envelope glycoproteins of the human and simian immunodeficiency viruses by soluble receptor binding. Journal of virology 67, 73837393.

Scheid, J., Mouquet, H., Feldhahn, N., Walker, B., Pereyra, F., Cutrell, E., Seaman, M., Mascola, J., Wyatt, R., Wardemann, H., et al. (2008). A method for identification of HIV gp140 binding memory B cells in human blood. Journal of immunological methods.

Scheid, J.F., Mouquet, H., Feldhahn, N., Seaman, M.S., Velinzon, K., Pietzsch, J., Ott, R.G., Anthony, R.M., Zebroski, H., Hurley, A., et al. (2009a). Broad diversity of neutralizing antibodies isolated from memory B cells in HIV-infected individuals. Nature 458, 636-640.

Scheid, J.F., Mouquet, H., Feldhahn, N., Walker, B.D., Pereyra, F., Cutrell, E., Seaman, M.S., Mascola, J.R., Wyatt, R.T., Wardemann, H., et al. (2009b). A method for identification of HIV gp140 binding memory B cells in human blood. Journal of immunological methods 343, 65-67.

Scheid, J.F., Mouquet, H., Kofer, J., Yurasov, S., Nussenzweig, M.C., and Wardemann, H. (2011a). Differential regulation of self-reactivity discriminates between IgG+ human circulating memory B cells and bone marrow plasma cells. Proceedings of the National Academy of Sciences of the United States of America 108, 18044-18048.

Scheid, J.F., Mouquet, H., Ueberheide, B., Diskin, R., Klein, F., Oliveira, T.Y., Pietzsch, J., Fenyo, D., Abadir, A., Velinzon, K., et al. (2011b). Sequence and structural convergence of broad and potent HIV antibodies that mimic CD4 binding. Science (New York, NY 333, 1633-1637. 
Schwickert, T.A., Lindquist, R.L., Shakhar, G., Livshits, G., Skokos, D., Kosco-Vilbois, M.H., Dustin, M.L., and Nussenzweig, M.C. (2007). In vivo imaging of germinal centres reveals a dynamic open structure. Nature 446, 83-87.

Seaman, M.S., Janes, H., Hawkins, N., Grandpre, L.E., Devoy, C., Giri, A., Coffey, R.T., Harris, L., Wood, B., Daniels, M.G., et al. (2010). Tiered categorization of a diverse panel of HIV-1 Env pseudoviruses for assessment of neutralizing antibodies. Journal of virology $84,1439-1452$.

Shen, H.M., Peters, A., Baron, B., Zhu, X., and Storb, U. (1998). Mutation of BCL-6 gene in normal B cells by the process of somatic hypermutation of Ig genes. Science (New York, NY 280, 1750-1752.

Shi, W., Bohon, J., Han, D.P., Habte, H., Qin, Y., Cho, M.W., and Chance, M.R. (2010). Structural characterization of HIV gp41 with the membrane-proximal external region. J Biol Chem 285, 24290-24298.

Shibata, R., Igarashi, T., Haigwood, N., Buckler-White, A., Ogert, R., Ross, W., Willey, R., Cho, M.W., and Martin, M.A. (1999). Neutralizing antibody directed against the HIV1 envelope glycoprotein can completely block HIV-1/SIV chimeric virus infections of macaque monkeys. Nature medicine 5, 204-210.

Simek, M.D., Rida, W., Priddy, F.H., Pung, P., Carrow, E., Laufer, D.S., Lehrman, J.K., Boaz, M., Tarragona-Fiol, T., Miiro, G., et al. (2009). Human immunodeficiency virus type 1 elite neutralizers: individuals with broad and potent neutralizing activity identified by using a high-throughput neutralization assay together with an analytical selection algorithm. Journal of virology 83, 7337-7348.

Smith, D.H., Byrn, R.A., Marsters, S.A., Gregory, T., Groopman, J.E., and Capon, D.J. (1987). Blocking of HIV-1 infectivity by a soluble, secreted form of the CD4 antigen. Science (New York, NY 238, 1704-1707.

Song, R., Franco, D., Kao, C.Y., Yu, F., Huang, Y., and Ho, D.D. (2010). Epitope mapping of ibalizumab, a humanized anti-CD4 monoclonal antibody with anti-HIV-1 activity in infected patients. Journal of virology 84, 6935-6942.

Stamatatos, L., Morris, L., Burton, D.R., and Mascola, J.R. (2009). Neutralizing antibodies generated during natural HIV-1 infection: good news for an HIV-1 vaccine? Nature medicine 15, 866-870.

Stanfield, R.L., Gorny, M.K., Williams, C., Zolla-Pazner, S., and Wilson, I.A. (2004). Structural rationale for the broad neutralization of HIV-1 by human monoclonal antibody 447-52D. Structure 12, 193-204. 
Stanfield, R.L., Gorny, M.K., Zolla-Pazner, S., and Wilson, I.A. (2006). Crystal structures of human immunodeficiency virus type 1 (HIV-1) neutralizing antibody 2219 in complex with three different $\mathrm{V} 3$ peptides reveal a new binding mode for HIV-1 crossreactivity. Journal of virology 80, 6093-6105.

Sun, Z.Y., Oh, K.J., Kim, M., Yu, J., Brusic, V., Song, L., Qiao, Z., Wang, J.H., Wagner, G., and Reinherz, E.L. (2008). HIV-1 broadly neutralizing antibody extracts its epitope from a kinked gp41 ectodomain region on the viral membrane. Immunity 28, 52-63.

Tamura, K., Dudley, J., Nei, M., and Kumar, S. (2007). MEGA4: Molecular Evolutionary Genetics Analysis (MEGA) software version 4.0. Mol Biol Evol 24, 1596-1599.

Taylor, B.S., and Hammer, S.M. (2008). The challenge of HIV-1 subtype diversity. The New England journal of medicine 359, 1965-1966.

Thali, M., Moore, J.P., Furman, C., Charles, M., Ho, D.D., Robinson, J., and Sodroski, J. (1993). Characterization of conserved human immunodeficiency virus type 1 gp120 neutralization epitopes exposed upon gp120-CD4 binding. Journal of virology 67, 39783988.

Thali, M., Olshevsky, U., Furman, C., Gabuzda, D., Posner, M., and Sodroski, J. (1991). Characterization of a discontinuous human immunodeficiency virus type 1 gp120 epitope recognized by a broadly reactive neutralizing human monoclonal antibody. Journal of virology 65, 6188-6193.

Tiller, T., Meffre, E., Yurasov, S., Tsuiji, M., Nussenzweig, M.C., and Wardemann, H. (2008). Efficient generation of monoclonal antibodies from single human B cells by single cell RT-PCR and expression vector cloning. Journal of immunological methods $329,112-124$.

Tiller, T., Tsuiji, M., Yurasov, S., Velinzon, K., Nussenzweig, M.C., and Wardemann, H. (2007). Autoreactivity in human IgG+ memory B cells. Immunity 26, 205-213.

Tomaras, G.D., Binley, J.M., Gray, E.S., Crooks, E.T., Osawa, K., Moore, P.L., Tumba, N., Tong, T., Shen, X., Yates, N.L., et al. (2011). Polyclonal B cell responses to conserved neutralization epitopes in a subset of HIV-1-infected individuals. Journal of virology $85,11502-11519$.

Tomaras, G.D., Yates, N.L., Liu, P., Qin, L., Fouda, G.G., Chavez, L.L., Decamp, A.C., Parks, R.J., Ashley, V.C., Lucas, J.T., et al. (2008). Initial B-cell responses to transmitted human immunodeficiency virus type 1: virion-binding immunoglobulin $\mathrm{M}(\mathrm{IgM})$ and $\mathrm{IgG}$ antibodies followed by plasma anti-gp41 antibodies with ineffective control of initial viremia. Journal of virology 82, 12449-12463.

Tonegawa, S. (1983). Somatic generation of antibody diversity. Nature 302, 575-581. 
Trkola, A., Kuster, H., Rusert, P., Joos, B., Fischer, M., Leemann, C., Manrique, A., Huber, M., Rehr, M., Oxenius, A., et al. (2005). Delay of HIV-1 rebound after cessation of antiretroviral therapy through passive transfer of human neutralizing antibodies. Nature medicine 11,615-622.

Trkola, A., Purtscher, M., Muster, T., Ballaun, C., Buchacher, A., Sullivan, N., Srinivasan, K., Sodroski, J., Moore, J.P., and Katinger, H. (1996). Human monoclonal antibody 2G12 defines a distinctive neutralization epitope on the gp120 glycoprotein of human immunodeficiency virus type 1 . Journal of virology 70, 1100-1108.

van Gils, M.J., Bunnik, E.M., Boeser-Nunnink, B.D., Burger, J.A., Terlouw-Klein, M., Verwer, N., and Schuitemaker, H. (2011). Longer V1V2 region with increased number of potential N-linked glycosylation sites in the HIV-1 envelope glycoprotein protects against HIV-specific neutralizing antibodies. Journal of virology 85, 6986-6995.

van Gils, M.J., Euler, Z., Schweighardt, B., Wrin, T., and Schuitemaker, H. (2009). Prevalence of cross-reactive HIV-1-neutralizing activity in HIV-1-infected patients with rapid or slow disease progression. AIDS (London, England) 23, 2405-2414.

Veazey, R.S., Shattock, R.J., Pope, M., Kirijan, J.C., Jones, J., Hu, Q., Ketas, T., Marx, P.A., Klasse, P.J., Burton, D.R., et al. (2003). Prevention of virus transmission to macaque monkeys by a vaginally applied monoclonal antibody to HIV-1 gp120. Nature medicine 9, 343-346.

Victora, G.D., and Nussenzweig, M.C. (2012). Germinal centers. Annu Rev Immunol 30, 429-457.

Walker, B.D. (2007). Elite control of HIV Infection: implications for vaccines and treatment. Top HIV Med 15, 134-136.

Walker, B.D., and Burton, D.R. (2008). Toward an AIDS vaccine. Science (New York, NY 320, 760-764.

Walker, L.M., and Burton, D.R. (2010). Rational antibody-based HIV-1 vaccine design: current approaches and future directions. Curr Opin Immunol 22, 358-366.

Walker, L.M., Huber, M., Doores, K.J., Falkowska, E., Pejchal, R., Julien, J.P., Wang, S.K., Ramos, A., Chan-Hui, P.Y., Moyle, M., et al. (2011). Broad neutralization coverage of HIV by multiple highly potent antibodies. Nature 477, 466-470.

Walker, L.M., Phogat, S.K., Chan-Hui, P.Y., Wagner, D., Phung, P., Goss, J.L., Wrin, T., Simek, M.D., Fling, S., Mitcham, J.L., et al. (2009). Broad and potent neutralizing antibodies from an African donor reveal a new HIV-1 vaccine target. Science (New York, NY 326, 285-289. 
Walker, L.M., Simek, M.D., Priddy, F., Gach, J.S., Wagner, D., Zwick, M.B., Phogat, S.K., Poignard, P., and Burton, D.R. (2010). A limited number of antibody specificities mediate broad and potent serum neutralization in selected HIV-1 infected individuals. PLoS Pathog 6, e1001028.

Wardemann, H., Yurasov, S., Schaefer, A., Young, J.W., Meffre, E., and Nussenzweig, M.C. (2003). Predominant autoantibody production by early human B cell precursors. Science (New York, NY 301, 1374-1377.

Wei, X., Decker, J.M., Wang, S., Hui, H., Kappes, J.C., Wu, X., Salazar-Gonzalez, J.F., Salazar, M.G., Kilby, J.M., Saag, M.S., et al. (2003). Antibody neutralization and escape by HIV-1. Nature 422, 307-312.

Weigert, M.G., Cesari, I.M., Yonkovich, S.J., and Cohn, M. (1970). Variability in the lambda light chain sequences of mouse antibody. Nature 228, 1045-1047.

Weiss, R.A., Clapham, P.R., Cheingsong-Popov, R., Dalgleish, A.G., Carne, C.A., Weller, I.V., and Tedder, R.S. (1985). Neutralization of human T-lymphotropic virus type III by sera of AIDS and AIDS-risk patients. Nature 316, 69-72.

Weiss, R.A., Clapham, P.R., McClure, M.O., McKeating, J.A., McKnight, A., Dalgleish, A.G., Sattentau, Q.J., and Weber, J.N. (1988). Human immunodeficiency viruses: neutralization and receptors. J Acquir Immune Defic Syndr 1, 536-541.

Weiss, R.A., Clapham, P.R., Weber, J.N., Dalgleish, A.G., Lasky, L.A., and Berman, P.W. (1986). Variable and conserved neutralization antigens of human immunodeficiency virus. Nature $324,572-575$.

Weissenhorn, W., Dessen, A., Harrison, S.C., Skehel, J.J., and Wiley, D.C. (1997). Atomic structure of the ectodomain from HIV-1 gp41. Nature 387, 426-430.

Wild, C., Oas, T., McDanal, C., Bolognesi, D., and Matthews, T. (1992). A synthetic peptide inhibitor of human immunodeficiency virus replication: correlation between solution structure and viral inhibition. Proceedings of the National Academy of Sciences of the United States of America 89, 10537-10541.

Wilson, P.C., de Bouteiller, O., Liu, Y.J., Potter, K., Banchereau, J., Capra, J.D., and Pascual, V. (1998). Somatic hypermutation introduces insertions and deletions into immunoglobulin $\mathrm{V}$ genes. The Journal of experimental medicine 187, 59-70.

Wood, N., Bhattacharya, T., Keele, B.F., Giorgi, E., Liu, M., Gaschen, B., Daniels, M., Ferrari, G., Haynes, B.F., McMichael, A., et al. (2009). HIV evolution in early infection: selection pressures, patterns of insertion and deletion, and the impact of APOBEC. PLoS Pathog 5, e1000414. 
Wu, L., Gerard, N.P., Wyatt, R., Choe, H., Parolin, C., Ruffing, N., Borsetti, A., Cardoso, A.A., Desjardin, E., Newman, W., et al. (1996). CD4-induced interaction of primary HIV-1 gp120 glycoproteins with the chemokine receptor CCR-5. Nature 384, 179-183.

Wu, X., Sambor, A., Nason, M.C., Yang, Z.Y., Wu, L., Zolla-Pazner, S., Nabel, G.J., and Mascola, J.R. (2008). Soluble CD4 broadens neutralization of V3-directed monoclonal antibodies and guinea pig vaccine sera against HIV-1 subtype B and C reference viruses. Virology 380, 285-295.

Wu, X., Yang, Z.Y., Li, Y., Hogerkorp, C.M., Schief, W.R., Seaman, M.S., Zhou, T., Schmidt, S.D., Wu, L., Xu, L., et al. (2010). Rational design of envelope identifies broadly neutralizing human monoclonal antibodies to HIV-1. Science (New York, NY $329,856-861$.

Wu, X., Zhou, T., Zhu, J., Zhang, B., Georgiev, I., Wang, C., Chen, X., Longo, N.S., Louder, M., McKee, K., et al. (2011). Focused evolution of HIV-1 neutralizing antibodies revealed by structures and deep sequencing. Science (New York, NY 333, 1593-1602.

Wyatt, R., Kwong, P.D., Desjardins, E., Sweet, R.W., Robinson, J., Hendrickson, W.A., and Sodroski, J.G. (1998). The antigenic structure of the HIV gp120 envelope glycoprotein. Nature 393, 705-711.

Wyatt, R., and Sodroski, J. (1998). The HIV-1 envelope glycoproteins: fusogens, antigens, and immunogens. Science (New York, NY 280, 1884-1888.

Xu, J.Y., Gorny, M.K., Palker, T., Karwowska, S., and Zolla-Pazner, S. (1991). Epitope mapping of two immunodominant domains of gp41, the transmembrane protein of human immunodeficiency virus type 1 , using ten human monoclonal antibodies. Journal of virology $65,4832-4838$.

Yang, X., Farzan, M., Wyatt, R., and Sodroski, J. (2000). Characterization of stable, soluble trimers containing complete ectodomains of human immunodeficiency virus type 1 envelope glycoproteins. Journal of virology 74, 5716-5725.

Yang, X., Lee, J., Mahony, E.M., Kwong, P.D., Wyatt, R., and Sodroski, J. (2002). Highly stable trimers formed by human immunodeficiency virus type 1 envelope glycoproteins fused with the trimeric motif of T4 bacteriophage fibritin. Journal of virology 76, 4634-4642.

Yurasov, S., Hammersen, J., Tiller, T., Tsuiji, M., and Wardemann, H. (2005). B-cell tolerance checkpoints in healthy humans and patients with systemic lupus erythematosus. Ann N Y Acad Sci 1062, 165-174. 
Zanetti, G., Briggs, J.A., Grunewald, K., Sattentau, Q.J., and Fuller, S.D. (2006). Cryoelectron tomographic structure of an immunodeficiency virus envelope complex in situ. PLoS Pathog 2, e83.

Zhang, M.Y., Vu, B.K., Choudhary, A., Lu, H., Humbert, M., Ong, H., Alam, M., Ruprecht, R.M., Quinnan, G., Jiang, S., et al. (2008). Cross-reactive human immunodeficiency virus type 1-neutralizing human monoclonal antibody that recognizes a novel conformational epitope on gp41 and lacks reactivity against self-antigens. Journal of virology $82,6869-6879$.

Zhou, T., Georgiev, I., Wu, X., Yang, Z.Y., Dai, K., Finzi, A., Kwon, Y.D., Scheid, J.F., Shi, W., Xu, L., et al. (2010). Structural basis for broad and potent neutralization of HIV1 by antibody VRC01. Science (New York, NY 329, 811-817.

Zhou, T., Xu, L., Dey, B., Hessell, A.J., Van Ryk, D., Xiang, S.H., Yang, X., Zhang, M.Y., Zwick, M.B., Arthos, J., et al. (2007). Structural definition of a conserved neutralization epitope on HIV-1 gp120. Nature 445, 732-737.

Zhu, P., Liu, J., Bess, J., Jr., Chertova, E., Lifson, J.D., Grise, H., Ofek, G.A., Taylor, K.A., and Roux, K.H. (2006). Distribution and three-dimensional structure of AIDS virus envelope spikes. Nature 441, 847-852.

Zhu, P., Winkler, H., Chertova, E., Taylor, K.A., and Roux, K.H. (2008). Cryoelectron tomography of HIV-1 envelope spikes: further evidence for tripod-like legs. PLoS Pathog $4, \mathrm{e} 1000203$.

Zolla-Pazner, S. (2004). Identifying epitopes of HIV-1 that induce protective antibodies. Nature reviews 4, 199-210.

Zolla-Pazner, S., Cohen, S., Pinter, A., Krachmarov, C., Wrin, T., Wang, S., and Lu, S. (2009). Cross-clade neutralizing antibodies against HIV-1 induced in rabbits by focusing the immune response on a neutralizing epitope. Virology 392, 82-93.

Zwick, M.B., Labrijn, A.F., Wang, M., Spenlehauer, C., Saphire, E.O., Binley, J.M., Moore, J.P., Stiegler, G., Katinger, H., Burton, D.R., et al. (2001a). Broadly neutralizing antibodies targeted to the membrane-proximal external region of human immunodeficiency virus type 1 glycoprotein gp41. Journal of virology 75, 10892-10905.

Zwick, M.B., Wang, M., Poignard, P., Stiegler, G., Katinger, H., Burton, D.R., and Parren, P.W. (2001b). Neutralization synergy of human immunodeficiency virus type 1 primary isolates by cocktails of broadly neutralizing antibodies. Journal of virology 75 , 12198-12208. 